\title{
DIETARY FAT SOURCE ALTERS PORK FAT QUALITY
}

\author{
A thesis presented to \\ the Faculty of the Graduate School \\ at the University of Missouri - Columbia
}

In Partial Fulfillment

of the Requirements for the Degree

Master of Science

by

DANIEL POMPEU

Dr. Bryon R. Wiegand, Thesis Supervisor

JULY 2010 
The undersigned, appointed by the Dean of the Graduate School, have examined the thesis entitled

\section{DIETARY FAT SOURCE ALTERS PORK FAT QUALITY}

presented by Daniel Pompeu

a candidate for the degree of Master of Science

and hereby certify that in their opinion it is worthy of acceptance.

Dr. Bryon R. Wiegand

Dr. Carol L. Lorenzen

Dr. George E. Rottinghaus

Dr. Scott N. Carr 


\section{ACKNOWLEDGENTS}

First of all, I would like to acknowledge my advisor Dr. Bryon Wiegand for the opportunity that was given to me and for all the support during these two years. Also, I'd like to thank all my committee members (Dr. Carol Lorenzen, Dr. George Rottinghaus and Dr. Scott Carr) and some other faculty members (Dr. Ledoux, Dr. Shannon and Dr. Allee) for all the help and attention provided during my masters degree. Moreover, I'd like to thank all my family, especially my wife Lucy. Additionally, I'd like to acknowledge my friends at work, my Brazilian friends in Columbia and some staff members, including Doris, Mary, JP and Rick. Finally, I'd like to thank God for this wonderful time I spent in Columbia, and for all the good things and friends I got in these two years. 


\section{TABLE OF CONTENTS}

ACKNOWLEDGMENTS...................................................... ii

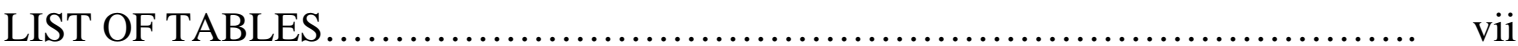

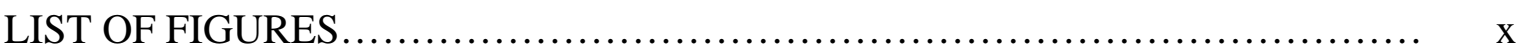

Chapter

1. LITERATURE REVIEW.............................................. 1

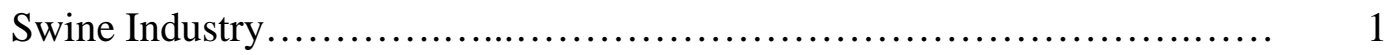

Fat in Swine Nutrition................................................... 2

Dietary Lipid Metabolism........................................ 2

Endogenous Fat Metabolism...................................... 3

Regulation................................................. 6

Utilization of Fat Stored in Adipose Tissue as Energy Source............ 7

Fat Quality..................................................... 7

Importance of Fatty Acids on Pork Quality........................ 9

Impact of Fat on Human Health.................................. 11

Fatty Acids Differences Between Species........................... 12

Soft Fat........................................................... 13

Sources of Fat in Swine Diets and Their Impact on Pork Quality............ 14

Vegetable Oil Sources............................................ 15

Dried Distillers Grains with Solubles......................... 17

Nutritional Value of DDGS................................. 18

DDGS Application in Swine Nutrition During GrowingFinishing Phase..

Animal Fat Sources............................................... 23

Metabolic Modifiers................................................. 27 
Ractopamine Hydrochloride (RAC).............................. 27

Mechanism of Action......................................... 28

Ractopamine Application in Swine Nutrition.................... 29

Conjugated Linoleic Acid......................................... 33

Mechanism of Action........................................... 34

CLA Application in Swine Nutrition............................... 35

2. DIETARY INCLUSION OF CORN DRIED DISTILLERS GRAINS WITH SOLUBLES (DDGS) UP TO FORTY FIVE PERCENT DOES NOT CHANGE PIG GROWTH PERFORMANCE OR CARCASS TRAITS BUT INCREASES IODINE VALUE TO UNACCEPTABLE VALUES.

Abstract.............................................................. 42

Introduction....................................................... 43

Materials and Methods................................................. 44

Animals and Diets............................................ 44

Growth Performance............................................... 45

Harvest and Carcass Quality....................................... 45

Fat Sample Collection and Fatty Acid Procedure........................ 46

Statistical Analysis............................................... 48

Results and Discussion............................................... 48

Growth Performance................................................ 48

Carcass and Meat Quality.......................................... 50

Fatty Acid Profiles.................................................. 52

Implications........................................................ 55

3. DIETARY INCLUSION OF CONJUGATED LINOLEIC ACID (CLA) CHANGES FATTY ACID PROFILES OF PIGS FED THIRTY PERCENT CORN DRIED DISTILLERS GRAINS WITH SOLUBLES (DDGS) DURING GROWING-FINISHING PHASE. 


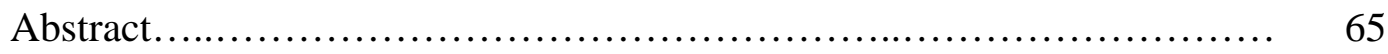

Introduction........................................................ 66

Materials and Methods...................................................... 67

Animals and Diets................................................ 67

Growth Performance............................................. 68

Harvest and Carcass Quality Evaluation............................. $\quad 69$

Meat Quality Evaluation........................................... 69

Statistical Analysis................................................. $\quad 70$

Results and Discussion.............................................. $\quad 71$

Growth Performance............................................. 71

Carcass and Meat Quality......................................... 73

Fatty Acid Profiles............................................... $\quad 77$

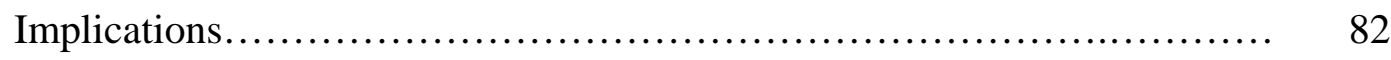

4. EFFECTS OF THE INCLUSION OF CONJUGATED LINOLEIC ACID (CLA) AND RACTOPAMINE (PAYLEAN®) ON GROWTH PERFORMANCE AND FAT QUALITY CHARACTERISTICS OF GROWING-FINISHING PIGS.......................................... 92

Abstract.............................................................. 92

Introduction......................................................... 93

Materials and Methods.................................................. 94

Animals and Diets............................................... 94

Growth Performance.............................................. 95

Harvest and Carcass Quality..................................... 95

Fat Sample Collection and Fatty Acid Procedure...................... 96

Statistical Analysis.............................................. 97

Results and Discussion............................................. 98 
Growth Performance........................................... 98

Carcass Quality................................................ 102

Fatty Acid Profiles............................................. 104

Implications........................................................... 111

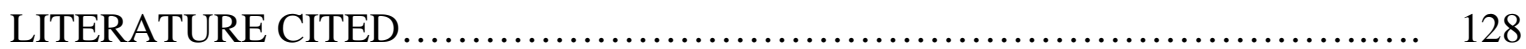




\section{LIST OF TABLES}

Table $\quad$ Page

1.1. Changes in loin eye area, carcass backfat and slaughter weight, 19561999

2.1. Percentage composition of experimental diets (as fed basis)............. 56

2.2. Analyzed composition of DDGS source........................... 57

2.3. Effects of DDGS on growth performance of growing-finishing pigs...... 58

2.4. Effects of feeding DDGS on carcass and meat quality of growing-

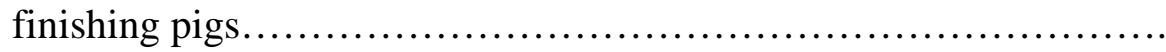

2.5. Effects of increasing levels of DDGS on fatty acid profile (indicated as percentages) of belly fat of growing-finishing pigs..................

2.6. Effects of increasing levels of DDGS on fatty acid profile (indicated as percentages) of jowl fat of growing-finishing pigs...................

2.7. Effects of increasing levels of DDGS on fatty acid profile (indicated as percentages) of subcutaneous fat of growing-finishing pigs....

2.8. Effects of increasing levels of DDGS on fatty acid profile (indicated as percentages) of longissimus muscle of growing-finishing pigs.........

3.1. Percentage composition of experimental diets (as fed basis) during phases 1 (d 1-10) and 2 (d 11-38) of the study

3.2. Effects of DDGS and CLA inclusion on growth performance of growing-finishing pigs during phases 1,2 and the total experimental

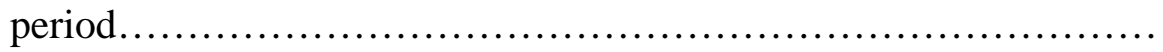

3.3. Effects of DDGS and CLA inclusion on carcass quality of growingfinishing pigs 
3.4. Effects of DDGS and CLA inclusion on meat quality of growingfinishing pigs

3.5. DDGS by dietary CLA treatment subclass for fatty acid profile of jowl samples of growing-finishing pigs.

3.6. Main effects of DDGS and CLA inclusion on fatty acid profile of jowl fat samples of growing-finishing pigs................................

3.7. DDGS by dietary CLA treatment subclass for fatty acid profile of belly samples of growing-finishing pigs..................................

3.8. Main effects of DDGS and CLA inclusion on fatty acid profile of belly fat samples of growing-finishing pigs................................

3.9. Iodine value (IV) correlation analysis between belly and jowl fat depot.

4.1. Percentage composition of pre-study diets (as fed basis)....................

4.2. Percentage composition of treatment diets (as fed basis).....................

4.3. Effect of diet source, ractopamine, and dietary CLA on weekly and overall performance traits of growing-finishing pigs.

4.4. Diet source by dietary CLA treatment subclass means for performance

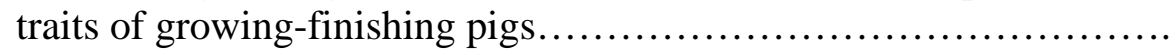

4.5. RAC by dietary CLA treatment subclass means for performance traits of growing-finishing pigs.

4.6. Diet source by dietary RAC treatment subclass means for performance traits of growing-finishing pigs....

4.7. Effects of diet source, ractopamine, and dietary CLA on carcass traits

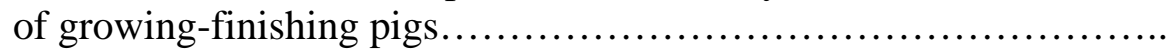

4.8. Main effects of diet source, ractopamine, and dietary CLA on fatty acid profile of belly samples of growing-finishing pigs.

4.9. Diet RAC by dietary CLA treatment subclass means for fatty acid profile of belly samples of growing-finishing pigs....................

4.10. Diet source by dietary RAC treatment subclass means for fatty acid profile of belly samples of growing-finishing pigs.................... 
4.11. Diet source by dietary CLA treatment subclass means for fatty acid profile of belly samples of growing-finishing pigs...................

4.12. Main effects of diet source, ractopamine, and dietary CLA on fatty acid profile of jowl samples of growing-finishing pigs....................

4.13. Diet source by dietary CLA treatment subclass means for fatty acid profile of jowl samples of growing-finishing pigs....................

4.14. Diet RAC by dietary CLA treatment subclass means for fatty acid profile of jowl samples of growing-finishing pigs...................

4.15. Diet source by dietary RAC treatment subclass means for fatty acid profile of jowl samples of growing-finishing pigs...................

4.16. Correlation analysis between iodine value (IV) of belly and jowl fat depots of growing-finishing pigs................................... 


\section{LIST OF FIGURES}

Figure Page

2.1. Correlation analysis among fat depots for iodine value (IV) at different

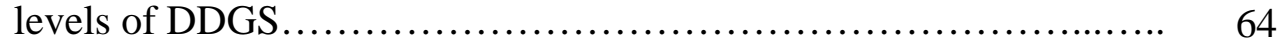




\section{CHAPTER 1}

\section{LITERATURE REVIEW}

\section{SWINE INDUSTRY}

During the past century, agriculture has made dramatic changes and a trend toward fewer farms and more production per farm has been observed in several segments of animal production. In swine production, the number of pigs in the United States has remained almost constant from 1910 to 2000 (58.2 vs. 60.4 million) while the number of farms decreased from 4.35 million to 78.9 thousand. Moreover, by considering all farms in the U.S., the percentage of farms that raised swine decreased from $68.4 \%$ in 1910 to 3.7\% in 2000 (Cromwell, 2009).

By comparing the pig that is produced today to the one of the 1940's, a $50 \%$ reduction in carcass fat can be noticed (Table 1.1). In the 40's, pigs had an average of 7.3 cm of backfat while in 2001 the average was below $2.3 \mathrm{~cm}$ (Hollis and Curtis, 2001). Furthermore, according to Carr et al. (2009), the average slaughter weight of pigs has increased over the past decade in the United States from $109 \mathrm{~kg}$ to an average of approximately $125 \mathrm{~kg}$. According to Pond and Lei (2001), this dramatic decrease in the amount of fat in pork has been accompanied by a decrease in the amount of cholesterol. Moreover, selection for lean genetics has resulted in a decline in intramuscular fat level 
(marbling) to less than $1.0 \%$ of muscle weight compared with 2.0 to $4.0 \%$ in studies from the 1960s (Wood, 1990).

This tendency towards leaner, more heavily muscled pigs has taken place in the U.S. because consumers nowadays, prefer lean pork due to health concerns. However, the adoption of leaner genetics and the increase in the use of polyunsaturated fat sources as more cost effective dietary energy sources has lead to an increase in the incidence of “soft” pork fat in the U.S. (Apple et al., 2007). Additionally, as described by Wood et al. (1989), as pigs become leaner, pork fat becomes softer.

\section{FAT IN SWINE NUTRITION}

Fat is incorporated into swine diets due to the high energy density that lipid has compared with proteins and carbohydrates. Additionally, fat is a source of essential fatty acids and other vitamins, and has the ability to reduce dust which brings benefits to animals and workers in the facilities. Usually, dietary fat is added at levels from 0.5 to $7.0 \%$ in swine diets and excess fat may cause management problems such as feed handling (Azain, 2001). Thus, pigs have three main sources of fat that can be used for

energy metabolism: dietary fat, endogenous fat which is synthesized when energy sources are abundant, and fat stored in adipose tissues.

\section{Dietary Lipid Metabolism}

The main component of fat is triacylglycerol (TAG) which is composed of a glycerol backbone and three fatty acids that are attached to the glycerol molecule. Other molecules also found in adipose tissue are phospholipids, sterols and sterol esters (Yen, 2001). Thus, after ingestion, dietary TAG is partially digested in the stomach into 
droplets which pass to the small intestine where bile salts emulsify the partially insoluble fat, forming micelles (Boyer, 2002). According to Yen (2001), fat needs to be emulsified in order to be subjected to the action of water-soluble hydrolytic enzymes.

Due to the action of an enzyme called pancreatic lipase, TAG is degraded and the end products obtained are monoglyceride and two non-esterified fatty acids. Moreover, phospholipids and sterols are hydrolyzed to non-esterified fatty acids, lysophospholipids and cholesterol (Yen, 2001). Then, water-soluble micelles are formed from monoglycerides, fatty acids, bile acid and phospholipids. These micelles are absorbed into the cells (enterocytes) where monoglycerides are re-esterified to diglycerides and later to triglycerides while short chain fatty acids are not esterified, passing directly into the portal blood (Yen, 2001).

At this point, complexes called chylomicrons are formed from TAG, cholesterol, phospholipids and other apoproteins. Chylomicrons move through the blood vessel into the blood stream and, when energy is not needed by the organism, chylomicrons travel to adipocytes for fat storage; at this moment, TAG molecules are cleaved by the action of a lipoprotein lipase, transported through the membrane, reconstituted and stored as TAG in fat droplets (Boyer, 2002). On the other hand, according to Boyer (2002), when energy is needed by the organism, chylomicrons travel to myocytes where fat is used as energy source by muscle cells and TAG is converted to $\mathrm{CO}_{2}$ and adenosine-triphosphate (ATP) in a process called $\beta$-oxidation.

\section{Endogenous fat metabolism}

Three major lipogenic tissues can be found in mammals: adipose tissue, liver and mammary tissue. Adipose tissue serves as a site for TAG storage to be used as an energy 
source. In the liver, synthesis of fatty acid takes place for export as plasma lipoproteins which are later stored or used in other tissues. Finally, in mammary tissue, TAGs are secreted in milk (Nelson and Cox, 2000). However, according to O’Hea and Leveille (1969), adipose tissue is the main depot where de novo lipogenesis takes place in pigs with liver having very little contribution.

In non ruminant animals, de novo fat synthesis occurs mainly from glucose which enters fatty acid biosynthesis via acetyl-CoA which is formed in mitochondria from pyruvate oxidation and from catabolism of the carbon skeleton of amino acids. However, the inner mitochondrial membrane is impermeable to acetyl-CoA and thus, it needs to be first converted to citrate which is then, transported to the cytoplasm where fatty acid synthesis takes place. Once in the cytoplasm, citrate is converted to acetyl-CoA by citrate lyase enzyme which can be activated by insulin (Nelson and Cox, 2000).

Next, acetyl-CoA is converted to malonyl-CoA through the action of acetyl-CoA carboxylase enzyme (ACC). After this, reactions of elongation and desaturation toward the methyl end take place and palmitate (palmitic acid; C16:0) is generated by a multifunctional enzyme complex called fatty acid synthase. This complex has several enzymes positioned with each active site near that of the proceeding and succeeding enzyme of the sequence (Rule et al., 1995; Nelson and Cox, 2000). According to Busboom et al. (1991), palmitic acid (C16:0) is the major saturated fatty acid in swine due to the accumulation of palmitate as the major end product of de novo fatty acid synthesis. The second major saturated fatty acid in swine is stearic acid (C18:0) being an intermediate in the production of another fatty acid (Rule et al., 1995). 
The final step of fatty acid synthesis is the elongation and desaturation process that takes place inside the endoplasmic reticulum. Endogenous palmitic acid, or even dietary fatty acids, can be transformed in this process into several other fatty acids; however, animals are not able to synthesize linoleic acid (C18:2) due to lack of specific enzymes (Nelson and Cox, 2000). Hence, certain fatty acids (i.e. linoleic and linolenic acids (C18:3)) are considered essential and the diet is the only source of these fatty acids. Thus, the concentration of linoleic acid (C18:2) in swine tissues reflects the concentration of this fatty acid in the diet (Rule et al., 1995). The elongation process is a result of the activity of a microsomal enzyme, fatty acid elongase, while desaturation is a result of the action of another microsomal enzyme called stearoyl CoA desaturase (also known as $\Delta 9$ desaturase). This enzyme is only active on saturated fatty acids where it inserts a double bond at carbon number nine from the carboxyl terminal end (Rule et al., 1995).

According to Yen (2001), the microflora present in the small and large intestine may also affect metabolism of lipids. There is an increase in the biohydrogenation of unsaturated fatty acids by the microflora resulting in increased proportion of saturated fatty acids especially stearic acid (C18:0). In the large intestine, microbial degradation of TAG results in free long-chain fatty acids and volatile fatty acids (VFA). After synthesis, fatty acids can be stored as TAG for energy purposes or can be used as substrates for production of membrane phospholipids especially during the growth period of an organism (Nelson and Cox, 2000). According to Martin et al. (1972), swine carcass fat can occur in four different depots (subcutaneous, intermuscular, intramuscular and body cavity) which are important to energy metabolism purposes. 
Regulation. As described by Mourot et al. (1995), as pigs increase in age, the deposition of fat increases as well as the level of lipogenic enzymes. Furthermore, according to Allee et al. (1971) and Berg (2001), as fat is added to swine diets, de novo synthesis of fatty acids decreases and the fatty acid profile of adipose tissue reflects the fatty acid composition of the diet. Additionally, according to Nelson and Cox (2000), fatty acid synthesis can be regulated by several methods including inhibition or activation of the citrate transporter and/or acetyl-CoA carboxylase enzyme. The citrate transporter is located at the inner mitochondrial membrane and high levels of long chain fatty AcylCoAs inhibit the function of this carrier, decreasing production rate of fatty acids. Another point of regulation is the acetyl-CoA carboxylase enzyme which can be regulated in three different ways. The first way is by altering the concentration of citrate in the cell; high levels of citrate tend to feed forward the reaction activating the enzyme. The second way is by the action of long chain fatty Acyl-CoAs which tend to feed back the reaction, inhibiting the activity of ACC enzyme. Finally, the last way to control ACC is by covalent modification when ACC is phosphorylated by a protein kinase A (PKA) due to the action of regulators such as glucagon and epinephrine. Phosphorylation inactivates this enzyme while dephosphorylation activates it.

According to Miner et al. (2001), dietary fat reduces lipogenesis by reducing the expression of fatty acid synthase (FAS) possibly via peroxisome proliferator-activated receptors. Dietary carbohydrates also have an impact on FAS, stimulating the expression of FAS, which may be related to insulin production when high levels of carbohydrates are fed. Finally, Nelson and Cox (2000) reported that fatty acid synthesis and $\beta$-oxidation processes are tightly regulated due to the action of malonyl-CoA. High concentrations of 
malonyl-CoA during fatty acid synthesis inhibit the action of carnitine acyltransferase I, shutting down $\beta$-oxidation.

\section{Utilization of fat stored in adipose tissue as energy source}

When ATP is needed and the glycogen concentration of the organism is not able to meet the requirements, fat stored in adipocytes is utilized through $\beta$-oxidation. This process begins when hormones such as glucagon or epinephrine bind to receptors located in the membrane of adipocytes. At this point, a conformational change takes place and ATP is converted to cyclic adenosine-mono-phosphate (cAMP) due to the action of adenylate cyclase. Next, cAMP phosphorylates and activates certain protein kinases, including TAG lipase which breaks TAG into free fatty acids and glycerol (Boyer, 2002). Finally, according to Boyer (2002), a protein called serum albumin picks up the free fatty acids in the blood stream and releases them into myocytes as needed where they will be oxidized to ATP and $\mathrm{CO}_{2}$.

\section{FAT QUALITY}

According to Azain (2001), the quality of fat is defined by the fatty acid profile and can be judged based on several factors including: titer or hardness, color, impurities

and stability. Hardness is determined by the degree of unsaturation and chain length of the fatty acids. Thus, fat with a high concentration of saturated fatty acid tends to be harder at room temperature when compared to fat with a high concentration of polyunsaturated fatty acids (PUFA) (Wood et al., 2005). A parameter that is largely used to indicate the degree of unsaturation of fat, and thus, hardness of fat, is called iodine value (IV). Hence, titer or hardness of fat is inversely related to IV, where an increase in 
hardness will cause a decrease in IV (Azain, 2001). According to Eggert et al. (2001), some producers may considered an IV greater than 65 as being unacceptable while other researches and institutes may consider other values as critical points. The Danish Meat Research Institute (Goodband et al., 2006) and Boyd et al. (1997) stated that an IV up to 70 or 74 is considered acceptable, respectively.

Color of fat may also be indicative of the fatty acid profile where solid fat tends to be whiter than liquid fat (Wood et al., 2003). However, according to Azain (2001), color has little to do with nutritional quality of fat. Moreover, presence of moisture, impurities (e.g. hair, bone, plastic) and unsaponifiable compounds such as cholesterol, vitamins, waxes and hydrocarbons may also be indicative of fat quality (Azain, 2001). Finally, stability is related to the ability of fat to support oxidative rancidity. In general, fat with high concentrations of PUFA will tend to have low stability due to the high probability of oxidative rancidity which takes place on the double bonds present in the structure of the fatty acid (Azain, 2001). Wood et al. (2003) reported that PUFA have more double bonds and are more readily oxidized, producing undesirable flavor, taste, and color, thus reducing the shelf-life. Thus, dietary fat has great importance because it will define the quality of pork fat due to the fact that the fatty acid profile of swine tissues tends to be similar to the profile of the dietary fat (Wood et al., 2003). According to Rosenvold and Andersen (2003), monogastric animals tend to transfer components from the feed unchanged directly to muscle and adipose tissue.

According to Warnants et al. (1999), TAGs are affected by changes in dietary fat while no effects on structural lipids, such as phospholipids, are observed. Hence, different anatomical sites have distinct responses to dietary fat due to differences in the lipogenic 
activity in adipose tissues which may be related to the presence of structural lipids. Additionally, IV may vary depending on the location of the adipose tissue (White et al., 2009). Anderson et al. (1972) reported that the inner and middle backfat layers have a more saturated fatty acid profile due to greater lipogenic activity and enhanced de novo synthetic enzyme activity when compared to the outer layer. Additionally, the more unsaturated fatty acid profile of the outer layer may be a response to preferential deposition of oleic and linoleic acids from the diets (Koch et al., 1968; Brooks, 1971).

\section{Importance of fatty acids on pork quality}

As described before, fatty acid profile of dietary fat will define the characteristics

and quality of pork fat. In general, fats derived from animal origin will tend to have a carbon chain with 16 to 18 carbons long and one or no double bonds, being solid at room temperature. However, fat or oils derived from plant sources contain mainly fatty acids with 18 carbons with two or three double bonds (Azain, 2001). According to Wiseman and Agunbiade (1998), the effects of dietary fat on pork fat are dependent on fat source and/or on the level of fat included to the diet. Furthermore, the same authors reported that during the first 14 to $35 \mathrm{~d}$ of feeding a specific dietary fat, changes of 50 to $60 \%$ in the fatty acid composition of swine adipose tissue are observed.

Other factors that can also affect fatty acid profile of pork are age, genetics, and muscle location. According to Wood (1984), as the amount of fat and muscle increases during the animal's life, the fatty acid profile of pigs changes, with a decrease in the concentration of C18:2 and an increase in the concentration of C18:0 and C18:1. The same authors stated that this fact could be related to an increase in de novo synthesis of 
saturated fatty acids (SFA) and monounsaturated fatty acids (MUFA) and less direct incorporation of PUFA, especially C18:2, from the diets into swine tissues.

Wood et al. (2008) reported that the amount of phospholipids remains constant, or increases little, during the animal's life. In other words, fat deposition is mainly driven by neutral lipids (triacylglycerol) with low contribution of phospholipids. Thus, neutral lipids have higher importance in total lipid content as the fattening process proceeds when compared to the role of phospholipids.

Genetic selection is another factor that can affect fatty acid profile of pork. According to Wood et al. (2008), genetic lines with low fat concentration in muscle will have a greater proportion of phospholipids due to the high presence of this type of fat in muscle tissue. This increase in phospholipids leads to a higher proportion of PUFA in total lipids. Additionally, muscle from lean animals has a high proportion of PUFA due to the fact that C18:2n6 (predominant PUFA) is present in higher proportions in phospholipids than in neutral lipids in all species. C18:2n6 is more rapidly taken up by meat tissues than C18:3n3, reaching thus, higher levels (Wood et al., 2008).

Finally, variation in the fatty acid profile can be found between muscles within the same species. Enser et al. (1998) compared longissimus ("white” muscle) with gluteobiceps ("red" muscle) muscle in 30 grass-fed steers. These authors found that white muscles had a lower amount of PUFA when compared to red muscles, which could be related to the lower amount of phospholipids in white muscles. Thus, by considering all these factors that can affect pork fat quality, the Pork Composition and Quality Assessment Procedures (NPPC, 2000) defined a high quality fat as having a total 
concentration of PUFA less than 15\%, a concentration of stearic acid (C18:0) higher than 15\%, and finally, an IV lower than $70 \mathrm{mg}$ iodine/100 g of fat.

According to Wood and Enser (1997), certain individual fatty acids may be used as indicators of fat quality, especially fat firmness. These authors reported that there are strong correlations between fatty acid profile and firmness of fat tissue where high linoleic acid and low stearic acid concentrations indicate softer fat in leaner carcasses. Moreover, Wood (1984) and Wood et al. (2008) showed that the concentration of linoleic acid can be considered a good predictor of fat firmness. According to these authors, the concentration of linoleic acid (C18:2n6), which is especially found in grains and oilseeds, increased linearly in tissues as dietary intake increased. This observation that stearic acid (C18:0) and linoleic acid (C18:2) are good predictors of fat firmness was also observed by Whittington et al. (1986). However, these authors stated that other factors such as connective tissue and thickness of the fat tissue have also great importance in predicting firmness of a pork carcass.

\section{Impact of fat on human health}

According to Wood et al. (2003), meat is the major dietary fat source, especially of SFA. However, SFA are related to several cardiovascular diseases and cancer (Wood et al., 2005). Thus, certain parameters such as the ratio between PUFA and SFA fatty acids (PUFA:SFA) and the ratio of n6 (omega 6) to n3 (omega 3) fatty acids are of great importance when quality of a product is defined. Besides SFA, n6 fatty acids are also associated with several diseases including cancers and coronary heart disease. Thus, in meats, the recommended level of PUFA:SFA should be higher than 0.4 while a maximum of 4.0 would be the recommended level for ratio of n6:n3 (Enser, 2001; Wood 
et al., 2003). According to Berg (2001), when fat is consumed in excess, there is an increase in the risk for coronary heart disease (CHD) and obesity. The major saturated fatty acid responsible for CHD is palmitic acid (C16:0) while stearic acid (C18:0), along with PUFA, are considered neutral in terms of CHD.

Additionally, meat is a source of essential fatty acids which are important to certain functions of the human organism. The main fatty acids considered essential are linoleic (C18:2n6), linolenic (C18:3n3) and arachidonic (C20:4n6) acids. These fatty acids are precursors of compounds called eicosanoids which have endocrine, paracrine and autocrine functions (Azain, 2001). Furthermore, Wood and Enser (1997) reported that an increase in the concentration of $\alpha$-linolenic acid could result in increased synthesis of long-chain fatty acids such as eicosapentaenoic (EPA; C20:5) and docosahexaenoic (DHA; C22:6) acids which are involved in decreasing the thrombotic tendency of blood. Another way to increase the concentration of EPA and DHA is by supplementing swine diets with fish oil. Thus, according to NRC (1998), the requirement for linoleic acid in swine diets is $0.10 \%$ of the diet.

\section{Fatty acids differences between species}

The main difference among species in fatty acid profile is related to the fact that ruminant animals (cattle and sheep) have a lower concentration of PUFA due to microbial biohydrogenation of fatty acids in the rumen. Biohydrogenation converts PUFA into SFA and MUFA and thus, only a small amount of PUFA is available for incorporation into tissue lipids making ruminant fat firmer than fat of non-ruminant animals (Wood et al., 2008). Moreover, unlike in pigs, as ruminant animals become fatter 
the concentration of C18:1 increases and the amount of C18:0 decreases, leading to an increase in unsaturation and softness (Wood and Enser, 1997).

Enser et al. (1996) attributed these differences due to the fact that pigs are usually fed cereal-based diets which have a high concentration of C18:2. According to these authors, this increase in the concentration of C18:2 in pork increases ratios of PUFA:SFA and n6:n3 fatty acids in non-ruminants as well. Finally, Wood et al. (2005) reported that due to the presence of the rumen, the fatty acid composition of tissues in ruminant animals is more difficult to manipulate by dietary changes when compared to pigs.

\section{SOFT FAT}

Since the 1990's, the importance of fat firmness has increased dramatically and is considered an important factor in the organoleptic and economic value of pork (Irie, 1999). However, several changes in management practices in the swine industry have led to an increase in the incidence of "soft" fat in pigs. Reduction in the fat content of pork has been achieved due to changes in genetics and incentives for improved carcass quality. Moreover, the use of metabolic modifiers in the swine industry has increased in order to enhance growth performance. Additionally, the increase in the use of polyunsaturated fat sources as more cost effective energy sources has led to an increase in the concentration of PUFA in pork (Azain, 2001; Dikeman, 2007).

Thus, the main causes of "soft" fat in pigs are genetic selection for leaner animals, reduction in the amount of fat in pork carcasses as a result of metabolic modifier's action, and the high levels of PUFA fed to pigs. Wood et al. (1986) reported that pigs with $8 \mathrm{~mm}$ of backfat was softer when compared to pigs with $16 \mathrm{~mm}$ of backfat, indicating that as 
animals become leaner fat becomes "softer". Moreover, high levels of PUFA will decrease the melting point of fat turning adipose tissue "soft".

Problems that may arise with "soft" fat include reduced yields, reduced shelf life due to oxidative rancidity, and discrimination by importers (Morgan et al., 1994; Wood and Enser, 1997). Furthermore, when considering bacon manufacturing, "soft" fat may cause additional problems such as slices sticking together, an undesirable wet or oily appearance, translucent and gray color development, and separation of fat from lean (NPPC, 1999, 2000). Finally, it may also be a concern in sausage manufacturing, where particle visualization of lean and fat is considered an important characteristic. In this case, high concentrations of PUFA will decrease the melting point of pork fat and due to an increase in the temperature during the grinding process, fat melts and an unattractive coat forms in the product (Carr et al., 2005b).

Thus, in order to reduce the incidence of "soft" fat in pigs, more attention has been placed to the dietary fat source used and on the effects that it may have on swine performance and carcass and meat quality. However, when high levels of PUFA are fed to pigs due to economic reasons, producers should consider the addition of feed ingredients and even withdrawal periods in order to diminish or eliminate the negative effects caused by dietary fat on pork fat.

\section{SOURCES OF FAT IN SWINE DIETS AND THEIR IMPACT ON PORK QUALITY}

Addition of fat to swine diets has some effects on performance and these effects are directly related to the stage of production. According to Azain (2001), some effects of 
dietary fat inclusion are decreased feed intake, and increased growth rate, feed efficiency and percentage of carcass fat. Thus, in order to better understand the effects of dietary fat inclusion on growth performance, carcass, fat quality and pork quality, sources will be divided into two categories: vegetable oils and animal fats.

\section{Vegetable Oil Sources}

The main vegetable oil sources used in swine nutrition are corn oil (CO) and soybean oil (SBO). According to NSNG (2010), dry matter, digestible, metabolizable and net energies are similar between these two fat sources. Additionally, CO has higher unsaturated fatty acids (UFA):SFA (6.53 vs. 5.64) and total amount of omega-6 fatty acids (58 vs. 51\%), and lower IV (125 vs. 130) and total concentration of omega-3 fatty acids (0.7 vs. 6.8\%) when compared to SBO.

A large variety of studies have been developed in order to verify the effects of CO and SBO on performance, carcass characteristics, fat quality and pork quality. Bee et al. (2002) analyzed the effects of the inclusion of SBO at a $5.0 \%$ level on growth performance, carcass characteristics and fatty acid profile of fat and lean tissues in pigs. No effects on growth performance traits, hot carcass weight (HCW), and lean and subcutaneous fat percentages were observed when SBO was added to the diets. These authors found that SBO increased proportions of PUFA and decreased concentrations of SFA and MUFA in swine adipose tissues when compared to pigs fed a beef tallow supplemented diet.

Apple et al. (2008) found that swine diets supplemented with 5.0\% SBO did not affect average daily gain (ADG), average feed intake (ADFI) and gain to feed (G:F) of finishing pigs. Moreover, backfat of pigs fed SBO-diets had greater amounts of PUFA, 
PUFA:SFA and IV, and lower amounts of SFA and MUFA when compared to pigs fed diets supplemented with beef tallow (BT) at a 5.0\% level. Additionally, SBO did not affect HCW, longissimus muscle depth, fat depth and lean muscle yields when compared to BT-fed pigs. Loins from SBO-fed pigs had improved subjective color scores and lower $\mathrm{L}^{*}$ values when compared to loins from BT-fed pigs.

In another study, Apple et al. (2009a) showed that inclusion of 5.0\% SBO did not affect ADG, ADFI, G:F, HCW or dressing percentage, but increased backfat depth when compared to pigs fed the control diet with no added fat. In a complementary study, Apple et al. (2009b) reported that the concentration of SFA and MUFA (especially oleic and vaccenic acids) in subcutaneous fat was lower in SBO-fed pigs when compared to the control-fed pigs at a slaughter weight of $113.6 \mathrm{~kg}$. Additionally, these same authors reported that PUFA concentration (especially linoleic and linolenic acids) and IV were higher in SBO-fed pigs than control animals.

Nordstrom et al. (1972) reported that increasing levels of CO in swine diets did not affect ADG but improved feed to gain (F:G). Moreover, no effects on backfat thickness, carcass length, longissimus muscle area, ham percentage and loin percentage were observed. However, carcass firmness was negatively affected when CO was added to the diets. Corn oil supplementation decreased the amount of SFA and increased the concentration of UFA in backfat when compared to animals fed the control diet.

Additionally, according to Nordstrom et al. (1972), other varieties of corn have been developed containing twice the amount of oil and a higher amount of protein when compared to normal corn. This is the case with the high oil corn (HOC). Rentfrow et al. (2003) analyzed the effects of the replacement of ground normal corn (control diet) by 
high oil corn (HOC) on the quality of fresh pork bellies. These authors reported that the concentration of SFA was lower while higher amounts of PUFA were observed in fresh bellies when HOC replaced normal corn. Furthermore, MUFA content was unaffected and belly flexibility decreased with HOC supplementation.

However, corn has been largely used, during the last decade, for ethanol production leading thus, to the production of by-products that can be incorporated into swine diets. One of the main by-products obtained is distillers dried grains with solubles which has been widely applied to swine diets as a protein, fat, and energy source.

Dried distillers grains with solubles. Over the past 10 years, ethanol production, especially from corn, has increased leading to production of different by-products which can be incorporated into swine diets (Stein and Shurson, 2009). Dried distillers grains with solubles (DDGS) is a co-product of ethanol production and has been used in swine nutrition (Fairbanks et al., 1944, 1945; Livingstone and Livingston, 1969). Due to construction of ethanol plants in the 1970s, DDGS became available and several studies have been designed to investigate its use as a feed additive for several livestock species.

However, depending on the level of DDGS included in swine diets, pork quality may be affected. Xu et al. (2010a) reported that DDGS has a high concentration of UFA (approximately 81\%), with linoleic acid being the main UFA (around 54\%), and low concentrations of SFA (approximately 13\%). Thus, depending on the level included in swine diets, DDGS may cause greater fat to lean separation (Widmer et al., 2008) and may turn fresh pork bellies into "soft", pliable, and undesirable from a consumer's stand point (Whitney et al., 2006; Weimer et al., 2008). Additionally, as described before, “soft” fat may cause several other processing problems. 
Nutritional value of DDGS. Most of the ethanol produced in the U.S. comes from corn, but wheat, sorghum, and even mixtures of cereals are also utilized (Stein, 2007). Thus, the composition of DDGS may vary largely depending on source and also on procedures used during ethanol production (Stein and Shurson, 2009; Cromwell et al., 1993; Spiehs et al., 2002). According to Pedersen et al. (2007), gross energy (GE) of corn DDGS is on average $5,434 \mathrm{kcal} / \mathrm{kg}$ of dry matter (DM), being higher than the GE of corn (approximately 4,500 kcal/kg). Digestible energy (DE) and metabolizable energy (ME) of DDGS are similar to corn. On average, DDGS has a DE of 4,140 and ME of 3,897 $\mathrm{kcal} / \mathrm{kg}$ of DM, while corn has a DE of 4,088 and ME of 3,989 kcal/kg of DM. However, energy digestibility (measured as a percentage of GE) of DDGS (76.8\%) is lower than that of corn (90.4\%) (Pedersen et al., 2007).

According to NRC (1998), the fiber content (NDF) of DDGS is three times greater than in corn and soybean meal. Due to the high concentration (approximately $35 \%$ insoluble and $6.0 \%$ soluble) and low digestibility (43.7\%), dietary fiber is the main reason for low DDGS digestibility (Stein and Shurson, 2009). The high fiber content in DDGS (ADF and NDF) is related to the fact that fiber present in corn is not converted to ethanol during production (Stein, 2007).

Apple (2010) reported that DDGS has a crude fat content between 10 and 15\%. Additionally, Stein (2007) described that the concentration and digestibility of amino acids, especially lysine, in DDGS may vary largely due to heat damage during DDGS production. Thus, diets should be fortified with amino acids due to the fact that DDGS is limiting in lysine when fed to pigs (Stein and Shurson, 2009). Furthermore, when DDGS is included in swine diets, the use or supplementation of inorganic phosphorous (P) is 
reduced due to the high concentration (from 0.60 to $0.70 \%$ ) and digestibility (59\%) of P in DDGS.

In a typical swine diet, DDGS is included at the expense of corn and soybean meal. In general, if crystalline lysine is supplemented at $0.10 \%$ level, DDGS inclusion at a $10 \%$ level replaces approximately $4.25 \%$ of soybean meal and $5.70 \%$ of corn (Stein, 2007). However, according to Stein (2007), producers should analyze the cost of both soybean meal and corn before deciding if DDGS shall or shall not be included into swine diets.

DDGS application in swine nutrition during growing-finishing phase. Studies have shown that corn DDGS can be included in swine diets during the growing-finishing phase at a level up to $20 \%$ without affecting growth performance parameters (Drescher $e t$ al., 2008; Duttlinger et al., 2008). Other studies have shown that inclusion of DDGS up to 30\% DDGS in swine diets did not affect growth performance (Cook et al., 2005; DeDecker et al., 2005). In contrast, some studies have shown that DDGS negatively affected pig performance when added during the growing-finishing phase. Hinson et al. (2007) showed that inclusion of 0, 10 or 20\% DDGS in swine diets reduced ADG and ADFI linearly. These results were in agreement with Fu et al. (2004) who fed 10, 20 or 30\% DDGS and found a linear decrease in ADG and ADFI as well. Gaines et al. (2007a,b) demonstrated that feed efficiency was negatively affected by the inclusion of $30 \%$ in the diets of growing-finishing pigs. These conflicts could be attributed to the quality (chemical composition, digestibility, etc.) of the source of DDGS utilized in the experiments (Stein and Shurson, 2009). Moreover, Rausch and Belyea (2006) attributed 
these inconsistent results to batch-to-batch variations in the drying method utilized, grain quality, or residual sugars.

Whitney et al. (2006) analyzed the effects of DDGS inclusion at levels up to 30\% in swine diets on growth performance and carcass characteristics of growing-finishing pigs. These authors reported a negative effect on G:F in pigs fed diets containing 30\% DDGS when compared to pigs fed the control diet or diets containing $10 \%$ DDGS. A liner decrease in slaughter weight, HCW, dressing percentage, and loin depth were observed while no linear or quadratic responses were observed for backfat depth or lean percentage with increasing levels of DDGS. Finally, the same authors found a linear reduction in thickness, belly firmness score and IV with increasing levels of DDGS.

Linneen et al. (2008) analyzed the effects of DDGS inclusion at levels up to 30\% in growing-finishing pigs on growth performance and carcass characteristics and found a linear decrease in ADG and ADFI with increasing levels of DDGS. No effects on backfat or loin depth were observed, while HCW was reduced linearly with increasing levels of DDGS. Furthermore, dressing percentage was reduced with DDGS supplementation, which could be related to the fact that DDGS has a high level of dietary fiber.

According to Kass et al. (1980), dressing percentage may be reduced due to the use of fiber-rich ingredients in swine diets which may increase gut fill and intestinal mass. Gill et al. (2000) stated that rate of passage is increased with high levels of dietary fiber, increasing thus, intestinal growth and gut cell proliferation. Moreover, Pluske et al. (2003) reported that DDGS may also increase the digesta weight thus, reducing dressing percentage. Studies have shown that inclusion of corn DDGS in swine diets decreased dressing percentage (Duttlinger et al., 2008; Stender and Honeyman, 2008) while no 
effects of DDGS on dressing percentage were observed in other studies (Hinson et al., 2007; Xu et al., 2007; Weimer et al., 2008).

Widmer et al. (2008) studied the effects of DDGS inclusion at a 10 or $20 \%$ level on pig performance, carcass traits, and pork quality. No effects on HCW, dressing percentage, loin muscle area, longissimus muscle depth, and $10^{\text {th }}$ rib backfat depth were observed when DDGS was added to swine diets at a 10 or $20 \%$ level. Additionally, no effect on belly thickness was observed when DDGS was included in swine diets, but a decrease in belly firmness was found with DDGS inclusion. Moreover, DDGS inclusion had no effects on marbling, subjective color, and $\mathrm{L}^{*}$ or $\mathrm{a}^{*}$ scores of longissimus muscle. However, a decrease in $b^{*}$ value was observed when the concentration of DDGS increased to 20\%. Finally, belly firmness decreased when DDGS was fed at the $20 \%$ level, while IV was not affected.

White et al. (2009) analyzed the effects of DDGS inclusion at 0, 20, or $40 \%$ levels for $30 \mathrm{~d}$ prior to slaughter and found no effects on final body weight, loin muscle area, $10^{\text {th }}$ and last rib backfat depth, loin color, firmness scores, and belly bend measures. Furthermore, a decrease in C16:0 and C18:0 and an increase in C18:1, C18:2 and C18:3 were observed in swine adipose tissue with increasing levels of DDGS. Finally, an increase in IV of belly and backfat and a decrease in the ratio SFA:PUFA was also observed when DDGS was included to the diets.

Xu et al. (2010a) studied the effects of increasing levels of DDGS (0, 10, 20 or $30 \%$ ) on growth performance, carcass composition and pork fat quality of growingfinishing pigs. These authors found that ADG was not affected, while ADFI decreased linearly and G:F was linearly improved with increasing levels of DDGS. Dressing 
percentage and last rib backfat depth were reduced linearly, while carcass fat-free lean increased linearly with DDGS addition. Moreover, longissimus muscle firmness score decreased linearly. Subjective color and $\mathrm{L}^{*}$ score of the longissimus muscle was not affected, while a reduction of $\mathrm{a}^{*}$ and $\mathrm{b}^{*}$ scores were noticed with increasing levels of DDGS. Finally, increasing levels of DDGS in the diets caused a linear increase in the total amount of PUFA and IV, and a linear decrease in the total concentration of SFA and MUFA in backfat, as well as a linear decrease in belly firmness. DDGS inclusion has been shown to negatively affect IV in swine carcasses (Xu et al., 2007; Stender and Honeyman, 2008). As described before, IV is a measurement of the concentration of unsaturated fatty acids in the pork carcass, used by some meat packers as a carcass quality parameter. High iodine values indicate "soft" and less valuable pork bellies and loins and thus, research has been developed in order to address this problem. One possible way to diminish some of the negative effects of DDGS inclusion would be the supplementation of certain feed additives in swine diets. White et al. (2007) found that the inclusion of $1.0 \%$ conjugated linoleic acid (CLA) into DDGS diets reduced fat IV in pigs when fed for 10 days prior to slaughter.

Another possible strategy to alleviate negative effects of DDGS inclusion may be a DDGS withdrawal period before slaughter. This period would reduce some of the negative impacts on pork carcasses caused by diets with a high concentration of polyunsaturated fatty acids (Stein and Shurson, 2009). Warnants et al. (1999) showed that a 60 to $70 \%$ change in carcass composition can be achieved within a two week period of dietary changes while nearly $100 \%$ of changes could be achieved in six to eight wk after a change in dietary fat. Moreover, Gatlin et al. (2002) reported a two percentage 
units decline in the concentration of C18:2 and 2.5 units of IV per week following a dietary fat source change for four, six, or eight weeks before slaughter. Additionally, Xu et al. (2010b) reported that DDGS withdrawal from swine diets for zero to nine wk before slaughter decreased linearly the amount of C18:2 and the IV of belly fat of growing-finishing pigs. These same authors reported that similar belly firmness to that in pigs fed the control diet could be achieved when diets containing DDGS at 10 or 30\% levels were withdrawn three, six, or nine weeks prior to slaughter.

\section{Animal fat sources}

The main animal fat sources utilized in swine nutrition are beef tallow (BT), choice white grease (CWG), and poultry fat (PF). According to NSNG (2010), BT has a dry matter of $99 \%$, digestible energy of 3,636 kcal/lb, metabolizable energy of 3,491 kcal/lb, net energy of 3,142 kcal/lb, UFA:SFA of 0.92 , IV of 44, total amount of omega-6 fatty acids of $3.1 \%$, and a total concentration of omega-3 fatty acids of $0.6 \%$.

Averette-Gatlin et al. (2002a) fed pigs diets containing 0, 2.5, or 5.0\% dietary fat comprised of 0,50 , or $100 \%$ BT. These authors found that feed intake decreased linearly and F:G was improved linearly as dietary fat level increased in the diet while no effects on ADG were observed. These authors found a linear decrease in PUFA and IV, and a liner increase in C16:1 and C18:1 in backfat of pork as the level of BT increased in the diet.

Weber et al. (2006) reported that ADFI decreased and G:F was improved when $5.0 \%$ of BT was added to a control diet (based on corn-soybean meal) with no added fat and fed to genetically lean gilts. These authors showed that BT increased carcass weight but did not affect backfat depth, dressing percentage, and predicted lean percentage when 
compared to the pigs fed the control diet. Beef tallow increased LM area but had no effect on $\mathrm{pH}$, color, marbling, and firmness score of the longissimus muscle. Belly firmness score and belly length were not affected by BT as well. Beef tallow inclusion decreased the amount of SFA, and increased MUFA and IV of belly fat, while no effects were observed on the concentration of PUFA.

Eggert et al. (2007) showed that BT had no effect on growth performance traits, carcass weight, and dressing percentage when included in swine diets. Additionally, BTfed pigs had lower ADFI and improved G:F when compared to the control group, while no effects on ADG were observed. No effects on 24-h pH, longissimus muscle area, drip loss, objective and subjective loin color, firmness, and marbling scores were observed with BT supplementation.

Finally, Apple et al. (2009a) demonstrated that ADG, ADFI, G:F, HCW and dressing percentage were not affected by the inclusion of beef tallow (BT) at a $5.0 \%$ level. Moreover, these authors reported that backfat depths increased with BT supplementation in the diets. In a complementary study, Apple et al. (2009b) showed that the concentrations of SFA (especially C16:0 and C18:0) and PUFA (especially linoleic acid) in subcutaneous fat were lower in BT-fed pigs at slaughter weight of $113.6 \mathrm{~kg}$ when compared to pigs fed a control diet (based on corn-soybean meal) devoid of supplemented fat. MUFA (especially oleic and vaccenic acids) was higher and IV was numerically lower in BT-fed pigs when compared to the animals in the control group.

Choice white grease has a dry matter of 99\%, digestible energy of 3,768 kcal/lb, metabolizable energy of 3,616 kcal/lb, net energy of 3,254 kcal/lb, UFA:SFA of 1.45, IV of 60 , total amount of omega- 6 fatty acids of $11.6 \%$ and a total concentration of omega-3 
fatty acids of 0.4\% (NSNG, 2010). Rentfrow et al. (2003) analyzed the effects of CWG inclusion at $4.91 \%$ level in a conventional diet based on corn and soybean meal with no added fat. These authors reported that the concentration of SFA was lower, while a higher concentration of MUFA and PUFA was observed in fresh bellies when CWG was added to the control diet. Furthermore, CWG decreased belly firmness when compared to the control fed pigs.

Engel et al. (2001) showed that CWG at a 6.0\% level did not affect ADG and body weight, but decreased ADFI and improved G:F when compared to animals fed a control diet. Additionally, dressing percentage, backfat thickness, carcass length, longissimus muscle area, lean percentages, and belly firmness were not affected by CWG inclusion. Finally, CWG supplementation decreased the amount of SFA and increased the concentration of UFA in belly samples of growing-finishing pigs.

Weber et al. (2006) reported that ADFI decreased and G:F was improved when 5.0\% of CWG was added to a control diet (based on corn-soybean meal) with no added fat and fed to genetically lean gilts. These authors showed that CWG increased carcass weight, $10^{\text {th }}$ rib backfat depth, and longissimus muscle area, but did not affect dressing percentage, predicted lean percentage, $\mathrm{pH}$, color, or marbling and firmness score of the longissimus muscle. Belly firmness score and belly length were not affected by CWG either. CWG inclusion decreased the amount of SFA, and increase MUFA and IV of belly fat, while no effects were observed on the concentration of PUFA.

Poultry fat is abundant in certain regions of the U.S. and an inexpensive animal fat source (Engel et al., 2001). Poultry fat has a dry matter of 99\%, digestible energy of 3,873 kcal/lb, metabolizable energy of 3,718 kcal/lb, net energy of 3,346 kcal/lb, 
UFA:SFA of 2.20 , IV of 78 , total amount of omega- 6 fatty acids of $19.5 \%$ and a total concentration of omega-3 fatty acids of $1.0 \%$ (NSNG, 2010). The effects of PF inclusion in swine diets at $0,2.5$ or $5.0 \%$ levels on performance, body composition and tissue lipids of swine were studied by Seerley et al. (1978). These authors reported that ADG was not affected by PF, but F:G was improved with increasing levels of PF in the diets. Dressing percentage, carcass length, longissimus muscle area, and lean cut percentages were not affected by PF inclusion. Backfat depth was higher in pigs fed PF at 5.0\% level than in pigs fed the control diet and PF inclusion decreased the concentration of C18:1 and increased the amount of C18:2 in intramuscular fat when compared to control-fed pigs.

Engel et al. (2001) analyzed the effects of PF supplementation in swine diets at 2.0, 4.0 or $6.0 \%$ levels on performance, carcass, and meat quality of growing-finishing pigs. These authors reported no effects on ADG and body weight, but a decrease in ADFI and an improvement in G:F when PF was included at 6.0\% level in swine diets. Additionally, no effects on HCW, dressing percentage, backfat depth, longissimus muscle area, percentage lean, and carcass length were observed when PF was included to the diets. Poultry fat inclusion did not affect belly firmness or the quality of longissimus muscle. However, increasing levels of PF linearly decreased the amount of C16:0 and linearly increased the concentration of C18:2 in intramuscular fat.

Apple et al. (2009a) showed that ADG, ADFI, G:F, HCW and dressing percentage were not affected by the inclusion of PF at a 5.0\% level, while a decrease in backfat depth was noticed with PF supplementation. In a complementary study, Apple et al. (2009b) reported that PF decreased the concentration of SFA (especially C16:0 and C18:0) and increased the amount of MUFA (especially oleic and vaccenic acids) in 
subcutaneous fat when compared to pigs fed a control diet (based on corn-soybean meal) devoid of supplemented fat at a slaughter weight of $113.6 \mathrm{~kg}$. Furthermore, PUFA (especially linoleic acid) was similar while IV was higher in PF-fed pigs than in control animals.

\section{METABOLIC MODIFIERS}

According to Dikeman (2007), metabolic modifiers are defined as compounds that can be fed, implanted, or injected in animals in order to enhance growth performance traits, improve visual meat quality, and/or extend shelf-life. They can be classified in several categories including: anabolic steroids, somatotropin, phenethanolamines or beta agonists, vitamins or vitamin-like compounds, “designer” lipids, and other modifiers.

\section{Ractopamine Hydrochloride (RAC)}

Ractopamine hydrochloride (RAC) is a phenethanolamine with similar properties to a beta-adrenergic agonist. Since 1999, RAC has been approved in the United States by the Food and Drug Administration (FDA) to be used in finishing swine weighing from 68 to $109 \mathrm{~kg}$. However, in May of 2006, FDA approved its use at levels from five to $10 \mathrm{ppm}$ in finishing swine for the last 20.4 to $40.8 \mathrm{~kg}$ prior to slaughter (Carr et al., 2009).

Ractopamine works by redirecting nutrients away from adipose tissue accretion and toward lean tissue deposition (Moody et al., 2000; Carr et al., 2005a). According to Moody et al. (2000) improvements in performance by RAC inclusion are affected by several factors including duration of RAC feeding, level of RAC inclusion, and nutrient concentration of the diets. Additionally, the same authors reported that RAC response diminishes overtime due to either down-regulation or desensitization of the $\beta 1$-adrenergic 
receptors. This observation was also noticed by Dunshea et al. (1993) who reported that RAC response increases, reaches a plateau for a certain period of time and then seems to decrease with the feeding of RAC. According to Fernández-Dueñas et al. (2008), the maximum response to RAC is usually obtained between 21 to 28 days of feeding. Furthermore, it has been determined that the response to RAC is greater in pigs with a high genetic potential for lean growth (Gu et al., 1991a,b; Bark et al., 1992).

Mechanism of action. Once in the organism, beta-adrenergic agonists ( $\beta \mathrm{AA})$ will bind to beta-adrenergic receptors $(\beta \mathrm{AR})$ which are similar to receptors that can bind to $\mathrm{G}$ proteins. These receptors have a total of seven cylindrical membrane-spanning domains which are responsible for the formation of the binding pocket for agonists and antagonists. Furthermore, these receptors have intervening stretches forming intra- or extracellular loops (Strader et al., 1989).

Once a ligand binds to a $\beta A R$, a conformational change happens in the receptor and a $G_{s}$ protein is activated. This $G_{s}$ protein is a GTP-binding protein, and when activated, its active site moves and binds to a membrane-bound adenylate cyclase (Nelson and Cox, 2000). Adenylate cyclase synthesizes a second messenger, cAMP, which phosphorylates several other cAMP-dependent protein kinases (Fain and GarciaSainz, 1983). Thus, on adipose tissue cells, phosphorylation activates hormone-sensitive lipases and the rate of lipolysis is increased.

During lipolysis, TAGs are hydrolyzed to free fatty acids, which leave adipocytes and are transported to myocytes by a protein called serum albumin in the blood. At myocytes, fatty acids are oxidized to $\mathrm{CO}_{2}$ and the energy is conserved in ATP, which is used for muscle contraction and other ATP-requiring metabolic processes (Nelson and 
Cox, 2000). After a certain period of exposure to high concentrations of an agonist, levels of cAMP are slightly affected, indicating a desensitization of the receptor. At this point, $\beta A R$ is phosphorylated by a cAMP-dependent protein kinase and a $\beta A R$-associated protein kinase ( $\beta$ ARK). This action will uncouple the $\beta A R$ from activation of $G_{s}$, decreasing the receptor's sensitivity and response to a ligand (Nelson and Cox, 2000).

Effects of $\beta \mathrm{AA}$ on muscle tissue have also been reported (Bergen et al., 1989; Helferich et al., 1990). Beta-adrenergic agonists act synergistically with insulin, promoting amino acids transport and protein synthesis and decreasing the rate proteins are degraded (Li and Jefferson, 1977; Deshaies et al., 1981). Other factors such as an increase in mRNA of $\alpha$-actin and myosin (Helferich et al., 1990; Killefer and Koohmarie, 1994) and a decrease in mRNA of cathepsins and calpains (Wang and Beerman, 1988; Forsberg et al., 1989; Killefer and Koohmarie, 1994) have also been reported, indicating increased protein accretion.

Ractopamine application in swine nutrition. The use and application of RAC in swine diets and its effect on growth performance, carcass characteristics, fat quality and pork quality has been well studied. Adeola et al. (1990) reported that supplementation of RAC at a 20 ppm level for 28 days improved G:F, increased HCW and loin depth, and decreased leaf fat in pigs. Moreover, these authors found an interaction between RAC and dietary protein, where RAC increased weight gain when added to a $17 \%$ protein diet while a decrease in gain was observed when RAC was added to a $13 \%$ protein diet. This agrees with the observation described before, that RAC response depends on the nutrient composition of the diet. 
Uttaro et al. (1993) showed that improvements in feed efficiency and ADG were obtained when crossbred pigs were fed diets containing 20 ppm of RAC. Furthermore, a decrease in $10^{\text {th }}$ rib backfat depth and an increase in longissimus muscle depth and predicted lean yield were also observed in RAC-treated pigs.

McKeith et al. (1994) found that RAC had neutral to positive effects on visual meat quality and sensory traits of both pork and beef including aspects such as marbling, color, and tenderness. However, some studies have shown that RAC may decrease tenderness, increasing Warner-Bratzler Shear Force (WBSF) values, when fed at high levels of 20 ppm (Aalhus et al., 1990; Uttaro et al., 1993).

Stoller et al. (2003) stated that RAC increased ADG and longissimus muscle area when fed to three genetic lines of swine at a level of $10 \mathrm{ppm}$ for 28 days. Moreover, a reduction in $10^{\text {th }}$ rib backfat depth was observed only in the high lean genetically line, indicating that RAC response may be genetic line dependent as described before. More recently, Armstrong et al. (2004) reported that RAC inclusion for 27 days prior to slaughter increased ADG and improved G:F of finishing pigs, while no effects on ADFI were observed. Moreover, preshipment live weight, HCW, and dressing percentage were higher in pigs fed RAC-containing diets compared with control-fed pigs. Additionally, loin eye area (LEA) and fat-free carcass lean were increased, while no differences in $10^{\text {th }}$ rib fat depth were observed when RAC was supplemented in swine diets.

Brumm et al. (2004) analyzed the effects of RAC supplementation for 28 days at a level of $10 \mathrm{ppm}$ and found that RAC decreased ADFI and improved feed efficiency of crossbred barrows. Additionally, loin depth and carcass lean percent increased when RAC was added to swine diets. In another study, See et al. (2004) analyzed the effects of 
RAC on growth performance and carcass quality of finishing pigs and found that RAC decreased ADG and improved G:F, but had no effects on ADFI. The same authors showed that HCW, percent yield, loin muscle area, and fat-free lean increased while backfat thickness decreased when RAC was fed in a constant feeding program.

Additionally, Carr et al. (2005a) noticed that ADFI was not affected, but ADG and feed efficiency were improved with increasing RAC concentration in swine diets. Furthermore, dressing percentage, HCW, loin muscle area, and fat-free lean trimmings were greater in pigs fed RAC-containing diets compared to RAC-untreated pigs, while no effects on backfat depth measurements were observed. In another study, Carr et al. (2005b) showed that late-finishing pigs fed RAC for $28 \mathrm{~d}$ at a level of $10 \mathrm{ppm}$ had numerically higher ADG, lower feed intake, and improved G:F when compared to pigs that did not receive RAC. The same authors also found lower leaf fat weights, $10^{\text {th }}$ rib backfat, last rib backfat, and belly firmness, and increased dressing percentage and LEA in pigs fed RAC. Moreover, no effects on IV and minimal differences on fatty acid profiles were observed when RAC was included to the diets.

$\mathrm{Xi}$ et al. (2005) reported that no effects on fatty acid profiles or IV of belly samples were observed when RAC was fed to finishing pigs at levels of five or $10 \mathrm{ppm}$ for five weeks. However, the same authors found that 10 ppm of RAC supplementation increased the concentration of linoleic acid, total PUFA, and IV in clearplate fat of finishing pigs.

Weber et al. (2006) demonstrated that feeding RAC at $10 \mathrm{ppm}$ level increased ADG and body weight, and improved feed efficiency of genetically lean gilts. In addition, RAC supplementation increased carcass weight, dressing percentage, predicted 
percent lean, and longissimus muscle area. Moreover, RAC-treated pigs had lower outerlayer backfat depth and tended to have lower $10^{\text {th }}$ rib backfat depth when compared to pigs that did not receive RAC. These authors also found that RAC inclusion had little to no effect on fatty acid profiles of pig tissues; a trend toward less SFA in belly samples was observed, while an increase in the total amount of PUFA was noticed in inner-layer backfat depth when RAC was added to the diets. RAC inclusion increased IV in innerlayer backfat depth and tended to increase IV in outer-layer backfat depth in pigs.

Apple et al. (2007) reported that RAC acts differently depending on the fat source. These authors found that RAC at the $10 \mathrm{ppm}$ level had little to no effect on SFA, PUFA:SFA and IV of belly samples when fed along with beef tallow. However, when RAC was included in diets containing SBO, it exacerbated the effects caused by SBO, decreasing the total amount of SFA and increasing PUFA:SFA and IV of belly samples. Additionally, RAC had no effects on MUFA and tended to increase PUFA (especially linoleic and linolenic acids) concentration, regardless of fat source.

More recently, Apple et al. (2008) observed that RAC inclusion at a level of 10 ppm increased ADG and improved G:F but did not affect ADFI of crossbred finishing pigs when fed for $35 \mathrm{~d}$. An increase in HCW, loin depth and lean muscle yield and a decrease in fat depth was also observed when RAC was included in the diets. The same authors found that RAC supplementation reduced the concentrations of SFA (especially palmitic acid) and MUFA (especially oleic acid), and increased the amount of PUFA (especially linoleic, $\alpha$-linolenic, eicosadienoic, and arachidonic acids), PUFA:SFA, and IV in backfat samples of finishing pigs. 
Fernández-Dueñas et al. (2008) demonstrated that RAC inclusion increased HCW and lean cut yields in heavy body weight pigs, while no effects on backfat depth or longissimus muscle depth were observed. Carr et al. (2009) analyzed the effects of RAC on carcass and meat quality of heavy pigs fed normal or amino acid (AA) fortified diets. They found that RAC inclusion in AA fortified diets increased hot and cold carcass weight, LEA, and decreased $10^{\text {th }}$ rib fat depth when compared to pigs that did not receive RAC.

\section{Conjugated Linoleic Acid}

Conjugated linoleic acid (CLA) is known as a group of positional and geometric isomers of linoleic acid which have in common double bounds with a single carbon bound in between instead of the usual methylene-separation. The double bonds in CLA isomers vary in location $(7,9 ; 8,10 ; 9,11 ; 10,12 ; 11,13)$ and also in geometry (cis,cis; cis,trans; trans,trans; trans/cis) (Schmid et al., 2006). However, according to Larsen et al. (2003) the main isomers of CLA found in synthetic CLA sources are 9 cis,11 trans and 10 trans,12 cis, while in beef and dairy products the isomer 9 cis,11 trans is responsible for approximately $80 \%$ of the total CLA content (Fritsche and Steinhardt, 1998).

According to Griinari and Bauman (1999), CLA is produced in the rumen via bacterial isomerisation and/or biohydrogenation of PUFA and in the mammary gland and adipose tissue via desaturation of trans-fatty acids. In the rumen, CLA can be directly obtained or important precursors can be formed instead with trans-vaccenic acid (C18:1trans11) being the main intermediate (Schmid et al., 2006). Once obtained, transvaccenic acid can be transported to muscle lipids and then, due to the action of $\Delta 9$ - 
desaturase enzyme, converted into the CLA isomer C18:2-9cis,11trans (Bauman et al, 1999; Griinari et al., 2000; Knight et al., 2003; Scollan et al., 2006).

However, due to the fact that dietary fat is not modified prior to digestion in nonruminant animals, pigs have to be fed a diet containing CLA or trans-vaccenic acid, which will serve as a substrate for endogenous CLA synthesis, in order to elevate the concentration of CLA in swine tissue (Schmid et al., 2006). Thus, the main sources of CLA are products from ruminant animals (Schmid et al., 2006) while low concentrations can also be found in fish and some vegetable products (Chin et al., 1992). Since July of 2009, CLA has being marketed in the U.S. under the trade name of Lutalin ${ }^{\circledR}$ (BASF SE, Ludwigschafen, Germany).

Mechanism of Action. According to Moya-Camarena et al. (1999), CLA induces peroxisomal $\beta$-oxidation (catabolism) of fatty acids because it has the ability to bind and activate peroxisome proliferator-activated receptor-alpha (PPAR- $\alpha$ ) in hepatoma which causes $\beta$-oxidation. Moreover, CLA inhibits FAS and ACC, depressing thus, de novo synthesis of fatty acids (Ostrowska et al., 1999; House et al., 2005). Additionally, CLA decreases stearoyl-CoA desaturase (SCD-1) gene expression (Demaree et al., 2002; Smith et al., 2002) which is responsible for the conversion of SFA to UFA. Thus, there is decreased conversion of SFA to UFA and increased carcass and belly firmness (Smith et al., 2002; Dobrzyn and Ntambi, 2005). Other studies have also shown the ability of CLA inhibiting activity of $\Delta 9$-desaturase, increasing the concentration of SFA in swine tissues (Lee et al., 1998; Bretillo et al., 1999). 
CLA application in swine diets. Several studies have been performed in order to analyze the effects of CLA inclusion in swine diets on growth performance, carcass traits, and fat and pork quality. However, according to Thiel-Cooper et al. (2001), variations in responses to the feeding of CLA can be obtained, being related to several factors including sex, genetics and season. Dunshea et al. (2005) stated that CLA response depends on the total percentage of fat of the animal. The higher the initial backfat depth in a pig, the greater the reduction in backfat depth, indicating a greater CLA response.

Dugan et al. (1997) studied the effects of CLA supplementation to finishing pigs and found no effects on ADG, while feed intake was decreased in pigs fed CLAcontaining diets. Moreover, the inclusion of CLA reduced the total amount of fat on the carcass which increased the amount of carcass lean in finishing pigs. Cook et al. (1998) analyzed the effects of CLA inclusion at a $0.6 \%$ level to diets of finishing pigs and reported that feed intake decreased while growth rate was unaffected, indicating thus, a positive effect on feed efficiency. Additionally, CLA inclusion increased LEA and belly firmness and decreased backfat thickness of finishing pigs.

In another study, Dugan et al. (1999) showed that when CLA was fed at a 2.0\% level, ADFI was reduced, feed efficiency was improved, and no effects on growth rate were observed in pigs from 61.5 to $106 \mathrm{~kg}$ live weight. Furthermore, marbling score and intramuscular fat content of the longissimus muscle were improved, while no effects on longissimus thoracis shear-force, drip loss, and color were noticed. Thiel-Cooper et al. (2001) showed that when pigs were fed diets with increasing levels of CLA (0.12 to 1\%), a linear increase in ADG and feed efficiency was obtained while no differences in ADFI were observed. Furthermore, these authors demonstrated that CLA supplementation in 
swine diets did not have an effect on LEA, or first and last rib backfat depth, but decreased $10^{\text {th }}$ rib backfat depth. CLA supplementation increased the concentration of myristic acid (C14:0) and C16:0 and decreased the concentration of C18:1 and C20:4 in lean tissue of pigs, indicating a shift to a lower PUFA:SFA. Changes in the fatty acid profile of adipose tissue were also observed with a decrease in C16:0 and an increase in C18:1 and C18:2. This increase in the concentration of C18:2 in swine adipose tissue was related to the fact that the source of CLA had higher levels of UFA when compared to the control diet utilized in the study. Finally, an increase in belly firmness was noticed in pigs fed CLA-containing diets.

Ramsay et al. (2001) found no differences in body weight, ADG, feed efficiency, HCW, or dressing percentage when CLA was supplemented at increasing levels to growing pigs. However, when fed at 0.25 and $0.5 \%$ of the diet, CLA inclusion increased $10^{\text {th }}$ rib backfat depth when compared to pigs fed the control diet. Moreover, CLA feeding increased the concentration of C16:0 and C18:0 and decreased the amount of C18:1, C18:2, C18:3 and C20:4 in subcutaneous adipose tissue of growing pigs.

Eggert et al. (2001) studied the effects of CLA inclusion at a 0.3\% level in diets of genetically lean pigs and reported an increase in ADG and no effects on backfat thickness or longissimus muscle area with CLA feeding. Additionally, the same authors showed an increase in the concentration of SFA and a decrease in the amount of UFA and IV in swine tissues when CLA was added to the diets. Finally, belly firmness was increased and no effects on subjective color and ultimate $\mathrm{pH}$ of the longissimus muscle were observed when CLA was supplemented in swine diets. 
Wiegand et al. (2001) found no effects on ADG and improvements in G:F when CLA was fed at $0.75 \%$ of the diet to different stress-genotype growing-finishing pigs. The same authors observed that pigs fed CLA had lower $10^{\text {th }}$ and last rib backfat depth when compared to pigs fed diets without CLA, while no effects on loin muscle area, subjective color, or ultimate $\mathrm{pH}$ of the longissimus muscle were observed in CLA-fed pigs. In another study, Wiegand et al. (2002) analyzed the effects of CLA supplementation in swine diets at a $0.75 \%$ level for different lengths of time. These authors found that ADG and ADFI were not affected, while G:F showed a quadratic response to CLA inclusion. Pigs fed CLA for the last 29 and $56 \mathrm{~kg}$ of weight gain before slaughter had improved efficiency when compared to pigs fed diets with no CLA included. Additionally, LEA linearly increased, while first, $10^{\text {th }}$ and last rib backfat depth decreased linearly with CLA supplementation. No effects on ultimate $\mathrm{pH}$ of the longissimus muscle were observed, and independent of storage day, lightness $\left(\mathrm{L}^{*}\right)$ and redness $\left(\mathrm{a}^{*}\right)$ were not affected by CLA inclusion while yellowness $\left(\mathrm{b}^{*}\right)$ increased over time with CLA supplementation when compared to pigs fed the control diet. Moreover, a linear increase in SFA and total CLA isomers and a quadratic decrease in C18:1 in loin chops and subcutaneous fat samples was observed. Finally, a linear decrease in PUFA was noticed in loin chops and a decrease in the amount of arachidonic acid was also observed in CLA-fed pigs.

Averette-Gatlin et al. (2002b) analyzed the effects of CLA supplementation at a $0.6 \%$ level in lean genotype gilts and found that CLA had no effects on longissimus muscle area, backfat depth, or percentage of fat-free lean. The same authors showed that pigs fed CLA had higher concentrations of C18:0 and lower amounts of C18:1 in various 
fat depots which was indicative of a reduction in the activity of $\Delta 9$-desaturase enzyme. The effectiveness of dietary CLA in decreasing the IV of belly fat was also demonstrated in this study.

Joo et al. (2002) designed another study where CLA was fed at increasing levels $(0,1.0,2.5$ and $5.0 \%)$ to pigs for 28 days prior to slaughter. These authors found that CLA had positive effects on intramuscular fat content, purge loss, and color stability during cold storage. Moreover, dietary CLA decreased the amount of UFA, especially C18:2 and C20:4, and increased the concentration of SFA and total CLA in intramuscular fat samples.

More recently, Lauridsen et al. (2005) studied the effects of CLA inclusion at a $0.5 \%$ level on growth performance of growing-finishing barrows and found that pigs fed CLA had improved feed utilization and higher live weights when compared to pigs fed the control diet, while ADG tended to be higher in CLA-fed pigs. No effects on backfat thickness, muscle percentage, $\mathrm{pH}$ and temperature (at $45 \mathrm{~min}$ and $24 \mathrm{~h}$ after slaughter), or fat content of the longissimus muscle were observed in CLA-fed pigs. Additionally, CLA feeding resulted in increased concentrations of SFA (especially C14:0 and C16:0) and decreased concentrations of MUFA (especially C18:1), while no differences were observed in the concentration of PUFA in muscle tissue.

Weber et al. (2006) found no effects on G:F when CLA was fed at $0.6 \%$ level to genetically lean pigs. Moreover, CLA increased predicted lean percentage, decreased last rib backfat depth, and tended to decrease $10^{\text {th }}$ rib fat depth. These authors reported that bellies from pigs fed CLA-containing diets had lower concentrations of MUFA and higher amounts of SFA and total CLA when compared to pigs fed a control diet. 
Furthermore, IV of bellies decreased while belly firmness increased when CLA was included in the diets.

Corino et al. (2008) reported that CLA feeding did not affect ADG, final weight, carcass weight, dressing percentage, and thickness of backfat depth when fed at $0.75 \%$ level to heavy pigs. Additionally, CLA supplementation did not affect objective color of longissimus muscle, except $\mathrm{b}^{*}$ score, which was increased in pigs fed CLA-containing diets. White et al. (2009) found no differences in body weight, ADG, feed efficiency, LEA, $10^{\text {th }}$ and last rib backfat depths, and subjective color of the longissimus muscle when CLA was fed to growing-finishing pigs at a $0.6 \%$ level. The same authors reported that CLA increased the amount of C14:0, C18:0, and total CLA, and decreased IV, C18:1, and C18:1n7 concentrations of belly and backfat.

Larsen et al. (2009) analyzed the effect of CLA inclusion at $0.75 \%$ level on carcass characteristics of crossbred barrows and found that carcass weight, loin muscle area, and last and $10^{\text {th }}$ rib backfat depth were not affected by CLA inclusion. However, CLA improved belly firmness, increased the concentrations of C16:0 and C18:0, and decreased the percentages of C18:1, C18:3 and C20:4 in bacon tissues. Finally, Cordero et al. (2010) reported that pigs fed CLA at levels up to $2.0 \%$ for 85 days had higher concentrations of SFA and lower concentrations of MUFA in muscle and adipose tissue when compared to pigs fed a control diet.

In addition to some positive effects on growth performance, carcass traits and fat and pork quality, CLA has shown anti-cancer properties and also the ability to reduce fat streak formation in the aortas and arteriosclerosis models (Cook, 1999). Some studies (Ramsay et al., 2001; Joo et al., 2002; Wiegand et al., 2002; Larsen et al., 2009) have 
also shown the ability of CLA to decrease the concentration of C20:4. Thus, due to the fact that C20:4 is an upstream precursor to prostaglandin E2 $\left(\mathrm{PGE}_{2}\right)$, which at high concentrations stimulates bone catabolism, CLA feeding may decrease the concentration of $\mathrm{PGE}_{2}$, resulting thus, in greater bone mass (Watkins and Seifert, 2000). 
Table 1.1. Changes in loin eye area, carcass backfat and slaughter weight, 1956-1999

\begin{tabular}{cccc}
\hline Year & Loin Eye Area $\left(\mathrm{cm}^{2}\right)$ & Backfat $(\mathrm{cm})$ & Average Slaughter Weight $(\mathrm{kg})$ \\
\hline 1956 & 26.2 & $3.61^{\mathrm{a}}$ & 98.4 \\
1960 & 28.8 & $3.56^{\mathrm{a}}$ & 96.3 \\
1966 & 32.0 & $3.23^{\mathrm{a}}$ & 98.4 \\
1970 & 34.2 & $2.97^{\mathrm{a}}$ & 99.8 \\
1975 & 34.2 & $3.17^{\mathrm{a}}$ & 107.0 \\
1980 & 29.6 & $2.64^{\mathrm{b}}$ & 96.6 \\
1985 & 30.2 & $2.92^{\mathrm{b}}$ & 103.0 \\
1990 & 31.8 & $2.79^{\mathrm{b}}$ & 104.3 \\
1995 & 43.2 & $1.80^{\mathrm{b}}$ & 109.1 \\
1999 & 42.1 & $1.48^{\mathrm{b}}$ & 108.2 \\
\hline
\end{tabular}

${ }^{a}$ Average of three measurements (first rib, last rib, last lumbar);

b Tenth rib backfat measurement.

Adapted from Hollis and Curtis (2001). 


\title{
CHAPTER 2
}

\section{DIETARY INCLUSION OF CORN DRIED DISTILLERS GRAINS WITH SOLUBLES (DDGS) UP TO FORTY FIVE PERCENT DOES NOT CHANGE PIG GROWTH PERFORMANCE OR CARCASS TRAITS BUT INCREASES IODINE VALUE TO UNACCEPTABLE LEVELS}

\begin{abstract}
The use of DDGS in swine diets has been widely studied and depending on the inclusion level, DDGS may cause negative effects on growth performance and carcass quality. Thus, this experiment evaluated the effects of increasing levels of DDGS on growth performance, carcass and meat quality of growing-finishing pigs. A total of 64 crossbred pigs (Monsanto genetics) were blocked by initial weight and randomly allotted to dietary treatment containing $0,15,30$ and 45\% DDGS. Considering the overall experimental period, $\mathrm{F}: \mathrm{G}$ tended to increase linearly $(\mathrm{P}=0.09)$ and no linear or quadratic responses were observed for ADG $(\mathrm{P}>0.10)$ and $\mathrm{ADFI}(\mathrm{P}>0.37)$. Furthermore, no linear ( $\mathrm{P}>0.14)$ or quadratic $(\mathrm{P}>0.17)$ effects were found for live weight, hot carcass weight, tenth and last rib backfat, loin eye area, dressing percentage, percentage lean and belly flexibility. Minolta color of the longissimus muscle did not show a linear $(\mathrm{P}>0.21)$ or quadratic $(\mathrm{P}>0.40)$ response to DDGS inclusion. Fatty acid analyzes revealed a linear increase ( $\mathrm{P}<0.0001)$ in iodine value (IV) with increasing levels of DDGS in belly, jowl and
\end{abstract}


subcutaneous fat samples. Strong correlations for IV among fat depots were obtained at low DDGS levels; as DDGS concentration increased (30 and 45\%) the correlations decreased. These results indicated that DDGS could be fed to growing-finishing pigs at a 30\% level without negative impacts on growth performance and carcass and meat quality.

\section{INTRODUCTION}

Dried distillers grains with solubles (DDGS) is a co-product of ethanol production and along with other polyunsaturated dietary fat sources it has been fed in swine diets as a more cost-effective energy source. However, depending on the level of DDGS included in swine diets, it can have some negative impacts on pork quality. Due to the high concentration of polyunsaturated fatty acids, DDGS may reduce belly firmness and increase IV (Whitney et al., 2006; Xu et al., 2010a), affecting thus, further processing by reducing bacon yields, increasing energy costs of bacon slicing and also reducing shelflife (Morgan et al., 1994; Wood and Enser, 1997; Apple et al. 2007).

According to Stein (2007), results from swine studies involving the feeding of DDGS were inconsistent with respect to the concentration that DDGS can be added to swine diets without having a negative impact on growth performance and carcass quality. Thus, the same author concluded that more research is needed in order to determine the effects of high inclusion rates on carcass quality, especially belly firmness. These variations in results may be related to several factors including variability in source of DDGS, quality of the grain, levels of residual sugar and also batch-to-batch variations in drying methods (Rausch and Belyea, 2006; Stein, 2007). 
Thus, the objective of this experiment was to determine if moderate to high levels of DDGS could be fed to growing-finishing pigs without negative impacts on growth performance, carcass quality, particularly belly firmness, and fatty acid composition of market hogs.

\section{MATERIALS AND METHODS}

\section{Animals and Diets}

Before initiation of this experiment, animal care and experimental protocols were approved by the University of Missouri Animal Care and Use Committee. Then, a study involving 64 crossbred (Monsanto genetics) pigs with an initial body weight of $31 \pm 1.8$ kg was designed to evaluate four dietary treatments (Table 2.1) consisting of a cornsoybean meal diet and three additional diets containing 15, 30, or 45\% DDGS. Diets were fed to growing-finishing pigs from $31 \pm 1.8 \mathrm{~kg}$ to $120 \pm 3.1 \mathrm{~kg}$ body weight in three phases. Diets were formulated to contain $0.83,0.70$, and $0.58 \%$ true ileal digestible (TID) lysine during the three phases of the study with diet changes made at 60 and $93 \mathrm{~kg}$ body weights, respectively. Diets and water were provided on an ad libitum basis.

The DDGS source (Table 2.2) was supplied by Archer Daniel Midland (Decatur,

IL) and replaced corn and soybean meal. In order to maintain constant TID levels of lysine and tryptophan, up to $0.22 \%$ L-lysine $\mathrm{HCl}(0.17 \%$ L-lysine) and $0.04 \% \mathrm{~L}$ tryptophan were added to the diets in each phase. Pigs were randomly allotted to treatments in a randomized complete block design (RCBD) with a total of four replications of four pigs per pen with sexes being penned separately. Pens were the experimental units. 


\section{Growth Performance}

To evaluate performance of the pigs, average daily gain (ADG), average daily feed intake (ADFI) and feed to gain ratio $(F: G)$ were determined at periodic intervals and at the end of each phase. Growth performance traits were terminated on a replication basis when the pigs in the control pen (Diet 1) of a given replication reached the target weight of $120 \mathrm{~kg}$. Pens within a replication that did not reach $120 \mathrm{~kg}$ were continued on their respective diets until they reached the target weight. Thus, growth performance traits were summarized on a constant time basis while carcass data on a constant weight basis.

\section{Harvest and carcass quality}

At the end of the experiment, pigs were humanely harvested using standard U.S. pork industry practices and USDA/FSIS inspection criteria. After slaughter, hot carcass weight (HCW) was recorded and carcasses were chilled at $2^{\circ} \mathrm{C}$ for $24 \mathrm{~h}$. At $24 \mathrm{~h}$ after slaughter, $10^{\text {th }}$ rib back fat $(\mathrm{TRBF})$, last rib back fat (LRBF), dressing percentage (DP) and loin eye area (LEA) were determined on the left side of the carcass. Carcass fat free lean (CFFL) was calculated following the NPPC (2000) equation. Furthermore, longissimus muscle objective color ( $\mathrm{L}^{*}, \mathrm{a}^{*}$ and $\mathrm{b}^{*}$ ) was measured using a Minolta Chroma Meter CR-410 (Minolta Camera Co., Osaka, Japan).

Moreover, by using the method described by Rentfrow et al. (2003), vertical and horizontal belly firmness was determined. After removal from the right side of the carcass, spareribs, cartilage and leaf fat were removed and bellies were squared. Next, bellies were placed, skin side-up, on a polyvinyl chloride (PVC) pipe mounted perpendicular to a board marked with a $2.5 \mathrm{~cm}$ grid matrix. Thus, belly flexibility was 
measured relative to the grid matrix where a vertical belly flex of zero meant the belly was completely parallel to the floor and completely stiff while a horizontal belly flex of six meant that the belly flexed to a point where there was approximately $15 \mathrm{~cm}$ between the ends of the squared belly. Thus, a lower horizontal and a higher vertical flex indicated a softer, more flexible belly.

\section{Fat sample collection and fatty acid procedure}

Fat samples from belly, jowl, and subcutaneous (SUB-Q), and a longissimus muscle sample (LMS) were collected from carcasses on the day after slaughter to determination of fatty acid profile and IV. Belly fat was removed posterior to the sternum and anterior to the teat line on the left side of the carcass. Jowl samples were collected on the anterior tip of the jowl at the site of head removal. Subcutaneous fat was collected at the $10^{\text {th }}$ rib while LMS was collected from the longissimus muscle exposed between the $10^{\text {th }}$ and $11^{\text {th }}$ rib. After collection, samples were frozen at $-10^{\circ} \mathrm{C}$ until analysis was performed.

The methodology utilized for fatty acid determination was an adaptation of the methods used by Folch et al. (1957) and Morrison and Smith (1964). At the moment of the analysis, approximately $100 \mathrm{mg}$ of adipose tissue (or $1 \mathrm{~g}$ of muscle) was placed in glass tube and $5 \mathrm{~mL}$ of a solution of chloroform:methanol $\left(\mathrm{CHCL}_{3}: \mathrm{CH}_{3} \mathrm{OH}, 2: 1\right.$, v/v) was added to the tube in order to extract lipids. Sample was filtered through a sintered glass filter funnel fitted with a Whatman $2.4 \mathrm{~cm} \mathrm{GF} / \mathrm{C}$ filter and a solution of $0.74 \% \mathrm{KCl}$ was added to the tube at a volume of $8 \mathrm{~mL}$. Sample was allowed to sit for $2 \mathrm{~h}$ to separate the phases and then, the upper phase was carefully removed and discarded. The lower phase 
was then, transferred to a glass tube and evaporated to dryness with nitrogen gas in a heated water bath at $70^{\circ} \mathrm{C}$.

A $1 \mathrm{~mL}$ solution of $0.5 \mathrm{~N} \mathrm{KOH}$ in $\mathrm{MeOH}$ was added to the sample and the tube was placed in a water bath at $70{ }^{\circ} \mathrm{C}$ for $10 \mathrm{~min}$. A $1 \mathrm{~mL}$ solution of $14 \%$ boron trifluoride $\left(\mathrm{BF}_{3}\right)$ in $\mathrm{MeOH}$ was added to the tube which was flushed with nitrogen, loosely capped and placed in a water bath at $70{ }^{\circ} \mathrm{C}$ for $30 \mathrm{~min}$. After $30 \mathrm{~min}$, sample was cooled to room temperature and $2 \mathrm{~mL}$ of HPLC grade hexane and $2 \mathrm{~mL}$ of saturated $\mathrm{NaCl}$ was added to the tube. Next, the upper layer was removed and placed in a glass tube with approximately $800 \mathrm{mg}$ of $\mathrm{Na}_{2} \mathrm{SO}_{4}$ in order to remove moisture from the sample. Following this, $2 \mathrm{~mL}$ of hexane was added to the tube with saturated $\mathrm{NaCl}$ and once more, the upper layer was removed and placed in the same tube with $\mathrm{Na}_{2} \mathrm{SO}_{4}$.

The liquid portion was then transferred to a scintillation vial which was placed in a water bath at $70{ }^{\circ} \mathrm{C}$ and the sample was evaporated with nitrogen. A Varian 3,800 gas chromatographer (Varian, Pala Alto, CA) was used to analyze fatty acid methyl esters; samples were injected onto a fused silica capillary column (SPTM - 2,560; 100 m x 0.25 mm x $0.2 \mu \mathrm{m}$ film thickness; Supelco, Bellefonte, PA). The temperature of the injector and of the flame-ionization detector was held constant at $240^{\circ} \mathrm{C}$ and $260^{\circ} \mathrm{C}$, respectively. Helium was used as the carrier gas at a constant pressure of 37 psi and the oven was operated at $140^{\circ} \mathrm{C}$ for 5 min (temperature programmed $2.5^{\circ} \mathrm{C} / \mathrm{min}$ to $240^{\circ} \mathrm{C}$ and held for $16 \mathrm{~min})$. Fatty acids were normalized which means that the area of each peak was represented as a percentage of the total area. Iodine value was determined based on the equation described by AOCS (1998): IV $=(0.95 \times \mathrm{C} 16: 1)+(0.86 \times \mathrm{C} 18: 1 \mathrm{n} 9)+(1.732 \times$ $\mathrm{C} 18: 2 \mathrm{n} 6)+(2.616 \times \mathrm{C} 18: 3 \mathrm{n} 3)+(0.785 \times \mathrm{C} 20: 1)$. The ratio between polyunsaturated 
(PUFA) and saturated (SFA) fatty acids was calculated using the equation: [(C18:2n6c) + $(\mathrm{C} 18: 3 n 3)] /[(\mathrm{C} 14: 0)+(\mathrm{C} 16: 0)+(\mathrm{C} 18: 0)]$.

\section{Statistical Analysis}

All performance and carcass data were analyzed using the GLM procedure of SAS (SAS Inst., Cary, NC) with pen as the experimental unit. Orthogonal contrasts were analyzed for linear and quadratic responses. Furthermore, correlation analysis among fat depots for the variable IV was performed by using PROC CORR procedure of SAS. An alpha level of 5\% was considered significant.

\section{RESULTS AND DISCUSSION}

\section{Growth Performance}

According to Table 2.3, no linear $(\mathrm{P}>0.20)$ and quadratic $(\mathrm{P}>0.81)$ responses were observed for ADG, ADFI and F:G during the first phase of the experiment when pigs weight ranged from 31 to $60 \mathrm{~kg}$. During the second phase of the experiment, when

pigs had weights between 60 and $93 \mathrm{~kg}$, no linear $(\mathrm{P}>0.12)$ and quadratic $(\mathrm{P}>0.69)$ responses were found for ADG and ADFI. When F:G was considered, a linear trend $(\mathrm{P}=$ 0.09) was observed indicating that increasing levels of DDGS tended to negatively affect feed conversion of the pigs.

A linear trend $(\mathrm{P}=0.08)$ was observed for ADG during the third phase of the experiment indicating that the addition of DDGS to the diets tended to decrease ADG of the pigs weighing between 93 and $120 \mathrm{~kg}$. No linear response was observed $(\mathrm{P}>0.83$ ) for ADFI, while a linear response $(\mathrm{P}<0.05)$ was found for $\mathrm{F}: \mathrm{G}$ during the third phase indicating higher F:G with increasing levels of DDGS. No quadratic responses were 
observed (P > 0.37) for ADG, ADFI and F:G during the third phase. Finally, when the three phases were considered (overall), no linear $(\mathrm{P}>0.10)$ and quadratic $(\mathrm{P}>0.77)$ responses were found while a linear trend $(\mathrm{P}=0.08)$ was observed for $\mathrm{F}: \mathrm{G}$ reporting that, as observed before, increasing levels of DDGS tended to increase F:G.

Our findings were in agreement with McEwen (2006) and Augspurger et al. (2008) who found that DDGS inclusion at levels up to $20 \%$ in amino acids fortified diets did not affect ADG, ADFI and G:F during growing-finishing phase. Furthermore, Widmer et al. (2008) showed that when the entire growing-finishing period was considered, no differences were observed in ADG, ADFI and G:F when 10 or $20 \%$ DDGS were fed. Moreover, Cook et al. (2005) reported that the inclusion of DDGS at levels up to $30 \%$ did not have a negative impact on ADG, ADFI and G:F of growingfinishing barrows and gilts.

On the other hand, Gaines et al. (2007a,b) found a reduction in G:F when finishing pigs were fed 30\% DDGS while Whitney et al. (2006) showed that inclusion of DDGS decreased linearly the ADG and G:F in growing-finishing pigs. Moreover, Fu et al. (2004) and Linneen et al (2008) found a linear decrease in ADG and ADFI when pigs were fed DDGS at levels 10, 20 or 30\%. According to Whitney et al. (2006), negative impacts of DDGS on growth performance traits could be related to the lower apparent amino acids digestibility of DDGS compared to soybean meal, which was replaced by DDGS in this experiment. These inconsistent results in growth performance may be related to the quality of DDGS grain, levels of sugar and variation in drying methods among batches (Rausch and Belyea, 2006). 


\section{Carcass and meat quality}

According to Table 2.4, no linear $(\mathrm{P}>0.14)$ or quadratic $(\mathrm{P}>0.17)$ responses were observed for live weight, HCW, TRBF, LRBF, LEA, DP, CFFL, and horizontal and vertical belly flexibility. Furthermore, objective color ( $\mathrm{L}^{*}, \mathrm{a}^{*}$ and $\mathrm{b}^{*}$ ) of the longissimus muscle did not show a linear $(\mathrm{P}>0.21)$ or quadratic $(\mathrm{P}>0.40)$ response with increasing levels of DDGS.

Our findings were in agreement with Whitney et al. (2006) who showed no effects on backfat depth and percentage lean with DDGS inclusion at levels up to $30 \%$. Moreover, Cook et al. (2005) reported that backfat level and carcass lean percentage were not affected by dietary DDGS level fed. Stein and Shurson (2009) summarized the effects of corn DDGS on carcass traits of growing-finishing pigs and showed that in most part of the studies DP, backfat, loin depth and percentage lean were not affected by DDGS inclusion.

In addition, Widmer et al. (2008) showed that inclusion of DDGS at 10 or $20 \%$ levels did not have any effects on live weight, HCW, DP, percentage lean, LEA and $10^{\text {th }}$ rib backfat of growing-finishing pigs. However, some studies have shown contrasting results regarding DDGS inclusion in grower-finisher diets. Xu et al. (2010a) found that DDGS inclusion at levels up to $30 \%$ linearly reduced DP and last rib back fat and increased percentage lean. A linear decrease in DP was observed by Whitney et al. (2006) when pigs were fed diets containing up to 30\% DDGS from 23 to $114 \mathrm{~kg}$ of body weight.

Objective color ( $\mathrm{L}^{*}, \mathrm{a}^{*}, \mathrm{~b}^{*}$ scores) of the longissimus muscle (LM) was unaffected by DDGS inclusion which agrees with a study performed by Whitney et al. 
(2006). Moreover, Widmer et al. (2008) showed no effect of DDGS inclusion at 10 or $20 \%$ levels on objective color scores of the LM, except a linear decrease in LM b* value as the concentration of DDGS increased in the diet. Xu et al. (2010a) reported that lightness $\left(\mathrm{L}^{*}\right)$ was not affected by DDGS inclusion, but a reduction in LM $\mathrm{a}^{*}$ and $\mathrm{b}^{*}$ values was noticed with increasing levels of DDGS in the diet.

Results obtained for belly firmness in the current experiment disagreed with the literature where studies have shown a decrease in belly firmness with DDGS inclusion (Stein and Shurson, 2009); our results showed no effects of DDGS on belly firmness when pigs were fed up to $45 \%$ DDGS from 30 to $120 \mathrm{~kg}$. According to Wood et al. (2003), linoleic acid (C18:2) is an important contributor to tissue firmness and, thus, a feeding system with a high concentration of unsaturated fat acids, especially, linoleic acid, will tend to decrease fat firmness.

Whitney et al. (2006) observed lower adjusted belly firmness score when pigs were fed a diet containing 30\% DDGS compared to pigs fed 0 or $20 \%$ DDGS. In addition, Widmer et al. (2008) found a decrease in belly firmness and adjusted belly firmness scores as the amount of DDGS increased in the grow-finish diet. Xu et al. (2010a) reported that belly firmness score and adjusted belly firmness degree were linearly reduced when increasing levels of DDGS were added to grow-finish diets.

However, no variation in belly firmness was found in this study which could be attributed to the amount of fat in the belly (belly thickness). It may be possible that bellies had a low amount of fat and thus, the effects of DDGS on belly firmness was not observed in this experiment. 


\section{Fatty acid profiles}

The fatty acid profiles of belly, jowl, subcutaneous and LMS are shown in Tables 2.5, 2.6, 2.7 and 2.8, respectively. As expected, a linear decrease $(\mathrm{P}<0.0001)$ in the total amount of saturated fatty acids (SFA) was observed in belly (Table 2.5), jowl (Table 2.6) and subcutaneous (Table 2.7) fat depots. This response could be attributed to the activity of two main SFAs: palmitic (C16:0) and stearic (C18:0) acids. The amount of monounsaturated fatty acids (MUFA) decreased linearly $(\mathrm{P}<0.0001)$ in belly (Table 2.5), jowl (Table 2.6) and subcutaneous (Table 2.7) fat depots as increasing levels of DDGS were added to the diets. The main MUFAs responsible were palmitoleic (C16:1), oleic (C18:1n9c), vaccenic (C18:1n7) and nervonic (C24:1) acids.

The concentration of polyunsaturated fatty acids (PUFA) increased linearly ( $<$ 0.0001) in belly (Table 2.5), jowl (Table 2.6) and subcutaneous (Table 2.7) fat depots with increasing levels of DDGS in the diets. Linoleic (C18:2n6c) and arachidonic (C20:4n6) acids were the main PUFAs responsible for these findings. These higher percentages of PUFA and lower percentages of SFA and MUFA were indicative of softer carcasses.

These results agreed with $\mathrm{Xu}$ et al. (2010a) who found that increasing levels of DDGS in swine grower-finisher diets linearly increased the amount of PUFA, expressed in higher proportions by linoleic and linolenic in backfat and belly samples. On the other hand, DDGS inclusion linearly decreased concentrations of SFA (especially C16:0 and C18:0) and MUFA (C16:1 and C18:1).

According to Table 2.8, no linear $(\mathrm{P}>0.31)$ and quadratic $(\mathrm{P}>0.74)$ responses were observed for SFA in LMS. On the other hand, the total amount of MUFA decrease 
linearly $(\mathrm{P}<0.05)$ while the total amount of PUFA increased linearly $(\mathrm{P}<0.05)$ with increasing levels of DDGS in the diets. Once again, C16:1, C18:1n9c and C18:1n7 acids were the main MUFA while C18:2n6c was the main individual PUFA.

As seen in our experiment, Xu et al. (2010a) showed that DDGS inclusion had a lower effect on intramuscular fat than on backfat and belly fat samples. This fact was noticed by Gatlin et al. (2003) who found less pronounced effects of dietary fatty acid composition on intramuscular fat than in belly and backfat samples when choice white grease was added in swine diets at a 5\% level and at different degrees of hydrogenation. According to $\mathrm{Xu}$ et al. (2010a), this fact could be related to differences in lipogenesis in each site analyzed and furthermore, to differences in lipid composition in muscle and adipose tissues.

A linear response $(\mathrm{P}<0.0001)$ for IV was observed in belly (Table 2.5), jowl (Table 2.6) and subcutaneous (Table 2.7) fat samples. As expected, increasing levels of DDGS in the diets had a negative impact on IV; 45\% inclusion of DDGS resulted in IV higher than 72, which is used as a threshold for packing plants as an indicator of soft bellies. However, once again, the effects of DDGS on IV of subcutaneous fat were less pronounced than in the other fat depots analyzed. When DDGS were included at a level of $45 \%$, the IV of LMS increased from 57.02 (control) to 62.94, still representing an acceptable value.

Whitney et al. (2006) showed that as dietary concentration of DDGS increased from 0 to 30\%, IV increased linearly from 66.8 (0\% DDGS) to 72.0 (30\% DDGS), indicating a more unsaturated fatty acid profile in belly fat samples. Furthermore, Xu et al. (2010a) found that IV of backfat and belly samples increased linearly when increasing 
levels of DDGS were added to grow-finish diets. When IV was considered, these authors reported a less pronounced effect on intramuscular fat samples when compared to backfat and belly samples. In contrast, despite finding effects of DDGS inclusion on belly firmness, Widmer et al. (2008) showed that IV was not affected when DDGS was included at levels of 10 or $20 \%$ in grower-finisher diets. However, the same authors described that both control and DDGS-containing diets had similar fatty acid profile and thus, IV was not expected to differ.

In pork processing plants, measurement of IV of fat in the jowl is a practice that has been largely used in order to predict the IV of belly fat thus, utilized as an indicative of belly firmness. Hence, correlation analyzes were performed in this study in order to detect if IV of jowl fat is a reliable predictor of IV of belly fat. According to Figure 2.1, significant and strong correlations were observed between jowl and belly $(r=0.95 ; \mathrm{P}<$ $0.05)$ and jowl and subcutaneous fat $(r=0.96 ; \mathrm{P}<0.05)$ when DDGS was not included to in the grow-finish diets. A high but not significant correlation $(r=0.81 ; \mathrm{P}>0.18)$ was observed between belly and sub-q fat in this experiment. Furthermore, at low levels of DDGS (15\%), similar results were obtained and significant $(\mathrm{P}<0.05)$ correlations of 0.95, 0.96 and 0.95 were obtained for jowl vs. belly, jowl vs. sub-q and belly vs. sub-q, respectively.

However, as the level of DDGS increased to 30 or $45 \%$ in the diet, the correlation between fat depots decreased. When a 30\% level of DDGS was considered, a moderate but not significant correlation ( $\mathrm{r}=0.79$; $\mathrm{P}>0.21$ ) was observed between jowl and belly. Moreover, a strong correlation $(\mathrm{r}=0.90 ; \mathrm{P}<0.10)$ could also be observed between belly and sub-q fat depots. When a high level (45\%) of DDGS was added to the diets, the 
correlation between IV of belly and jowl decreased ( $\mathrm{r}=-0.56$; $\mathrm{P}>0.43$ ). This fact could be due to suppression of lipogenic enzyme activities in adipose tissue when high concentrations of unsaturated fatty acids were included to the diet (Kouba and Mourot, 1999) or due to a delay in maturity as increasing levels of PUFA were fed to the pigs. Furthermore, the correlation between IV of LMS and the other fat depots was weak for all treatments analyzed which could be related to the fact that tissues have different levels of lipogenic activity (Camara et al., 1996) and that intramuscular fat is a different type of fat having different lipid composition when compared to the other fat depots analyzed (Wood et al., 2008).

\section{IMPLICATIONS}

In summary, these results showed that a 30\% DDGS inclusion could be fed to growing-finishing pigs from 30 to $120 \mathrm{~kg}$ without having much of an effect on growth performance or carcass traits analyzed. However, by increasing the level of DDGS, the amount of polyunsaturated fatty acids increased and so did the IV, indicating that softer bellies were obtained when high concentrations of DDGS were fed to the pigs. Furthermore, this increase in the amount of PUFA could decrease the shelf-life stability of the product with an increase in the rate of lipid oxidation. Thus, further research is needed in order to investigate ways of preventing the softer carcasses in pigs fed high levels of DDGS during the growing-finishing phase. 
Table 2.1. Percentage composition of experimental diets (as fed basis)

\begin{tabular}{|c|c|c|c|c|c|c|c|c|c|c|c|c|}
\hline \multirow[b]{2}{*}{ Item } & \multicolumn{4}{|c|}{ Phase I (\% of DDGS $\left.{ }^{1}\right)$} & \multicolumn{4}{|c|}{ Phase II (\% of DDGS) } & \multicolumn{4}{|c|}{ Phase III (\% of DDGS) } \\
\hline & 0 & 15 & 30 & 45 & 0 & 15 & 30 & 45 & 0 & 15 & 30 & 45 \\
\hline \multicolumn{13}{|l|}{ Ingredients, \% } \\
\hline Corn & 72.23 & 61.69 & 51.15 & 40.62 & 77.66 & 67.31 & 56.96 & 46.61 & 82.46 & 71.85 & 61.25 & 50.64 \\
\hline Soybean meal, dehulled (48 \% CP) & 25.20 & 20.80 & 16.40 & 12.00 & 19.80 & 15.20 & 10.60 & 6.00 & 15.00 & 10.67 & 6.33 & 2.00 \\
\hline DDGS & - & 15.00 & 30.00 & 45.00 & - & 15.00 & 30.00 & 45.00 & - & 15.00 & 30.00 & 45.00 \\
\hline L-lysine-HCl & - & 0.067 & 0.133 & 0.200 & - & 0.073 & 0.147 & 0.220 & - & 0.065 & 0.130 & 0.195 \\
\hline DL-tryptophan & - & 0.011 & 0.022 & 0.033 & - & 0.014 & 0.027 & 0.041 & - & 0.012 & 0.024 & 0.036 \\
\hline Dicalcium phosphate (21 \% P) & 1.24 & 0.83 & 0.41 & - & 1.24 & 0.83 & 0.41 & -- & 1.24 & 0.83 & 0.41 & - \\
\hline Limestone & 0.58 & 0.85 & 1.13 & 1.40 & 0.58 & 0.85 & 1.13 & 1.40 & 0.58 & 0.85 & 1.13 & 1.40 \\
\hline Salt, $\mathrm{NaCl}$ & 0.30 & 0.30 & 0.30 & 0.30 & 0.30 & 0.30 & 0.30 & 0.30 & 0.30 & 0.30 & 0.30 & 0.30 \\
\hline TM mix ${ }^{2}$ & 0.15 & 0.15 & 0.15 & 0.15 & 0.15 & 0.15 & 0.15 & 0.15 & 0.15 & 0.15 & 0.15 & 0.15 \\
\hline Vitamin $^{3}$ & 0.25 & 0.25 & 0.25 & 0.25 & 0.25 & 0.25 & 0.25 & 0.25 & 0.25 & 0.25 & 0.25 & 0.25 \\
\hline Tylan-40 (Antibacterial agent) ${ }^{4}$ & 0.050 & 0.050 & 0.050 & 0.050 & 0.025 & 0.025 & 0.025 & 0.025 & 0.025 & 0.025 & 0.025 & 0.025 \\
\hline \multicolumn{13}{|l|}{ Calculated analysis } \\
\hline Protein, \% & 18.00 & 19.00 & 20.00 & 20.90 & 15.90 & 16.80 & 17.70 & 18.60 & 14.00 & 15.00 & 16.00 & 17.00 \\
\hline Total lysine, \% & 0.95 & 0.98 & 1.02 & 1.06 & 0.80 & 0.84 & 0.87 & 0.91 & 0.67 & 0.70 & 0.74 & 0.78 \\
\hline TID lysine, $\%^{5}$ & 0.83 & 0.83 & 0.83 & 0.83 & 0.70 & 0.70 & 0.70 & 0.70 & 0.58 & 0.58 & 0.58 & 0.58 \\
\hline TID tryptophan, \% & 0.18 & 0.18 & 0.18 & 0.18 & 0.16 & 0.16 & 0.16 & 0.16 & 0.13 & 0.13 & 0.13 & 0.13 \\
\hline Fat, \% & 3.60 & 4.50 & 5.40 & 6.30 & 3.60 & 4.60 & 5.50 & 6.40 & 3.70 & 4.60 & 5.50 & 6.40 \\
\hline NDF, \% & 9.20 & 13.00 & 16.80 & 20.60 & 9.20 & 13.00 & 16.80 & 20.60 & 9.30 & 13.10 & 16.90 & 20.60 \\
\hline Calcium, \% & 0.60 & 0.60 & 0.60 & 0.60 & 0.58 & 0.58 & 0.58 & 0.58 & 0.57 & 0.57 & 0.57 & 0.57 \\
\hline Total Phosphorus, \% & 0.61 & 0.60 & 0.59 & 0.58 & 0.58 & 0.58 & 0.57 & 0.56 & 0.56 & 0.56 & 0.55 & 0.54 \\
\hline Digestible Phosphorus, \% & 0.26 & 0.26 & 0.26 & 0.26 & 0.26 & 0.26 & 0.26 & 0.26 & 0.25 & 0.25 & 0.25 & 0.25 \\
\hline ME, Mcal/kg & 3.33 & 3.33 & 3.34 & 3.34 & 3.33 & 3.34 & 3.34 & 3.34 & 3.34 & 3.34 & 3.34 & 3.35 \\
\hline
\end{tabular}

\footnotetext{
${ }^{1}$ Distillers dried grains with solubles;
}

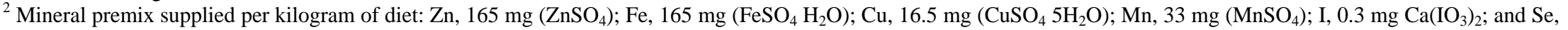
$0.3 \mathrm{mg}\left(\mathrm{Na}_{2} \mathrm{SeO}_{3}\right)$;

${ }^{3}$ Vitamin premix supplied per kilogram of diet: retinyl acetate, 11,000 IU; cholecalciferol, 1,100 IU; dl- $\alpha$-tocopheryl acetate, 44,1 IU; menadione Na Dimethylpyrimidinol

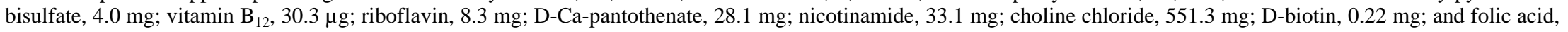
$1.65 \mathrm{mg}$;

${ }^{4}$ Tylosin phosphate (Tylan ${ }^{\circledR} 40$ Type A Medicated Article; Elanco Animal Health, Greenfield, IN) was added in place of corn;

${ }^{5}$ The true ileal digestible (TID) lysine requirement for pigs at the midpoint of the three phases is $0.80,0.67$, and $0.62 \%$, respectively. 
Table 2.2. Analyzed composition of DDGS ${ }^{1}$ source

\begin{tabular}{lc}
\hline Item & $\%$ \\
\hline Dry matter & 88.9 \\
Crude protein & 26.3 \\
Crude fat & 9.7 \\
Acid detergent fiber & 14.0 \\
Neutral detergent fiber & 34.6 \\
Crude fiber & 6.5 \\
Ash & 5.1 \\
Calcium & 0.03 \\
Phosphorus & 0.86 \\
Sulfur & 0.68 \\
Lysine & 0.96 \\
Tryptophan & 0.18 \\
Threonine & 0.99 \\
Methionine & 0.50 \\
Cysteine & 0.50 \\
Valine & 1.35 \\
Isoleucine & 1.01 \\
\hline
\end{tabular}

${ }^{\mathrm{I}}$ Distillers dried grains with solubles. 
Table 2.3. Effects of DDGS ${ }^{1}$ on growth performance of growing-finishing pigs

\begin{tabular}{|c|c|c|c|c|c|c|c|}
\hline \multirow[b]{2}{*}{ Item } & \multicolumn{4}{|c|}{ Treatment } & \multirow[b]{2}{*}{ SEM } & \multicolumn{2}{|c|}{ P-value } \\
\hline & $\begin{array}{c}0 \% \\
\text { DDGS }\end{array}$ & $\begin{array}{c}15 \% \\
\text { DDGS }\end{array}$ & $\begin{array}{c}30 \% \\
\text { DDGS }\end{array}$ & $\begin{array}{c}45 \% \\
\text { DDGS }\end{array}$ & & Linear & Quadratic \\
\hline \multicolumn{8}{|l|}{ First Phase ${ }^{2}$} \\
\hline $\mathrm{ADG}, \mathrm{kg}$ & 0.94 & 0.92 & 0.89 & 0.88 & 0.04 & 0.2010 & 0.8129 \\
\hline ADFI, kg & 2.54 & 2.43 & 2.50 & 2.44 & 0.09 & 0.5937 & 0.8189 \\
\hline$F: G^{3}$ & 2.69 & 2.68 & 2.84 & 2.79 & 0.12 & 0.4140 & 0.8492 \\
\hline \multicolumn{8}{|c|}{ Second Phase } \\
\hline ADG, kg & 0.97 & 0.95 & 0.84 & 0.82 & 0.08 & 0.1287 & 0.9617 \\
\hline ADFI, kg & 2.70 & 2.64 & 2.53 & 2.60 & 0.16 & 0.5758 & 0.6909 \\
\hline$F: G$ & 2.82 & 2.82 & 3.01 & 3.24 & 0.18 & 0.0922 & 0.5147 \\
\hline \multicolumn{8}{|c|}{ Third Phase } \\
\hline $\mathrm{ADG}, \mathrm{kg}$ & 0.84 & 0.88 & 0.76 & 0.67 & 0.07 & 0.0830 & 0.3927 \\
\hline ADFI, kg & 2.71 & 2.66 & 2.75 & 2.64 & 0.11 & 0.8377 & 0.7739 \\
\hline$F: G$ & $3.29^{\mathrm{a}, \mathrm{b}}$ & $3.10^{\mathrm{b}}$ & $3.69^{\mathrm{a}, \mathrm{b}}$ & $4.02^{\mathrm{a}}$ & 0.28 & 0.0481 & 0.3721 \\
\hline \multicolumn{8}{|l|}{ Overall $^{6}$} \\
\hline ADG, kg & 0.93 & 0.92 & 0.84 & 0.80 & 0.06 & 0.1073 & 0.7769 \\
\hline ADFI, kg & 2.64 & 2.58 & 2.54 & 2.51 & 0.11 & 0.3779 & 0.8803 \\
\hline$F: G$ & 2.88 & 2.85 & 3.06 & 3.17 & 0.13 & 0.0880 & 0.5875 \\
\hline
\end{tabular}

${ }^{1}$ Distillers dried grains with solubles;

${ }^{2}$ First phase when pig's weight ranged from 31 to $60 \mathrm{~kg}$;

${ }^{3}$ Feed to gain ratio;

${ }^{4}$ Second phase when pig's weight ranged from 61 to $93 \mathrm{~kg}$

${ }^{5}$ Third phase when pig's weight ranged from 94 to $120 \mathrm{~kg}$

${ }^{6}$ Overall experiment period when pig's weight ranged from 31 to $120 \mathrm{~kg}$;

${ }^{\mathrm{a}, \mathrm{b}}$ within a row, means lacking a common superscript differ from each other $(\mathrm{P}<0.05)$. 
Table 2.4. Effects of feeding DDGS $^{1}$ on carcass and meat quality of growingfinishing pigs

\begin{tabular}{|c|c|c|c|c|c|c|c|}
\hline \multirow[b]{2}{*}{ Item } & \multicolumn{4}{|c|}{ Treatment } & \multirow[b]{2}{*}{ SEM } & \multicolumn{2}{|c|}{ P-value } \\
\hline & $\begin{array}{c}0 \% \\
\text { DDGS }\end{array}$ & $\begin{array}{c}15 \% \\
\text { DDGS }\end{array}$ & $\begin{array}{c}30 \% \\
\text { DDGS }\end{array}$ & $\begin{array}{c}45 \% \\
\text { DDGS }\end{array}$ & & Linear & Quadratic \\
\hline \multicolumn{8}{|l|}{ Carcass traits } \\
\hline Final live wt, kg & 120.72 & 120.13 & 121.31 & 117.36 & 1.47 & 0.1998 & 0.2751 \\
\hline $\mathrm{HCW}, \mathrm{kg}$ & 88.99 & 88.44 & 89.79 & 85.93 & 1.14 & 0.1496 & 0.1716 \\
\hline 10th rib fat, mm & 19.80 & 21.80 & 21.80 & 20.80 & 2.03 & 0.8116 & 0.4412 \\
\hline Last rib fat, mm & 26.20 & 26.90 & 26.70 & 27.40 & 1.57 & 0.6311 & 0.9219 \\
\hline $\mathrm{LEA}^{2}, \mathrm{~cm}^{2}$ & 49.68 & 47.81 & 50.26 & 46.65 & 1.65 & 0.3648 & 0.6189 \\
\hline $\mathrm{DP}, \%$ & 73.75 & 73.68 & 73.98 & 73.20 & 0.53 & 0.5820 & 0.5242 \\
\hline Lean, \% & 53.93 & 52.72 & 53.11 & 53.02 & 1.27 & 0.6879 & 0.6667 \\
\hline Horizontal flex., cm & 10.80 & 8.64 & 10.80 & 8.74 & 1.78 & 0.6236 & 0.9764 \\
\hline Vertical flex., cm & 33.66 & 32.82 & 32.39 & 33.35 & 0.91 & 0.7429 & 0.3470 \\
\hline \multicolumn{8}{|l|}{ Meat quality traits } \\
\hline Minolta $\mathrm{L}^{* 3}$ & 56.93 & 58.85 & 59.51 & 59.29 & 1.31 & 0.2125 & 0.4322 \\
\hline Minolta $\mathrm{a}^{*^{4}}$ & 16.71 & 16.15 & 16.74 & 16.27 & 0.37 & 0.6813 & 0.9067 \\
\hline Minolta $b^{*^{5}}$ & 9.23 & 9.66 & 10.16 & 9.66 & 0.54 & 0.4752 & 0.4004 \\
\hline
\end{tabular}


Table 2.5. Effects of increasing levels of DDGS ${ }^{1}$ on fatty acid profile (indicated as percentages) of belly fat of growing-finishing pigs

\begin{tabular}{|c|c|c|c|c|c|c|c|}
\hline \multirow[b]{2}{*}{ Item } & \multicolumn{4}{|c|}{ Treatment } & \multirow[b]{2}{*}{ SEM } & \multicolumn{2}{|c|}{$\mathrm{P}$-value } \\
\hline & $\begin{array}{c}0 \% \\
\text { DDGS }\end{array}$ & $\begin{array}{c}15 \% \\
\text { DDGS }\end{array}$ & $\begin{array}{c}30 \% \\
\text { DDGS }\end{array}$ & $\begin{array}{c}45 \% \\
\text { DDGS }\end{array}$ & & Linear & Quadratic \\
\hline C_14:0 & $1.39^{\mathrm{a}}$ & $1.37^{\mathrm{a}}$ & $1.33^{\mathrm{a}}$ & $1.21^{\mathrm{b}}$ & 0.04 & 0.0049 & 0.2081 \\
\hline C_16:0 & $25.31^{\mathrm{a}}$ & $24.47^{\mathrm{a}}$ & $23.28^{\mathrm{b}}$ & $21.68^{\mathrm{c}}$ & 0.32 & $<0.0001$ & 0.2597 \\
\hline C_16:1 & $2.67^{\mathrm{a}}$ & $2.59^{\mathrm{a}, \mathrm{b}}$ & $2.32^{\mathrm{b}}$ & $1.87^{\mathrm{C}}$ & 0.10 & $<0.0001$ & 0.0947 \\
\hline C_17:0 & 0.38 & 0.37 & 0.35 & 0.33 & 0.03 & 0.2317 & 0.9017 \\
\hline C_17:1 & $0.35^{\mathrm{a}}$ & $0.32^{\mathrm{a}, \mathrm{b}}$ & $0.25^{\mathrm{b}, \mathrm{c}}$ & $0.21^{\mathrm{c}}$ & 0.03 & 0.0009 & 0.6976 \\
\hline C_18:0 & $11.89^{\mathrm{a}}$ & $10.79^{\mathrm{b}}$ & $9.89^{c}$ & $9.11^{\mathrm{c}}$ & 0.26 & $<0.0001$ & 0.5467 \\
\hline C_18:1n9t & 0.03 & 0.01 & 0.09 & 0.05 & 0.03 & 0.3619 & 0.7500 \\
\hline C_18:1n9c & $41.31^{\mathrm{a}}$ & $39.81^{\mathrm{a}}$ & $38.09^{\mathrm{b}}$ & $35.53^{c}$ & 0.55 & $<0.0001$ & 0.3569 \\
\hline C_18:1n7 & $3.09^{\mathrm{a}}$ & $2.94^{\mathrm{a}}$ & $2.65^{\mathrm{b}}$ & $2.20^{\mathrm{c}}$ & 0.09 & $<0.0001$ & 0.1334 \\
\hline C_18:2n6c & $11.93^{\mathrm{d}}$ & $15.48^{\mathrm{c}}$ & $19.66^{\mathrm{b}}$ & $25.65^{\mathrm{a}}$ & 0.82 & $<0.0001$ & 0.1618 \\
\hline C_20:0 & $0.16^{\mathrm{a}}$ & $0.15^{\mathrm{a}, \mathrm{b}}$ & $0.11^{\mathrm{a}, \mathrm{b}}$ & $0.10^{\mathrm{b}}$ & 0.02 & 0.0265 & 0.9493 \\
\hline C_20:1 & 0.55 & 0.54 & 0.55 & 0.56 & 0.02 & 0.6521 & 0.4744 \\
\hline C_18:3n3 & 0.19 & 0.31 & 0.37 & 0.24 & 0.10 & 0.5998 & 0.2147 \\
\hline C_20:2n6 & $0.45^{\mathrm{d}}$ & $0.57^{\mathrm{c}}$ & $0.68^{\mathrm{b}}$ & $0.83^{\mathrm{a}}$ & 0.03 & $<0.0001$ & 0.5536 \\
\hline C_20:3n6 & 0.02 & 0.00 & 0.05 & 0.05 & 0.01 & 0.0532 & 0.6708 \\
\hline C_20:4n6 & $0.30^{\mathrm{b}}$ & $0.31^{\mathrm{a}, \mathrm{b}}$ & $0.31^{\mathrm{a}, \mathrm{b}}$ & $0.37^{\mathrm{a}}$ & 0.02 & 0.0448 & 0.2772 \\
\hline C_24:1 & $0.02^{\mathrm{a}, \mathrm{b}}$ & $0.01^{\mathrm{b}}$ & $0.05^{\mathrm{a}, \mathrm{b}}$ & $0.07^{\mathrm{a}}$ & 0.02 & 0.0390 & 0.5459 \\
\hline SFU & $39.12^{\mathrm{a}}$ & $37.14^{\mathrm{b}}$ & $34.96^{c}$ & $32.41^{\mathrm{d}}$ & 0.42 & $<0.0001$ & 0.5180 \\
\hline MUFA & $48.01^{\mathrm{a}}$ & $46.20^{\mathrm{a}}$ & $43.99^{\mathrm{b}}$ & $40.47^{c}$ & 0.64 & $<0.0001$ & 0.2071 \\
\hline PUFA & $12.88^{\mathrm{d}}$ & $16.66^{\mathrm{c}}$ & $21.07^{\mathrm{b}}$ & $27.12^{\mathrm{a}}$ & 0.87 & $<0.0001$ & 0.2159 \\
\hline PUFA:SFA ${ }^{2}$ & $0.32^{\mathrm{d}}$ & $0.44^{\mathrm{c}}$ & $0.59^{\mathrm{b}}$ & $0.82^{\mathrm{a}}$ & 0.03 & $<0.0001$ & 0.0536 \\
\hline Total omega-6 & $12.69^{\mathrm{d}}$ & $16.35^{\mathrm{c}}$ & $20.69^{\mathrm{b}}$ & $26.88^{\mathrm{a}}$ & 0.86 & $<0.0001$ & 0.1676 \\
\hline Total omega-3 & 0.19 & 0.31 & 0.37 & 0.24 & 0.10 & 0.5998 & 0.2147 \\
\hline Iodine Value & $59.64^{\mathrm{d}}$ & $64.73^{c}$ & $70.40^{\mathrm{b}}$ & $77.82^{\mathrm{a}}$ & 1.00 & $<0.0001$ & 0.2638 \\
\hline
\end{tabular}

${ }^{1}$ Distillers dried grains with solubles;

${ }^{2}$ Ratio between poly and saturated fatty acids;

$\mathrm{a}, \mathrm{b}, \mathrm{c}, \mathrm{d}$ within a row, means lacking a common superscript differ from each other $(\mathrm{P}<0.05)$. 
Table 2.6. Effects of increasing levels of DDGS ${ }^{1}$ on fatty acid profile (indicated as percentages) of jowl fat of growing-finishing pigs

\begin{tabular}{|c|c|c|c|c|c|c|c|}
\hline \multirow[b]{2}{*}{ Item } & \multicolumn{4}{|c|}{ Treatment } & \multirow[b]{2}{*}{ SEM } & \multicolumn{2}{|c|}{$\mathrm{P}$-value } \\
\hline & $\begin{array}{c}0 \% \\
\text { DDGS }\end{array}$ & $\begin{array}{c}15 \% \\
\text { DDGS }\end{array}$ & $\begin{array}{c}30 \% \\
\text { DDGS }\end{array}$ & $\begin{array}{c}45 \% \\
\text { DDGS }\end{array}$ & & Linear & Quadratic \\
\hline C_14:0 & $1.36^{\mathrm{a}}$ & $1.33^{\mathrm{a}}$ & $1.30^{\mathrm{a}}$ & $1.15^{\mathrm{b}}$ & 0.04 & 0.0026 & 0.1166 \\
\hline C_16:0 & $24.39^{\mathrm{a}}$ & $23.64^{\mathrm{a}, \mathrm{b}}$ & $22.73^{\mathrm{b}}$ & $20.76^{c}$ & 0.46 & 0.0001 & 0.2127 \\
\hline C_16:1 & $2.77^{\mathrm{a}}$ & $2.75^{\mathrm{a}}$ & $2.44^{\mathrm{b}}$ & $2.10^{\mathrm{c}}$ & 0.09 & 0.0001 & 0.1155 \\
\hline C_17:0 & $0.38^{\mathrm{a}}$ & $0.35^{\mathrm{a}, \mathrm{b}}$ & $0.33^{\mathrm{b}}$ & $0.32^{\mathrm{b}}$ & 0.02 & 0.0127 & 0.4030 \\
\hline C_17:1 & $0.37^{\mathrm{a}}$ & $0.33^{\mathrm{b}}$ & $0.29^{c}$ & $0.25^{\mathrm{d}}$ & 0.01 & $<0.0001$ & 0.7292 \\
\hline C_18:0 & $10.45^{\mathrm{a}}$ & $9.64^{\mathrm{b}}$ & $9.32^{\mathrm{b}}$ & $8.48^{\mathrm{c}}$ & 0.25 & 0.0001 & 0.9614 \\
\hline C_18:1n9t & 0.14 & 0.08 & 0.07 & 2.31 & 1.14 & 0.2287 & 0.3346 \\
\hline C_18:1n9c & $43.63^{\mathrm{a}}$ & $42.94^{\mathrm{a}}$ & $40.84^{\mathrm{a}}$ & $36.97^{\mathrm{b}}$ & 1.22 & 0.0016 & 0.2183 \\
\hline C_18:1n7 & $3.32^{\mathrm{a}}$ & $3.29^{\mathrm{a}}$ & $2.92^{\mathrm{b}}$ & $2.44^{c}$ & 0.10 & $<0.0001$ & 0.0459 \\
\hline C_18:2n6c & $11.69^{\mathrm{d}}$ & $14.07^{\mathrm{C}}$ & $17.87^{\mathrm{b}}$ & $22.92^{\mathrm{a}}$ & 0.67 & $<0.0001$ & 0.0704 \\
\hline C_20:0 & 0.19 & 0.18 & 0.18 & 0.17 & 0.01 & 0.0681 & 0.7153 \\
\hline C_20:1 & $0.40^{\mathrm{b}}$ & $0.40^{\mathrm{b}}$ & $0.45^{\mathrm{a}, \mathrm{b}}$ & $0.52^{\mathrm{a}}$ & 0.03 & 0.0038 & 0.2174 \\
\hline C_18:9c11t; CLA & 0.04 & 0.03 & 0.05 & 0.08 & 0.02 & 0.0884 & 0.2399 \\
\hline C_20:2n6 & $0.53^{\mathrm{c}}$ & $0.64^{\mathrm{c}}$ & $0.76^{\mathrm{b}}$ & $0.96^{\mathrm{a}}$ & 0.04 & $<0.0001$ & 0.2215 \\
\hline C_20:3n6 & $0.04^{\mathrm{b}, \mathrm{c}}$ & $0.03^{\mathrm{c}}$ & $0.07^{\mathrm{b}}$ & $0.11^{\mathrm{a}}$ & 0.01 & 0.0003 & 0.0378 \\
\hline C_20:4n6 & $0.25^{\mathrm{b}}$ & $0.25^{\mathrm{b}}$ & $0.29^{\mathrm{a}, \mathrm{b}}$ & $0.33^{\mathrm{a}}$ & 0.02 & 0.0075 & 0.2730 \\
\hline C_24:1 & $0.06^{\mathrm{c}}$ & $0.07^{\mathrm{b}, \mathrm{c}}$ & $0.11^{\mathrm{a}, \mathrm{b}}$ & $0.14^{\mathrm{a}}$ & 0.01 & 0.0012 & 0.3768 \\
\hline SFU & $36.76^{\mathrm{a}}$ & $35.14^{\mathrm{a}, \mathrm{b}}$ & $33.85^{\mathrm{b}}$ & $30.87^{c}$ & 0.69 & $<0.0001$ & 0.3451 \\
\hline MUFA & $50.70^{\mathrm{a}}$ & $49.85^{\mathrm{a}}$ & $47.12^{\mathrm{b}}$ & $44.73^{c}$ & 0.35 & $<0.0001$ & 0.0479 \\
\hline PUFA & $12.55^{\mathrm{d}}$ & $15.02^{\mathrm{c}}$ & $19.03^{\mathrm{b}}$ & $24.40^{\mathrm{a}}$ & 0.72 & $<0.0001$ & 0.0674 \\
\hline PUFA:SFA ${ }^{2}$ & $0.33^{\mathrm{c}}$ & $0.41^{\mathrm{c}}$ & $0.54^{\mathrm{b}}$ & $0.76^{\mathrm{a}}$ & 0.03 & $<0.0001$ & 0.0340 \\
\hline Total omega- 6 & $12.51^{\mathrm{d}}$ & $14.99^{\mathrm{c}}$ & $18.99^{\mathrm{b}}$ & $24.32^{\mathrm{a}}$ & 0.73 & $<0.0001$ & 0.0725 \\
\hline Iodine Value & $60.70^{\mathrm{c}}$ & $64.23^{\mathrm{c}}$ & $68.75^{\mathrm{b}}$ & $73.90^{\mathrm{a}}$ & 1.33 & $<0.0001$ & 0.5512 \\
\hline
\end{tabular}


Table 2.7. Effects of increasing levels of DDGS ${ }^{1}$ on fatty acid profile (indicated as percentages) of subcutaneous fat of growing-finishing pigs

\begin{tabular}{|c|c|c|c|c|c|c|c|}
\hline \multirow[b]{2}{*}{ Item } & \multicolumn{4}{|c|}{ Treatment } & \multirow[b]{2}{*}{ SEM } & \multicolumn{2}{|c|}{ P-value } \\
\hline & $\begin{array}{c}0 \% \\
\text { DDGS }\end{array}$ & $\begin{array}{c}15 \% \\
\text { DDGS }\end{array}$ & $\begin{array}{c}30 \% \\
\text { DDGS }\end{array}$ & $\begin{array}{c}45 \% \\
\text { DDGS }\end{array}$ & & Linear & Quadratic \\
\hline C_14:0 & $1.29^{\mathrm{a}}$ & $1.31^{\mathrm{a}}$ & $1.25^{\mathrm{a}}$ & $1.08^{\mathrm{b}}$ & 0.04 & 0.0008 & 0.0232 \\
\hline C_16:0 & $25.83^{\mathrm{a}}$ & $24.95^{\mathrm{a}}$ & $23.29^{b}$ & $21.17^{\mathrm{C}}$ & 0.40 & $<0.0001$ & 0.1475 \\
\hline C_16:1 & $2.06^{\mathrm{a}}$ & $1.99^{\mathrm{a}}$ & $1.71^{\mathrm{b}}$ & $1.39^{c}$ & 0.08 & $<0.0001$ & 0.1526 \\
\hline C_17:0 & $0.45^{\mathrm{a}}$ & $0.42^{\mathrm{a}, \mathrm{b}}$ & $0.39^{\mathrm{a}, \mathrm{b}}$ & $0.37^{\mathrm{b}}$ & 0.02 & 0.0198 & 0.7397 \\
\hline C_17:1 & $0.35^{\mathrm{a}}$ & $0.30^{\mathrm{b}}$ & $0.24^{\mathrm{C}}$ & $0.20^{\mathrm{d}}$ & 0.01 & $<0.0001$ & 0.6739 \\
\hline C_18:0 & $14.72^{\mathrm{a}}$ & $12.97^{\mathrm{b}}$ & $11.48^{\mathrm{c}}$ & $10.01^{\mathrm{d}}$ & 0.29 & $<0.0001$ & 0.6443 \\
\hline C_18:1n9t & 0.09 & 0.05 & 0.05 & 0.08 & 0.03 & 0.8748 & 0.2648 \\
\hline C_18:1n9c & $39.01^{\mathrm{a}}$ & $37.07^{\mathrm{b}}$ & $34.97^{\mathrm{c}}$ & $33.24^{c}$ & 0.60 & $<0.0001$ & 0.8676 \\
\hline C_18:1n7 & $2.54^{\mathrm{a}}$ & $2.37^{\mathrm{a}}$ & $2.07^{\mathrm{b}}$ & $1.83^{c}$ & 0.07 & $<0.0001$ & 0.5965 \\
\hline C_18:2n6c & $12.17^{\mathrm{d}}$ & $16.85^{\mathrm{c}}$ & $22.53^{\mathrm{b}}$ & $28.33^{\mathrm{a}}$ & 1.00 & $<0.0001$ & 0.5864 \\
\hline C_20:0 & 0.25 & 0.23 & 0.20 & 0.21 & 0.02 & 0.0766 & 0.3546 \\
\hline C_20:1 & $0.52^{\mathrm{b}}$ & $0.54^{\mathrm{b}}$ & $0.62^{\mathrm{a}}$ & $0.68^{\mathrm{a}}$ & 0.02 & 0.0002 & 0.4650 \\
\hline C_20:2n6 & $0.48^{\mathrm{d}}$ & $0.63^{\mathrm{C}}$ & $0.78^{\mathrm{b}}$ & $0.94^{\mathrm{a}}$ & 0.02 & $<0.0001$ & 0.8633 \\
\hline C_20:4n6 & $0.23^{c}$ & $0.25^{\mathrm{b}, \mathrm{c}}$ & $0.29^{\mathrm{a}, \mathrm{b}}$ & $0.32^{\mathrm{a}}$ & 0.02 & 0.0010 & 0.7694 \\
\hline C_24:1 & $0.01^{\mathrm{c}}$ & $0.06^{\mathrm{b}}$ & $0.11^{\mathrm{a}}$ & $0.13^{\mathrm{a}}$ & 0.01 & $<0.0001$ & 0.1389 \\
\hline SFU & $42.54^{\mathrm{a}}$ & $39.87^{b}$ & $36.60^{c}$ & $32.84^{\mathrm{d}}$ & 0.64 & $<0.0001$ & 0.4120 \\
\hline MUFA & $44.56^{\mathrm{a}}$ & $42.38^{\mathrm{b}}$ & $39.77^{c}$ & $37.55^{d}$ & 0.69 & $<0.0001$ & 0.9759 \\
\hline PUFA & $12.88^{\mathrm{d}}$ & $17.73^{c}$ & $23.59^{\mathrm{b}}$ & $29.59^{\mathrm{a}}$ & 1.03 & $<0.0001$ & 0.5884 \\
\hline PUFA:SFA ${ }^{2}$ & $0.29^{\mathrm{d}}$ & $0.44^{\mathrm{c}}$ & $0.63^{\mathrm{b}}$ & $0.89^{a}$ & 0.04 & $<0.0001$ & 0.1478 \\
\hline Total omega- 6 & $12.88^{\mathrm{d}}$ & $17.73^{\mathrm{C}}$ & $23.59^{\mathrm{b}}$ & $29.59^{\mathrm{a}}$ & 1.03 & $<0.0001$ & 0.5884 \\
\hline Iodine Value & $56.99^{d}$ & $63.38^{c}$ & $71.20^{\mathrm{b}}$ & $79.51^{\mathrm{a}}$ & 1.32 & $<0.0001$ & 0.4799 \\
\hline
\end{tabular}


Table 2.8. Effects of increasing levels of DDGS ${ }^{1}$ on fatty acid profile (indicated as percentages) of longissimus muscle of growing-finishing pigs

\begin{tabular}{|c|c|c|c|c|c|c|c|}
\hline \multirow[b]{2}{*}{ Item } & \multicolumn{4}{|c|}{ Treatment } & \multirow[b]{2}{*}{ SEM } & \multicolumn{2}{|c|}{ P-value } \\
\hline & $\begin{array}{c}0 \% \\
\text { DDGS }\end{array}$ & $\begin{array}{c}15 \% \\
\text { DDGS }\end{array}$ & $\begin{array}{c}30 \% \\
\text { DDGS }\end{array}$ & $\begin{array}{c}45 \% \\
\text { DDGS }\end{array}$ & & Linear & Quadratic \\
\hline C_14:0 & 0.80 & 1.11 & 0.86 & 0.90 & 0.14 & 0.9119 & 0.3577 \\
\hline C_15:0 & 1.41 & 1.13 & 1.42 & 1.15 & 0.13 & 0.3994 & 0.9698 \\
\hline C_16:0 & 24.69 & 24.88 & 24.13 & 23.56 & 0.50 & 0.0862 & 0.4578 \\
\hline C_16:1 & $3.47^{\mathrm{a}, \mathrm{b}}$ & $3.63^{\mathrm{a}}$ & $3.27^{\mathrm{a}, \mathrm{b}}$ & $3.07^{\mathrm{b}}$ & 0.16 & 0.0516 & 0.2996 \\
\hline C_17:0 & 0.14 & 0.15 & 0.26 & 0.32 & 0.10 & 0.1677 & 0.8626 \\
\hline C_17:1 & $0.15^{\mathrm{a}}$ & $1.46^{\mathrm{b}}$ & $0.26^{\mathrm{a}}$ & $0.34^{\mathrm{a}}$ & 0.33 & 0.6712 & 0.0877 \\
\hline C_18:0 & 11.50 & 9.93 & 11.11 & 11.08 & 0.63 & 0.9821 & 0.2447 \\
\hline C_18:1n9c & 38.90 & 38.76 & 36.39 & 36.21 & 0.89 & 0.0219 & 0.9846 \\
\hline C_18:1n7 & $4.35^{\mathrm{a}, \mathrm{b}}$ & $4.43^{\mathrm{a}}$ & $4.06^{\mathrm{a}, \mathrm{b}}$ & $3.94^{\mathrm{b}}$ & 0.15 & 0.0397 & 0.5400 \\
\hline C_18:2n6c & $11.59^{\mathrm{b}}$ & $11.78^{\mathrm{b}}$ & $15.15^{\mathrm{a}}$ & $16.59^{\mathrm{a}}$ & 0.86 & 0.0004 & 0.4797 \\
\hline C_20:1 & 0.25 & 0.29 & 0.16 & 0.19 & 0.08 & 0.4292 & 0.9749 \\
\hline C_20:4n6 & 2.77 & 2.47 & 2.95 & 2.65 & 0.28 & 0.9245 & 1.0000 \\
\hline SFU & 38.53 & 37.19 & 37.77 & 37.01 & 0.84 & 0.3116 & 0.7360 \\
\hline MUFA & $47.12^{\mathrm{a}, \mathrm{b}}$ & $48.55^{\mathrm{a}}$ & $44.13^{b}$ & $43.75^{\mathrm{b}}$ & 1.32 & 0.0298 & 0.5029 \\
\hline PUFA & $14.36^{\mathrm{b}}$ & $14.25^{\mathrm{b}}$ & $18.10^{\mathrm{a}}$ & $19.24^{\mathrm{a}}$ & 1.13 & 0.0032 & 0.5906 \\
\hline PUFA:SFA ${ }^{2}$ & $0.32^{\mathrm{c}}$ & $0.34^{\mathrm{b}, \mathrm{c}}$ & $0.42^{\mathrm{a}, \mathrm{b}}$ & $0.47^{\mathrm{a}}$ & 0.03 & 0.0010 & 0.6331 \\
\hline Total omega-6 & $14.36^{\mathrm{b}}$ & $14.25^{\mathrm{b}}$ & $18.10^{\mathrm{a}}$ & $19.24^{\mathrm{a}}$ & 1.13 & 0.0032 & 0.5906 \\
\hline Iodine Value & $57.02^{\mathrm{b}}$ & $57.40^{\mathrm{b}}$ & $60.76^{\mathrm{a}}$ & $62.94^{\mathrm{a}}$ & 0.81 & $<0.0001$ & 0.2885 \\
\hline
\end{tabular}




\begin{tabular}{|c|c|c|c|c|c|c|c|c|c|}
\hline \multicolumn{5}{|c|}{ 0\% DDGS Inclusion } & \multicolumn{5}{|c|}{ 15\% DDGS Inclusion } \\
\hline & Jowl & Belly & Sub-Q $\mathbf{Q}^{2}$ & $\mathbf{L M S}^{3}$ & & Jowl & Belly & Sub-Q & LMS \\
\hline Jowl & 1.00 & $0.95 *$ & 0.96* & 0.53 & Jowl & 1.00 & $0.95 *$ & $0.96^{*}$ & 0.47 \\
\hline Belly & & 1.00 & 0.81 & 0.71 & Belly & & 1.00 & $0.95 *$ & 0.35 \\
\hline Sub-Q & & & 1.00 & 0.33 & Sub-Q & & & 1.00 & 0.22 \\
\hline LMS & & & & 1.00 & LMS & & & & 1.00 \\
\hline \multicolumn{5}{|c|}{ 30\% DDGS Inclusion } & \multicolumn{5}{|c|}{ 45\% DDGS Inclusion } \\
\hline & Jowl & Belly & Sub-Q & LMS & & Jowl & Belly & Sub-Q & LMS \\
\hline Jowl & 1.00 & 0.79 & 0.45 & 0.13 & Jowl & 1.00 & -0.56 & $-0.97 *$ & 0.81 \\
\hline Belly & & 1.00 & $0.90 * *$ & 0.24 & Belly & & 1.00 & 0.75 & 0.02 \\
\hline Sub-Q & & & 1.00 & 0.30 & Sub-Q & & & 1.00 & -0.64 \\
\hline LMS & & & & 1.00 & LMS & & & & 1.00 \\
\hline
\end{tabular}

Figure 2.1. Correlation analysis among fat depots for iodine value (IV) at different levels of DDGS ${ }^{1}$

${ }^{1}$ Distillers dried grains with solubles; ${ }^{2}$ Subcutaneous fat; ${ }^{3}$ Longissimus muscle sample; *Values represent significant correlations $(\mathrm{P}<0.05)$; **Values represent significant correlations $(\mathrm{P}<0.10)$. 


\title{
CHAPTER 3
}

\section{DIETARY INCLUSION OF CONJUGATED LINOLEIC ACID (CLA) CHANGES FATTY ACID PROFILES OF PIGS FED THIRTY PERCENT CORN DRIED DISTILLERS GRAINS WITH SOLUBLES (DDGS) DURING GROWING- FINISHING PHASE}

\begin{abstract}
Due to the increase in the use of polyunsaturated fatty sources as more cost effective energy sources, pork quality has become a large concern and alternatives to diminish the negative effects that these diets could cause on pork fat quality have been studied. Thus, this study evaluated the effects of dietary inclusion of corn distillers dried grains with solubles (DDGS) at $30 \%$ and conjugated linoleic acid (CLA) at $0.6 \%$ on growth performance and carcass and meat quality of growing-finishing pigs. Forty barrows were assigned to a $2 \times 2$ factorial arrangement within a completely randomized block design. Pigs were slaughtered at a live weight of $129.9 \pm 1.2 \mathrm{~kg}$ and data was collected for growth performance, carcass and meat quality and fatty acid profile analysis. CLA supplementation reduced $(\mathrm{P}<0.05)$ final body weight of the pigs from 131.75 to $128.01 \mathrm{~kg}$, while no effects on body weight were observed $(\mathrm{P}>0.62)$ with DDGS inclusion. During the second phase of the study, from days 11 to 38, CLA inclusion reduced $(\mathrm{P}<0.05)$ ADG from 1.50 to $1.37 \mathrm{~kg}$ and ADFI from 3.86 to $3.61 \mathrm{~kg}$,
\end{abstract}


while no effects on F:G were observed $(\mathrm{P}>0.39$ ). During the overall experimental period (d 1-38), ADFI decreased $(\mathrm{P}<0.05)$ and $\mathrm{F}: \mathrm{G}$ tended $(\mathrm{P}=0.06)$ to decrease with DDGS inclusion. CLA supplementation did not affect any of the carcass $(\mathrm{P}>0.07)$ and meat quality $(\mathrm{P}>0.25)$ traits analyzed. However, the inclusion of DDGS decreased redness ( $\mathrm{P}$ $<0.05$ ) of the longissimus muscle and increased flexibility $(\mathrm{P}<0.05)$ of pork belly. An interaction ( $\mathrm{P}<0.05)$ was observed on the iodine value (IV) of jowl and belly samples. CLA inclusion decreased IV in both jowl and belly fat when added to diets without DDGS. However, when included to DDGS-containing diets, CLA numerically decreased IV. In conclusion, CLA inclusion in swine grower-finisher diets could counteract some of the negative effects caused by DDGS when considering fat quality.

\section{INTRODUCTION}

Several changes have been noticed in the swine industry during the last decade including the use of leaner genetics and an increase in the use of polyunsaturated fat sources as more cost effective energy sources (Apple et al., 2007; Carr et al., 2009). However, according to Wood et al. (1989) and Sather et al. (1995), these changes may affect pork quality because as carcasses became leaner pork fat becomes softer (less saturated).

Distillers dried grains with solubles (DDGS) is a by-product of the ethanol production and has been widely used in swine diets because it is largely available and has a high protein and energy content from lipid (McEwen, 2006; Augspurger et al., 2008; Stein and Shurson, 2009). However, knowing that the fatty acid profile of pigs reflects the fatty acid profile of the diet (Ellis and Isbell, 1926; Warnants et al., 1999) and due to 
the fact that DDGS contain 10 to $15 \%$ lipids and high concentration of polyunsaturated fatty acids, pork quality may be severely affected by the inclusion of high levels of DDGS in the diets (Rausch and Belyea, 2006; White et al., 2009). According to Azain (2001) and Wood et al. (2003), polyunsaturated fats are more subject to oxidation and can lead to shorter shelf-life.

Thus, the inclusion of CLA to swine diets during the growing-finishing phase has been shown to reduce carcass fat and increase the concentration of saturated fatty acids (SFA) resulting in positive effects on belly firmness (Thiel-Cooper et al., 2001; Wiegand et al., 2002; Weber et al., 2006; Larsen, et al. 2009). Conjugated linoleic acid acts by decreasing the activity of stearoyl-CoA desaturase gene expression (Demaree et al., 2002; Smith et al., 2002), reducing de novo synthesis of fatty acid and inhibiting acetylCoA carboxylase (Ostrowska et al., 1999; House et al., 2005).

Thus, this study evaluated the effects of dietary inclusion of DDGS at a level of $30 \%$ and CLA at a level of $0.6 \%$ on growth performance, carcass and meat quality traits and fatty acid profiles of growing-finishing pigs.

\section{MATERIALS AND METHODS}

\section{Animals and Diets}

Animal care and experimental protocols were approved by the University of Missouri Animal Care and Use Committee before initiation of this experiment. Then, a total number of 40 crossbred (PIC 337 x C22) growing-finishing barrows were blocked by initial weight $(76.7 \pm 0.8 \mathrm{~kg}$ ) and randomly assigned to treatments. Pigs were individually fed during a total duration of 38 days which was divided into two phases: 1) 
from day 1 to 10 (phase 1; acclimation phase) and 2) from day 11 to 38 (phase 2). Pigs had ad libitum access to water and feed during the experiment which was defined as a $2 \mathrm{x}$ 2 factorial arrangement within a completely randomized block design with a total of 10 pigs per treatment.

During the acclimation phase (phase 1), half of the pigs were fed the control diet (Table 3.1) based on corn and soybean meal while the other half were fed the control diet with the inclusion of DDGS at a level of 30\%. Distillers dried grains with solubles was added to the diets at the expense of corn and soybean meal. At the beginning of the second phase (days 11 to 38), CLA was included at a level of $0.6 \%$ to two (a control and a control + DDGS diets) of the four diets and ractopamine hydrochloride (RAC) was added to all of the diets at a level of $7.4 \mathrm{ppm}$. The source of CLA used was obtained from BASF Corporation (Florham Park, NJ) and its commercial name is Luta-CLA ${ }^{\circledR}$ 60. This product consists of $60 \%$ CLA isomers and thus, it was included at a $1 \%$ level in the diets in order to obtain a $0.6 \%$ level of CLA.

\section{Growth Performance}

In order to characterize growth performance of the pigs, average daily gain (ADG), average daily feed intake (ADFI) and feed efficiency $(F: G)$ were recorded during the two phases of the experimental period. During the experiment, pigs were weighed three times: at the beginning of the experiment (day 0 ), at the beginning of the second phase (day 11) and at the end of the experiment (day 38). Amounts of feed offered were recorded and unconsumed feed was weighed at the end. 


\section{Harvest and Carcass Quality Evaluation}

Pigs were humanely harvested and fabricated at the University of Missouri Abattoir at an average live weight of $129.9 \pm 1.2 \mathrm{~kg}$. Pigs were electrically stunned; following exsanguination, carcasses were scalded, dehaired and eviscerated. At this point, hot carcass weight (HCW) was measured and recorded. At 24 h post mortem, carcasses were ribbed between $10^{\text {th }}$ and $11^{\text {th }}$ back ribs and measurements of loin eye area (LEA), $10^{\text {th }}$ and last rib backfat were performed. Then, carcasses were fabricated at the University of Missouri Meat Processing Facilities and bellies from the left side of the carcass were removed and weighed.

Subjective belly firmness was measured by using the bar-suspension method (Rentfrow et al., 2003) where the flexibility was determined by both vertical and horizontal measurements. Length of the belly was suspended perpendicular to the bar, and the distance between belly ends was determined (horizontal flexibility) as well as the distance between the bar and belly ends (vertical flexibility).

\section{Meat Quality Evaluation}

At $24 \mathrm{~h}$ after slaughter, longissimus muscle objective color ( $\mathrm{L}^{*}, \mathrm{a}^{*}$ and $\mathrm{b}^{*}$ values) was measured using a Minolta Chroma Meter CR-410 (Minolta Camera Co., Osaka, Japan) after a 30 min of bloom time. Furthermore, $\mathrm{pH}$ of the longissimus muscle was also determined by using a portable MPI pH-meter (MPI, Topeka, KS). Additionally, fat samples from belly and jowl were collected from the left side of the carcasses to determination of fatty acid profiles and iodine value (IV). Belly fat samples were removed posterior to the sternum and anterior to the teat line while jowl samples were 
collected on the anterior tip of the jowl at the site of head removal. After collection, samples were frozen at $-10^{\circ} \mathrm{C}$ until analysis was performed.

For fatty acid determination, an adaptation of the methods described by Folch et al. (1957) and Morrison and Smith (1964) was utilized. Lipids were extracted with a solution of chloroform:methanol $(2: 1, \mathrm{v} / \mathrm{v})$ and then saponified by boron trifluoride $\left(\mathrm{BF}_{3}\right)$. Fatty acid methyl esters were analyzed and normalized by using a gas chromatographer (Varian 3,800; Varian, Pala Alto, CA) and a fused silica capillary column (SPTM 2,560; $100 \mathrm{~m} \times 0.25 \mathrm{~mm} \times 0.2 \mu \mathrm{m}$ film thickness; Supelco, Bellefonte, PA). The temperature of the injector was held constant at $240^{\circ} \mathrm{C}$ while the temperature of the flame-ionization detector was held at $260^{\circ} \mathrm{C}$. The carrier gas utilized was helium and the pressure of the system was held constant at $37 \mathrm{psi}$. The oven was operated at $140^{\circ} \mathrm{C}$ for 5 min and then the temperature was increased at a rate of $2.5^{\circ} \mathrm{C} / \mathrm{min}$ until $240^{\circ} \mathrm{C}$ and held at this temperature for $16 \mathrm{~min}$. IV was determined based on the equation described by AOCS (1998): IV $=(0.95 \times$ C16:1 $)+(0.86 \times$ C18:1n9 $)+(1.732 \times$ C18:2n6 $)+(2.616 \times$ C18:3n3) $+(0.785 \times$ C20:1). The ratio between polyunsaturated (PUFA) and saturated (SFA) fatty acids was calculated following the equation: [(C18:2n6c) + $(\mathrm{C} 18: 3 \mathrm{n} 3)] /[(\mathrm{C} 14: 0)+(\mathrm{C} 16: 0)+(\mathrm{C} 18: 0)]$.

\section{Statistical Analysis}

Statistical analyses were performed using the GLM procedure of SAS (SAS Inst., Cary, NC) and considering pig as the experimental unit in a completely randomized block design. The main effects CLA and DDGS and its interaction (when significant) were included to the model and differences were analyzed by the LSMEANS procedure. Furthermore, correlation analysis between IV of belly and jowl fat depots was performed 
by using PROC CORR procedure of SAS. An alpha level of 5\% was considered significant.

\section{RESULTS AND DISCUSSION}

\section{Growth Performance}

According to Table 3.2, pigs fed CLA-containing diets had a lower final body weight when compared to pigs fed diets without CLA inclusion (128.01 vs. $131.75 \mathrm{~kg}$; P $<0.05)$. Furthermore, DDGS inclusion did not have an effect $(\mathrm{P}>0.62)$ on the final body weight of the pigs during the experimental period. When phase 1 was considered (days 0 to 10), the inclusion of DDGS in the diets did not have an effect on ADG (P > 0.93) and F:G $(P>0.26)$. However, the addition of DDGS reduced $(P<0.05)$ ADFI from 3.76 to $3.52 \mathrm{~kg}$, representing a decrease of approximately $6.4 \%$. It is important to remember that none of the treatment diets had the inclusion of CLA during the first phase.

During the second phase (days 11 to 38), the inclusion of CLA reduced $(\mathrm{P}<0.05)$ ADG from 1.50 to $1.37 \mathrm{~kg}$ and ADFI from 3.86 to $3.61 \mathrm{~kg}$, but no effects on F:G were found ( $\mathrm{P}>0.39$ ). These effects on ADG and ADFI during phase 2 may have contributed to the decrease of the final body weight of the pigs fed CLA. Additionally, during phase 2, the inclusion of DDGS improved $(\mathrm{P}<0.05)$ feed efficiency by decreasing F:G from 2.67 to 2.53. ADG was not affected $(\mathrm{P}>0.60)$ by DDGS inclusion but a trend $(\mathrm{P}=0.08)$ toward a decrease of ADFI was observed when DDGS was included to the diets.

By considering the total duration of the experiment (days 0 to 38), the inclusion of DDGS did not have an effect on ADG $(\mathrm{P}>0.89)$. However, DDGS decreased $(\mathrm{P}<0.05)$ ADFI from 3.79 to $3.59 \mathrm{~kg}$ and tended $(\mathrm{P}=0.06)$ to decrease $\mathrm{F}: \mathrm{G}$ from 2.77 to 2.62 , 
representing a favorable improvement in feed efficiency of approximately $5.4 \%$. No conclusions about CLA supplementation could be drawn during the entire experiment period (d 1 to 38) due to the fact that CLA was not fed during the first phase (d 1 to 10) of the project.

White et al. (2009) showed that inclusion of DDGS at a level up to $40 \%$ in swine diets did not have an effect on final body weight, ADG and feed efficiency of growingfinishing pigs. Widmer et al. (2008) observed that ADG, ADFI and G:F were not affected during the entire experimental period when DDGS was fed to growing-finishing pigs at levels of 10 or $20 \%$. The same response was observed by Cook et al. (2005), who reported that DDGS inclusion at levels up to 30\% did not impact ADG, ADFI and G:F of growing-finishing pigs. Furthermore, McEwen (2006) and Augspurger et al. (2008) indicated that the inclusion of DDGS in amino acids fortified diets did not affect ADG, ADFI and G:F during growing-finishing phase when fed at levels up to $20 \%$. However, according to Stein and Shurson (2009), contrasting results regarding the effects of DDGS on growth performance of swine have been obtained which could be related to several factors including quality of DDGS grain, lower apparent amino acid digestibility of DDGS, levels of sugar and variation on the drying method utilized (Rausch and Belyea, 2006; Whitney et al., 2006).

The supplementation of CLA has also shown little effect on growth performance of pigs. Corino et al. (2008) reported that CLA feeding did not affect final weight and ADG when fed at $0.75 \%$ level to heavy pigs. Furthermore, Ramsay et al. (2001) and White et al. (2009) found no differences in body weight, ADG and feed efficiency when CLA was fed to pigs. Moreover, Wiegand et al. (2002) indicated that ADG and ADFI 
were not affected by CLA inclusion at $0.75 \%$ level in swine diets. No effects on G:F were observed by Weber et al. (2006) when CLA was fed to genetically lean pigs.

On the other hand, literature shows some positive effects of CLA supplementation on swine growth performance. According to Thiel-Cooper et al. (2001), this variation in responses observed for growth performance traits could be related to several factors including sex, genetics and season. These same authors reported a linear increase in ADG and feed efficiency with increasing levels of CLA in swine diets while no differences were observed in ADFI. Cook et al. (1998) showed that feed intake decreased while growth rate was unaffected when $0.6 \%$ of CLA was fed to finishing pigs, indicating a positive effect on feed efficiency with CLA supplementation.

\section{Carcass and meat quality}

According to Table 3.3, no effects $\left(\mathrm{P}>0.12\right.$ ) were observed on HCW, LEA, $10^{\text {th }}$ rib backfat, last rib backfat and belly weight when DDGS was included to the diets. However, the inclusion of DDGS negatively affected belly flexibility. When vertical flexibility was considered, DDGS increased $(\mathrm{P}<0.05)$ the vertical distance between the bar and belly ends from 18.29 to $21.72 \mathrm{~cm}$, indicating that softer bellies were obtained. Soft bellies were also observed when horizontal flexibility was considered; the inclusion of DDGS decreased $(\mathrm{P}<0.05)$ the horizontal distance between belly ends from 14.61 to $8.13 \mathrm{~cm}$, which was indicative of softer bellies.

Our findings were in agreement with Widmer et al. (2008) who found no effects on HCW, dressing percentage (DP), percentage lean, LEA and $10^{\text {th }}$ rib backfat when pigs were fed DDGS at 10 or $20 \%$ levels during the growing-finishing phase. Cook et al. (2005) and Whitney et al. (2006) also reported no effects on backfat depth and 
percentage lean when pigs were fed diets containing DDGS. No effects on LEA, $10^{\text {th }}$ and last rib fat depths were also observed by White et al. (2009) when DDGS was fed at a level up to $40 \%$ to growing-finishing pigs. Moreover, according to Stein and Shurson (2009), most of the studies have shown that the inclusion of corn DDGS to swine diets did not have an effect on carcass traits such as DP, backfat, loin depth and percentage lean. Results obtained from the belly flexibility tests in the current study were in agreement with other studies in which DDGS feeding has been found to reduce adjusted belly firmness in pigs (Whitney et al., 2006; Widmer et al., 2008; Xu et al., 2010a).

The inclusion of CLA did not have an effect $(\mathrm{P}>0.23)$ on LEA, $10^{\text {th }}$ rib backfat, last rib backfat, vertical and horizontal belly flexibility and belly weight. However, CLA inclusion tended $(\mathrm{P}=0.07)$ to decrease HCW from 97.18 to $94.46 \mathrm{~kg}$, which was related to the decrease in the final weight of the pigs fed CLA. Similar results were found in other studies where the effects of CLA inclusion on pork carcass quality were analyzed. White et al. (2009) demonstrated that LEA, and $10^{\text {th }}$ and last rib fat depths were not affected by inclusion of CLA at a $0.6 \%$ level in swine diets of growing-finishing pigs. Thiel-Cooper et al. (2001) and Larsen et al. (2009) demonstrated that CLA supplementation to swine diets did not have an effect on LEA, and first and last rib backfat depth. Averette-Gatlin et al. (2002b) also reported that CLA supplementation did not affect LEA and back fat when fed to lean genotype gilts. Moreover, Corino et al. (2008) showed that carcass weight, and thickness of backfat and longissimus muscle were not affected in heavy pigs by dietary CLA. However, according to Dugan et al. (1997), the inclusion of CLA in swine diets reduced the amount of carcass fat, thus increasing the amount of carcass lean in finishing pigs. Smith et al. (2002) reported that CLA may 
decrease adiposity in pigs due to its effects on the inhibition of the enzyme steroyl coenzyme A desaturase.

Thiel-Cooper et al. (2001) observed this effect and found that CLA inclusion decreased $10^{\text {th }}$ rib backfat depth of pigs when compared to control groups. Furthermore, Wiegand et al. (2002) demonstrated that LEA increased linearly while first, tenth and last rib backfat depth decreased linearly when CLA was supplemented to barrows at different durations. Weber et al. (2006) indicated that genetically lean pigs fed 0.6\% CLA had greater predicted lean percentage than pigs fed the control diets. Additionally, these authors reported that CLA decreased last rib and tended to decrease $10^{\text {th }}$ rib fat depth.

Finally, Cook et al. (1998), Eggert et al. (2001), Thiel-Cooper et al. (2001), Weber et al. (2006) and Larsen et al. (2009) showed that belly firmness was increased when CLA was added to swine diets. This response was not observed in the current study when flexibility tests were performed. However, as it will be described later, improvements in IV were obtained with the feeding of CLA.

This lack of response to CLA feeding in the present study, especially in backfat thickness, could be attributed to the lean genetics utilized. Thus, in order to analyze the effects of CLA on adipose tissue, a genetic line with predisposition to fattening should be used as the model. According to Thiel-Cooper et al. (2001), variations in responses to the feeding of CLA can be related to several factors including sex, genetics and season. Dunshea et al. (2005) stated that CLA response depends on the amount of fat amount of animal and thus, the higher the initial backfat depth in a pig, the greater is the reduction in backfat, indicating greater CLA response. 
Table 3.4 shows that DDGS inclusion did not have an effect $(\mathrm{P}>0.22)$ on $\mathrm{pH}$, lightness (Minolta $\mathrm{L}^{*}$ score) and yellowness (Minolta $\mathrm{b}^{*}$ score) of the longissimus muscle. However, inclusion of DDGS in the diets decreased $(\mathrm{P}<0.05)$ the red color (Minolta a* score) from 18.58 to 17.72 . No effects $(\mathrm{P}>0.25)$ on meat quality traits were observed when CLA was added to the diets.

Our results were in agreement with Whitney et al. (2006) who found that DDGS inclusion in swine diets did not have a negative effect on objective color $\left(L^{*}, a^{*}, b^{*}\right.$ scores) and ultimate $\mathrm{pH}$ of the longissimus muscle. Moreover, White et al. (2009) found no effect on subjective color measurements with DDGS inclusion in swine diets. On the other hand, $\mathrm{Xu}$ et al. (2010a) reported that $\mathrm{pH}$ and L* was unaffected by inclusion of DDGS, but $\mathrm{a}^{*}$ and $\mathrm{b}^{*}$ scores were reduced in longissimus muscle with increasing levels of DDGS in the diet. In addition, Widmer et al. (2008) showed that ultimate pH and objective color of pork was unaffected by DDGS inclusion, except that a linear decrease in b* score was observed when the concentration of DDGS increased in the diet.

Regarding the effects of CLA on pork quality, our results were in agreement with Joo et al. (2002) who found that $\mathrm{L}^{*}, \mathrm{a}^{*}, \mathrm{~b}^{*}$ and $\mathrm{pH}$ of fresh (day 0) longissimus muscle was not affected when CLA was added to swine diets at increasing levels. Moreover, no effects on subjective color (Eggert et al., 2001; Wiegand et al., 2001; White et al., 2009) and ultimate pH (Eggert et al., 2001; Wiegand et al., 2001, 2002) of the longissimus muscle were observed when CLA was supplemented in swine diets. However, some studies have shown that CLA may have an effect on objective color of fresh pork. Wiegand et al. (2002) reported that, independent of storage day, lightness ( $\left.\mathrm{L}^{*}\right)$ and redness $\left(a^{*}\right)$ were not affected by CLA inclusion while yellowness $\left(b^{*}\right)$ increased when 
compared to pigs fed the control diet. In addition, Corino et al. (2008) reported that CLA supplementation did not affect objective color of longissimus muscle, except b* score which was increased in pigs fed CLA-containing diets.

\section{Fatty acid profiles}

Table 3.5 shows interactions $(\mathrm{P}<0.05)$ between DDGS and dietary CLA for jowl samples. CLA inclusion increased the concentration of SFA from 34.88 to $41.06 \%$ when added to diets without DDGS and from 33.03 to $35.70 \%$ when added to DDGScontaining diets. Moreover, DDGS inclusion decreased SFA from 34.88 to 33.03\% when fed without CLA and from 41.06 to $35.70 \%$ when CLA was also added to the diets. The main individual saturated fatty acids responsible for these observations were myristic (C14:0), palmitic (C16:0) and stearic (C18:0) acids. Thus, similar results as those

observed for total SFA were observed for these three fatty acids, except that no differences were observed on the amount of C16:0 when CLA was added to DDGScontaining diets.

According to Table 3.5, an interaction $(\mathrm{P}<0.05)$ was found for the total amount of polyunsaturated fatty acids (PUFA) of jowl samples. When included in diets without DDGS, CLA did not change the concentration of PUFA while an increase in the amount of PUFA from 20.53 to $22.53 \%$ was observed when CLA was added to DDGScontaining diets. The inclusion of DDGS increased the concentration of PUFA in jowl samples when added to diets with or without the presence of CLA. This response was expected due to the fact that DDGS has a high concentration of polyunsaturated fatty acids in its composition (Rausch and Belyea, 2006). 
Similar effects were also observed for the main individual polyunsaturated fatty acid, linoleic acid (C18:2n6c). As observed for total PUFA, CLA did not affect the amount of C18:2n6c in diets without DDGS but increased the concentration of C18:2n6c in diets with DDGS inclusion. In addition, an interaction $(\mathrm{P}<0.05)$ was found for IV of jowl samples where inclusion of CLA in diets without DDGS reduced IV from 65.83 to 59.83. This observation could be related to the fact that CLA may act by decreasing the activity of stearoyl-CoA desaturase gene expression (Demaree et al., 2002; Smith et al., 2002), shifting the fatty acid profile of the carcass to a more saturated profile.

Additionally, DDGS inclusion in diets without CLA increased IV from 65.83 to 71.18 and from 59.83 to 69.74 when included in CLA-containing diets. As described before, due to the high concentration of polyunsaturated fatty acids in DDGS, IV of the carcass was expected to increase with the feeding of DDGS. However, IV obtained for all of the treatments were below the threshold of 72 which has been used as an indicator of soft bellies by some packing plants.

Table 3.6 shows the main effects of DDGS and CLA on fatty acid profile of jowl fat samples. The total amount of monounsaturated fatty acids (MUFA) was affected by both DDGS and CLA inclusion. CLA supplementation reduced $(\mathrm{P}<0.05)$ the amount of MUFA from 47.83 to $42.46 \%$ while DDGS inclusion reduced $(\mathrm{P}<0.05)$ MUFA from 46.18 to $44.11 \%$. Similar effects were also observed on the concentrations of oleic (C18:1n9c) and vaccenic (C18:1n7) acids. Palmitoleic acid (C16:1) was only affected (P $<0.05$ ) by DDGS inclusion which decreased its concentration from 2.08 to $1.83 \%$. In addition, according to Table 3.6, the feeding of CLA increased $(\mathrm{P}<0.05)$ the total amount of CLA from 0.11 to $0.52 \%$ in jowl samples demonstrating the ability of dietary 
CLA to be deposited in adipose tissue when fed to pigs during the growing-finishing phase.

Tables 3.7 and 3.8 show that similar responses as those observed for jowl samples were also obtained for belly samples. According to Table 3.7, an interaction was found (P $<0.05$ ) for the total amount of SFA and CLA supplementation increased the concentration of SFA in belly samples from 33.02 to $39.32 \%$ when added to the diets without DDGS and from 32.21 to $34.86 \%$ when added to DDGS-containing diets. Moreover, DDGS inclusion decreased SFA from 39.32 to $34.86 \%$ when fed with CLA, but was unable to decrease the amount of SFA in diets without the inclusion of CLA.

Furthermore, there was a DDGS by CLA interaction $(\mathrm{P}<0.05)$ for the total amount of PUFA in belly samples. As observed previously, CLA did not change the concentration of PUFA when included in diets without DDGS. However, when included in DDGS-containing diets, CLA increased the concentration of PUFA from 20.87 to 23.76\%. DDGS inclusion, as observed before, increased the concentration in diets with or without the presence of CLA. Similar responses were also observed for C18:2n6c which was the main individual polyunsaturated fatty acid in belly samples.

In addition, when IV of belly samples was considered, similar results were obtained and an interaction $(\mathrm{P}<0.05)$ was found. When included in diets without DDGS, CLA reduced IV from 65.83 to 61.25 . Furthermore, IV of belly samples was increased with the addition of DDGS to the diets; IV increased from 65.83 to 72.19 in diets without CLA and from 61.25 to 71.14 in CLA-containing diets.

According to Table 3.8, the total concentration of MUFA in belly samples was affected $(\mathrm{P}<0.05)$ by DDGS and CLA inclusion. The inclusion of DDGS reduced 
MUFA content from 47.13 to $44.15 \%$ while the inclusion of CLA decreased MUFA from 48.71 to $42.57 \%$. Once again, similar responses were observed for the concentrations of C18:1n9. Furthermore, Table 3.8 shows that dietary CLA was also effectively deposited in belly adipose tissue which is shown by an increase $(\mathrm{P}<0.05)$ in the total amount of CLA from 0.12 to $0.80 \%$.

Our findings were in agreement with White et al. (2009) who found that DDGS inclusion decreased the amounts of SFA, especially C16:0 and C18:0, and increased the concentration of unsaturated fatty acids (UFA), especially C18:2, in swine adipose tissues. Moreover, the same authors reported that CLA supplementation increased the amount of C14:0, C18:0 and total CLA and decreased the amount of C18:1 and C18:1n7. These authors also reported that CLA and DDGS demonstrated opposing effects on IV of belly and backfat; IV decreased with CLA feeding and increased with DDGS inclusion. Additionally, Weber et al. (2006) demonstrated that bellies from pigs fed CLAcontaining diets had lower concentrations of MUFA and higher amounts of SFA and total CLA when compared to pigs fed a control diet. Furthermore, IV of bellies decreased when CLA was included to the diets.

Ramsay et al. (2001) reported that CLA addition to swine diets increased the concentration of C18:0 in muscle tissue when fed at 1 or $2 \%$ levels and decreased the amount of C18:1 in muscle when supplemented at a 2\% level. Larsen et al. (2009) also reported that the concentrations of C18:0 increased while C18:1 amount decreased in bacon tissues from pigs fed CLA. Other studies have also shown the ability of CLA to increase the concentration of SFA and decrease the amount of UFA in swine tissues (Eggert et al., 2001; Joo et al., 2002; Wiegand et al., 2002; Cordero et al., 2010). 
Furthermore, Eggert et al. (2001) and Averette-Gatlin et al. (2002b) also demonstrated the effectiveness of dietary CLA in decreasing IV of belly fat.

Regarding the effects of DDGS on the fatty acid profile, as seen in the current study, Xu et al. (2010a) found that DDGS inclusion to grower-finisher diets increased the concentration of PUFA (especially C18:2) in backfat and belly samples. Furthermore, as observed in our study DDGS decreased the concentrations of SFA and MUFA when included in the diets. According to Stein and Shurson (2009), most studies have shown that DDGS increased IV when included in swine diets. Due to the high concentration of PUFA in DDGS, Whitney et al. (2006) and Xu et al. (2010a) found an increase in the IV of belly samples when the level of DDGS in swine diets was increased.

Finally, Table 3.9 shows the correlation analyses between IV of belly and jowl samples. These analyzes were performed in order to verify if IV of jowl fat samples can be safely used as a predictor of the IV of belly samples. This practice has been largely done in several pork processing plants, being an indicator of belly firmness. Thus, according to Table 3.9, moderate correlations $(\mathrm{P}<0.05)$ between IV of belly and jowl fat samples were obtained when no DDGS was included in the diets; $r=0.72$ (without CLA) and $r=0.78$ (with the presence of CLA). However, strong correlations were obtained when DDGS was fed without CLA $(r=0.88$; $P<0.05)$ and along with CLA $(r=0.83$; P $<0.05)$. These results indicated that inclusion of DDGS and CLA in grower-finisher diets may impact maturity of the pigs. By assuming that once maturity is reached the fatty acid profile of jowl and belly samples would be similar (highly correlated) to each other, one could presume that at time of death, pigs in this study had reached different maturity end points which would explain the correlation differences among treatments. 


\section{IMPLICATIONS}

In summary, these results indicated that, although no negative effects were observed on growth performance and on some carcass and meat quality traits, DDGS inclusion at a 30\% level could negatively affect belly firmness in pigs which could be observed by flexibility tests and increased IV. On the other hand, CLA inclusion at a $0.6 \%$ could diminish some of these negative effects of DDGS which could also be observed by a decrease in the IV of pigs fed CLA. Thus, the inclusion of CLA in growerfinisher diets could be a viable way of counteracting the negative effects caused by diets with high concentration of PUFA. This study also demonstrated that CLA was able to affect composition of adipose tissue without increasing overall fatness of the pigs. 
Table 3.1. Percentage composition of experimental diets (as fed basis) during phases 1 (d 1-10) and 2 (d 11-38) of the study

\begin{tabular}{|c|c|c|c|c|c|c|}
\hline & \multirow{2}{*}{\multicolumn{2}{|c|}{$\frac{\text { Phase } 1}{\text { DDGS }^{1}}$}} & \multicolumn{4}{|c|}{ Phase 2} \\
\hline & & & \multicolumn{2}{|c|}{ No CLA } & \multicolumn{2}{|c|}{ CLA } \\
\hline & - & + & $\begin{array}{c}\text { No } \\
\text { DDGS }\end{array}$ & DDGS & $\begin{array}{c}\text { No } \\
\text { DDGS }\end{array}$ & DDGS \\
\hline \multicolumn{7}{|l|}{ Ingredients, \% } \\
\hline Corn & 81.85 & 58.96 & 76.85 & 52.40 & 76.20 & 51.75 \\
\hline Soybean meal 48\% & 14.50 & 7.50 & 19.00 & 13.75 & 19.00 & 13.75 \\
\hline DDGS & 0.00 & 30.00 & 0.00 & 30.00 & 0.00 & 30.00 \\
\hline Choice white grease & 1.00 & 1.00 & 1.35 & 1.35 & 1.00 & 1.00 \\
\hline Luta-CLA $^{\circledR} 60$ & 0.00 & 0.00 & 0.00 & 0.00 & 1.00 & 1.00 \\
\hline Monocal & 0.50 & 0.00 & 0.65 & 0.00 & 0.65 & 0.00 \\
\hline Limestone & 0.95 & 1.23 & 0.83 & 1.17 & 0.83 & 1.17 \\
\hline Salt & 0.50 & 0.50 & 0.50 & 0.50 & 0.50 & 0.50 \\
\hline L-Lysine & 0.30 & 0.44 & 0.35 & 0.43 & 0.35 & 0.43 \\
\hline Alimet & 0.06 & 0.06 & 0.06 & 0.03 & 0.06 & 0.03 \\
\hline L-Threonine & 0.09 & 0.08 & 0.13 & 0.09 & 0.13 & 0.09 \\
\hline Vitamin Premix & 0.15 & 0.15 & 0.15 & 0.15 & 0.15 & 0.15 \\
\hline Mineral Premix & 0.10 & 0.10 & 0.10 & 0.10 & 0.10 & 0.10 \\
\hline Paylean & 0.00 & 0.00 & 0.04 & 0.04 & 0.04 & 0.04 \\
\hline \multicolumn{7}{|l|}{ Calculated analysis } \\
\hline Crude Protein, \% & 14.06 & 17.00 & 15.86 & 19.41 & 15.84 & 19.39 \\
\hline Total lysine, \% & 0.89 & 0.95 & 1.05 & 1.11 & 1.05 & 1.11 \\
\hline TID ${ }^{2}$ lysine, \% & 0.80 & 0.80 & 0.95 & 0.95 & 0.95 & 0.95 \\
\hline TID tryptophan, \% & 0.13 & 0.12 & 0.15 & 0.15 & 0.15 & 0.15 \\
\hline Calcium, \% & 0.50 & 0.50 & 0.50 & 0.50 & 0.50 & 0.50 \\
\hline Total Phosphorus, \% & 0.43 & 0.45 & 0.48 & 0.48 & 0.48 & 0.48 \\
\hline Available Phosphorus, \% & 0.16 & 0.25 & 0.20 & 0.26 & 0.20 & 0.26 \\
\hline ME, Mcal/kg & 3.39 & 3.33 & 3.40 & 3.34 & 3.36 & 3.31 \\
\hline
\end{tabular}

${ }^{1}$ Distillers dried grains with solubles;

2 True ileal digestible. 
Table 3.2. Effects of DDGS and CLA inclusion on growth performance of growing-finishing pigs during phases 1, 2 and the total experimental period

\begin{tabular}{|c|c|c|c|c|c|c|c|}
\hline \multirow[b]{2}{*}{ Traits } & \multicolumn{2}{|c|}{$\mathrm{DDGS}^{1}$} & \multicolumn{2}{|c|}{$\mathrm{CLA}^{2}$} & \multirow{2}{*}{ S.E. } & \multicolumn{2}{|c|}{ P-values } \\
\hline & - & + & - & + & & DDGS & CLA \\
\hline \multicolumn{8}{|l|}{$B W, k g$} \\
\hline Day 0 & 76.52 & 76.90 & 76.91 & 76.50 & 0.787 & 0.735 & 0.720 \\
\hline Day 10 & 89.53 & 89.85 & 89.83 & 89.54 & 0.460 & 0.807 & 0.820 \\
\hline Day 38 & 129.46 & 130.29 & 131.75 & 128.01 & 1.210 & 0.630 & 0.036 \\
\hline \multicolumn{8}{|c|}{ Phase 1 (day 1 to 10 ) } \\
\hline ADG, kg & 1.30 & 1.30 & N.A. ${ }^{4}$ & N.A. & 0.053 & 0.933 & N.A. \\
\hline ADFI, kg & 3.76 & 3.52 & N.A. & N.A. & 0.082 & 0.046 & N.A. \\
\hline$F: G^{3}$ & 2.89 & 2.71 & N.A. & N.A. & 0.085 & 0.268 & N.A. \\
\hline \multicolumn{8}{|c|}{ Phase 2 (day 11 to 38) } \\
\hline ADG, kg & 1.43 & 1.44 & 1.50 & 1.37 & 0.025 & 0.608 & 0.001 \\
\hline ADFI, kg & 3.81 & 3.66 & 3.86 & 3.61 & 0.061 & 0.082 & 0.005 \\
\hline $\mathrm{F}: \mathrm{G}$ & 2.67 & 2.53 & 2.58 & 2.62 & 0.049 & 0.035 & 0.391 \\
\hline \multicolumn{8}{|c|}{ Phase $1+2$ (day 1 to 38$)$} \\
\hline $\mathrm{ADG}, \mathrm{kg}$ & 1.37 & 1.37 & N.A. & N.A. & 0.031 & 0.893 & N.A. \\
\hline ADFI, kg & 3.79 & 3.59 & N.A. & N.A. & 0.064 & 0.036 & N.A. \\
\hline $\mathrm{F}: \mathrm{G}$ & 2.77 & 2.62 & N.A. & N.A. & 0.053 & 0.060 & N.A. \\
\hline
\end{tabular}


Table 3.3. Effects of DDGS and CLA inclusion on carcass quality of growingfinishing pigs

\begin{tabular}{|c|c|c|c|c|c|c|c|}
\hline \multirow[b]{2}{*}{ Traits } & \multicolumn{2}{|c|}{$\mathrm{DDGS}^{1}$} & \multicolumn{2}{|c|}{ CLA $^{2}$} & \multirow{2}{*}{ S.E. } & \multicolumn{2}{|c|}{ P-values } \\
\hline & - & + & - & + & & DDGS & CLA \\
\hline HCW, kg & 96.12 & 95.53 & 97.18 & 94.46 & 1.053 & 0.694 & 0.076 \\
\hline $\mathrm{LEA}^{3}, \mathrm{~cm}^{2}$ & 52.45 & 54.74 & 53.97 & 53.23 & 1.161 & 0.172 & 0.654 \\
\hline $10^{\text {th }}$ Rib BackFat, mm & 20.45 & 18.67 & 20.19 & 18.92 & 0.809 & 0.129 & 0.274 \\
\hline Last Rib BackFat, mm & 26.92 & 28.32 & 28.32 & 26.92 & 0.826 & 0.240 & 0.240 \\
\hline Vertical Flex, cm & 18.29 & 21.72 & 19.56 & 20.45 & 0.612 & 0.001 & 0.311 \\
\hline Horizontal Flex, cm & 14.61 & 8.13 & 10.80 & 11.94 & 0.786 & $<0.0001$ & 0.311 \\
\hline Belly Weight, kg & 5.23 & 5.31 & 5.27 & 5.27 & 0.161 & 0.733 & 0.972 \\
\hline
\end{tabular}

${ }^{1}$ Distillers dried grains with solubles was included at a 30\% level in the diets;

${ }^{2}$ Conjugated linoleic acid was included at a $0.6 \%$ level in the diets;

${ }^{3}$ Loin eye area. 
Table 3.4. Effects of DDGS and CLA inclusion on meat quality of growingfinishing pigs

\begin{tabular}{|c|c|c|c|c|c|c|c|}
\hline \multirow[b]{2}{*}{ Traits } & \multicolumn{2}{|c|}{$\mathrm{DDGS}^{1}$} & \multicolumn{2}{|c|}{$\mathrm{CLA}^{2}$} & \multirow{2}{*}{ S.E. } & \multicolumn{2}{|c|}{ P-values } \\
\hline & - & + & - & + & & DDGS & CLA \\
\hline $\mathrm{pH}$ & 5.90 & 5.88 & 5.89 & 5.90 & 0.015 & 0.360 & 0.759 \\
\hline Minolta $\mathrm{L}^{* 3}$ & 59.04 & 60.33 & 59.97 & 59.40 & 0.743 & 0.225 & 0.593 \\
\hline Minolta $\mathrm{a}^{*^{4}}$ & 18.58 & 17.72 & 17.91 & 18.39 & 0.293 & 0.044 & 0.258 \\
\hline Minolta $\mathrm{b}^{*^{5}}$ & 12.02 & 11.81 & 12.00 & 11.83 & 0.176 & 0.403 & 0.508 \\
\hline $\begin{array}{l}{ }^{1} \text { Distillers dried } \\
{ }^{2} \text { Conjugated lin } \\
{ }^{3} \text { Longissimus } \\
{ }^{4} \text { Longissimus } \\
\\
{ }^{5} \text { Longissimus } \mathrm{n}\end{array}$ & $\begin{array}{l}\text { Is with } \\
\text { acid wa } \\
\text { lightne } \\
\text { rednes } \\
\text { yellow }\end{array}$ & $\begin{array}{l}\text { oles } n \\
\text { clude }\end{array}$ & $\begin{array}{l}\text { ded at } \\
5 \% \text { lev }\end{array}$ & $\begin{array}{l}\% \text { lev } \\
\text { the di }\end{array}$ & e die & & \\
\hline
\end{tabular}


Table 3.5. DDGS by dietary CLA treatment subclass for fatty acid profile of jowl samples of growing-finishing pigs

\begin{tabular}{|c|c|c|c|c|c|c|c|c|}
\hline \multirow{2}{*}{$\frac{\mathrm{DDGS}^{1}}{\mathrm{CLA}^{2}}$} & \multicolumn{2}{|c|}{-} & \multicolumn{2}{|c|}{+} & \multirow{2}{*}{ S.E. } & \multicolumn{3}{|c|}{ P-values } \\
\hline & - & + & - & + & & DDGS & CLA & CLA*DDGS \\
\hline \multicolumn{9}{|l|}{ Fatty Acid, \% } \\
\hline C_14:0 & $1.28^{\mathrm{c}}$ & $1.82^{\mathrm{a}}$ & $1.22^{\mathrm{C}}$ & $1.51^{\mathrm{b}}$ & 0.056 & 0.002 & $<0.001$ & 0.033 \\
\hline C_15:0 & $0.05^{\mathrm{b}}$ & $0.05^{\mathrm{b}}$ & $0.05^{\mathrm{b}}$ & $0.07^{\mathrm{a}}$ & 0.003 & 0.035 & 0.053 & 0.009 \\
\hline C_16:0 & $22.56^{\mathrm{b}}$ & $24.00^{\mathrm{a}}$ & $21.40^{\mathrm{c}}$ & $21.39^{c}$ & 0.351 & $<0.001$ & 0.048 & 0.045 \\
\hline C_18:0 & $10.53^{\mathrm{C}}$ & $14.43^{\mathrm{a}}$ & $9.85^{\mathrm{c}}$ & $11.99^{\mathrm{b}}$ & 0.303 & $<0.001$ & $<0.001$ & 0.006 \\
\hline C_18:2n6c & $12.95^{\mathrm{C}}$ & $12.79^{c}$ & $17.41^{\mathrm{b}}$ & $19.27^{\mathrm{a}}$ & 0.386 & $<0.001$ & 0.033 & 0.013 \\
\hline C_20:3n6 & $0.11^{\mathrm{b}}$ & $0.10^{\mathrm{C}}$ & $0.13^{\mathrm{a}}$ & $0.13^{\mathrm{a}}$ & 0.003 & $<0.001$ & 0.262 & 0.047 \\
\hline C_20:3n3 & 0.14 & 0.13 & 0.14 & 0.15 & 0.004 & 0.011 & 0.743 & 0.055 \\
\hline C_20:4n6 & $0.26^{\mathrm{a}}$ & $0.22^{\mathrm{b}}$ & $0.27^{\mathrm{a}}$ & $0.26^{\mathrm{a}}$ & 0.010 & 0.008 & 0.022 & 0.049 \\
\hline C_22:5n3 & $0.05^{\mathrm{a}}$ & $0.04^{\mathrm{b}}$ & $0.05^{\mathrm{a}}$ & $0.05^{\mathrm{a}}$ & 0.002 & 0.039 & 0.209 & 0.031 \\
\hline Total SFA & $34.88^{\mathrm{b}}$ & $41.06^{\mathrm{a}}$ & $33.03^{c}$ & $35.70^{\mathrm{b}}$ & 0.616 & $<0.001$ & $<0.001$ & 0.007 \\
\hline Total PUFA & $15.91^{\mathrm{c}}$ & $15.79^{c}$ & $20.53^{\mathrm{b}}$ & $22.53^{\mathrm{a}}$ & 0.382 & $<0.001$ & 0.019 & 0.009 \\
\hline Total omega-6 & $14.18^{\mathrm{C}}$ & $13.96^{\mathrm{c}}$ & $18.94^{\mathrm{b}}$ & $20.84^{\mathrm{a}}$ & 0.410 & $<0.001$ & 0.049 & 0.014 \\
\hline PUFA:SFA ${ }^{3}$ & $0.42^{\mathrm{b}}$ & $0.35^{\mathrm{c}}$ & $0.58^{\mathrm{a}}$ & $0.58^{\mathrm{a}}$ & 0.017 & $<0.001$ & 0.065 & 0.023 \\
\hline Iodine value & $65.83^{\mathrm{b}}$ & $59.83^{\mathrm{C}}$ & $71.18^{\mathrm{a}}$ & $69.74^{\mathrm{a}}$ & 0.721 & $<0.001$ & $<0.001$ & 0.003 \\
\hline
\end{tabular}


Table 3.6. Main effects of DDGS and CLA inclusion on fatty acid profile of jowl fat samples of growing-finishing pigs

\begin{tabular}{|c|c|c|c|c|c|c|c|}
\hline & \multicolumn{2}{|c|}{ DDGS $^{1}$} & \multicolumn{2}{|c|}{$\mathrm{CLA}^{2}$} & \multirow{2}{*}{ S.E. } & \multicolumn{2}{|c|}{ P-values } \\
\hline & - & + & - & + & & DDGS & CLA \\
\hline C_10:0 & 0.05 & 0.04 & 0.04 & 0.05 & 0.001 & 0.124 & 0.288 \\
\hline C_12:0 & 0.08 & 0.07 & 0.06 & 0.08 & 0.002 & 0.020 & $<0.001$ \\
\hline C_1 $14: 0^{3}$ & 1.55 & 1.37 & 1.25 & 1.67 & 0.040 & 0.002 & $<0.001$ \\
\hline C_15: $0^{3}$ & 0.05 & 0.06 & 0.05 & 0.06 & 0.002 & 0.035 & 0.053 \\
\hline C_16:0 $0^{3}$ & 23.28 & 21.39 & 21.98 & 22.70 & 0.248 & $<0.001$ & 0.048 \\
\hline C_17:0 & 0.10 & 0.17 & 0.11 & 0.15 & 0.041 & 0.226 & 0.464 \\
\hline C_18:0 $0^{3}$ & 12.48 & 10.92 & 10.19 & 13.21 & 0.214 & $<0.001$ & $<0.001$ \\
\hline C_20:0 & 0.23 & 0.21 & 0.21 & 0.22 & 0.006 & 0.006 & 0.319 \\
\hline C_21:0 & 0.13 & 0.11 & 0.02 & 0.21 & 0.036 & 0.679 & 0.001 \\
\hline C_22:0 & 0.03 & 0.03 & 0.03 & 0.03 & 0.001 & 0.456 & 0.777 \\
\hline Total SFA ${ }^{3}$ & 37.97 & 34.36 & 33.95 & 38.38 & 0.436 & $<0.001$ & $<0.001$ \\
\hline C_14:1 & 0.01 & 0.01 & 0.01 & 0.01 & 0.002 & 0.203 & 0.047 \\
\hline C_16:1 & 2.08 & 1.83 & 2.01 & 1.91 & 0.052 & 0.002 & 0.169 \\
\hline C_17:1 & 0.17 & 0.21 & 0.19 & 0.20 & 0.031 & 0.368 & 0.924 \\
\hline C_18:1n7 & 2.64 & 2.35 & 2.64 & 2.36 & 0.050 & 0.001 & 0.001 \\
\hline C_18:1n9c & 41.01 & 39.48 & 42.76 & 37.74 & 0.303 & 0.001 & $<0.001$ \\
\hline C_18:1n9t & 0.23 & 0.20 & 0.20 & 0.23 & 0.022 & 0.414 & 0.252 \\
\hline C_20:1 & 0.02 & 0.02 & 0.02 & 0.02 & 0.003 & 0.836 & 0.705 \\
\hline Total MUFA & 46.18 & 44.11 & 47.83 & 42.46 & 0.332 & $<0.001$ & $<0.001$ \\
\hline C_18:2n6c ${ }^{3}$ & 12.87 & 18.34 & 15.18 & 16.03 & 0.273 & $<0.001$ & 0.033 \\
\hline C_18:2n6t & 0.04 & 0.04 & 0.03 & 0.04 & 0.002 & 0.139 & 0.005 \\
\hline C_18:2c9t11; CLA & 0.15 & 0.14 & 0.05 & 0.23 & 0.034 & 0.746 & 0.001 \\
\hline C_18:2t10c12; CLA & 0.01 & 0.01 & 0.00 & 0.02 & 0.007 & 0.360 & 0.087 \\
\hline C_18:2c9c11; CLA & 0.10 & 0.09 & 0.02 & 0.16 & 0.008 & 0.309 & $<0.001$ \\
\hline C_18:2t9t11; CLA & 0.07 & 0.07 & 0.03 & 0.11 & 0.003 & 0.098 & $<0.001$ \\
\hline C_18:3n3 & 1.25 & 1.14 & 1.35 & 1.05 & 0.056 & 0.163 & 0.001 \\
\hline C_18:3n6 & 0.02 & 0.03 & 0.03 & 0.03 & 0.002 & 0.003 & 0.898 \\
\hline C_20:2n6 & 0.80 & 1.08 & 0.94 & 0.94 & 0.019 & $<0.001$ & 0.889 \\
\hline C_-20:3n $6^{3}$ & 0.11 & 0.13 & 0.12 & 0.12 & 0.002 & $<0.001$ & 0.262 \\
\hline C_20:3n $3^{3}$ & 0.13 & 0.15 & 0.14 & 0.14 & 0.003 & 0.011 & 0.743 \\
\hline C_ $20: 4 n 6^{3}$ & 0.24 & 0.27 & 0.26 & 0.24 & 0.007 & 0.008 & 0.022 \\
\hline C_22:5n3 $3^{3}$ & 0.05 & 0.05 & 0.05 & 0.05 & 0.001 & 0.885 & 0.478 \\
\hline Total PUFA ${ }^{3}$ & 15.85 & 21.53 & 18.21 & 19.16 & 0.270 & $<0.001$ & 0.019 \\
\hline Total omega-3 & 1.44 & 1.35 & 1.54 & 1.24 & 0.057 & 0.235 & 0.001 \\
\hline Total omega- $6^{3}$ & 14.07 & 19.89 & 16.56 & 17.40 & 0.290 & $<0.001$ & 0.049 \\
\hline Omega-6:Omega-3 & 10.14 & 15.70 & 11.18 & 14.67 & 0.818 & $<0.001$ & 0.005 \\
\hline Total CLA & 0.34 & 0.29 & 0.11 & 0.52 & 0.036 & 0.381 & $<0.001$ \\
\hline PUFA:SFA ${ }^{3,4}$ & 0.38 & 0.58 & 0.50 & 0.47 & 0.012 & $<0.001$ & 0.065 \\
\hline Iodine value $^{3}$ & 62.83 & 70.46 & 68.51 & 64.79 & 0.510 & $<0.001$ & $<0.001$ \\
\hline
\end{tabular}


Table 3.7. DDGS by dietary CLA treatment subclass for fatty acid profile of belly samples of growing-finishing pigs

\begin{tabular}{|c|c|c|c|c|c|c|c|c|}
\hline \multirow{2}{*}{$\begin{array}{c}\mathrm{DDGS}^{1} \\
\mathrm{CLA}^{2}\end{array}$} & \multicolumn{2}{|c|}{ - } & \multicolumn{2}{|c|}{+} & \multirow[b]{2}{*}{ S.E. } & \multicolumn{3}{|c|}{ P-values } \\
\hline & - & + & - & + & & DDGS & CLA & CLA*DDGS \\
\hline \multicolumn{9}{|l|}{ Fatty Acid, \% } \\
\hline C_14:0 & $1.29^{\mathrm{c}, \mathrm{b}}$ & $1.91^{\mathrm{a}}$ & $1.26^{\mathrm{c}}$ & $1.57^{\mathrm{b}}$ & 0.069 & 0.012 & $<0.001$ & 0.027 \\
\hline C_17:0 & $0.05^{\mathrm{b}}$ & $0.02^{\mathrm{b}}$ & $0.04^{\mathrm{b}}$ & $0.22^{\mathrm{a}}$ & 0.047 & 0.039 & 0.128 & 0.032 \\
\hline C_18:0 & $9.73^{c}$ & $13.62^{\mathrm{a}}$ & $9.37^{\mathrm{c}}$ & $11.67^{\mathrm{b}}$ & 0.330 & 0.001 & $<0.001$ & 0.021 \\
\hline C_18:2n6c & $12.55^{c}$ & $12.98^{\mathrm{c}}$ & $17.49^{\mathrm{b}}$ & $19.84^{\mathrm{a}}$ & 0.459 & $<0.001$ & 0.005 & 0.044 \\
\hline C_18:3n6 & 0.03 & 0.03 & 0.04 & 0.04 & 0.002 & 0.001 & 0.982 & 0.057 \\
\hline Total SFA & $33.02^{\mathrm{b}, \mathrm{c}}$ & $39.32^{\mathrm{a}}$ & $32.21^{c}$ & $34.86^{\mathrm{b}}$ & 0.869 & 0.005 & $<0.001$ & 0.042 \\
\hline Total PUFA & $16.48^{\mathrm{c}}$ & $16.93^{c}$ & $20.87^{\mathrm{b}}$ & $23.76^{a}$ & 0.571 & $<0.001$ & 0.006 & 0.039 \\
\hline Total omega-6 & $14.61^{\mathrm{c}}$ & $14.54^{\mathrm{c}}$ & $18.97^{\mathrm{b}}$ & $21.34^{\mathrm{a}}$ & 0.592 & $<0.001$ & 0.060 & 0.046 \\
\hline PUFA:SFA ${ }^{3}$ & 0.43 & 0.38 & 0.60 & 0.62 & 0.021 & $<0.001$ & 0.428 & 0.066 \\
\hline Iodine value & $65.83^{\mathrm{b}}$ & $61.25^{c}$ & $72.19^{\mathrm{a}}$ & $71.14^{\mathrm{a}}$ & 0.791 & $<0.001$ & 0.001 & 0.032 \\
\hline
\end{tabular}


Table 3.8. Main effects of DDGS and CLA inclusion on fatty acid profile of belly fat samples of growing-finishing pigs

\begin{tabular}{|c|c|c|c|c|c|c|c|}
\hline & \multicolumn{2}{|c|}{$\mathrm{DDGS}^{1}$} & \multicolumn{2}{|c|}{$\mathrm{CLA}^{2}$} & \multirow{2}{*}{ S.E. } & \multicolumn{2}{|c|}{ P-values } \\
\hline & - & + & - & + & & DDGS & CLA \\
\hline C_10:0 & 0.06 & 0.05 & 0.05 & 0.06 & 0.002 & 0.052 & 0.234 \\
\hline C_12:0 & 0.08 & 0.07 & 0.06 & 0.09 & 0.003 & 0.019 & $<0.001$ \\
\hline C_1 $14: 0^{3}$ & 1.60 & 1.42 & 1.28 & 1.74 & 0.049 & 0.012 & $<0.001$ \\
\hline C_15:0 & 0.05 & 0.06 & 0.05 & 0.06 & 0.003 & 0.015 & 0.006 \\
\hline C_16:0 & 22.42 & 21.05 & 21.34 & 22.13 & 0.408 & 0.023 & 0.181 \\
\hline C_1 $17: 0^{3}$ & 0.03 & 0.13 & 0.04 & 0.12 & 0.033 & 0.039 & 0.128 \\
\hline C_18:0 $0^{3}$ & 11.67 & 10.52 & 9.55 & 12.64 & 0.233 & 0.001 & $<0.001$ \\
\hline C_20:0 & 0.22 & 0.20 & 0.20 & 0.21 & 0.007 & 0.085 & 0.632 \\
\hline C_21:0 & 0.00 & 0.01 & 0.01 & 0.01 & 0.007 & 0.450 & 0.621 \\
\hline C_22:0 & 0.03 & 0.03 & 0.03 & 0.03 & 0.001 & 0.447 & 0.536 \\
\hline Total SFA ${ }^{3}$ & 36.17 & 33.54 & 32.62 & 37.09 & 0.615 & 0.005 & $<0.001$ \\
\hline C_14:1 & 0.02 & 0.01 & 0.01 & 0.02 & 0.002 & 0.006 & 0.052 \\
\hline C_16:1 & 2.16 & 1.85 & 2.12 & 1.89 & 0.099 & 0.037 & 0.104 \\
\hline C_17:1 & 0.19 & 0.25 & 0.23 & 0.21 & 0.027 & 0.078 & 0.573 \\
\hline C_18:1n7 & 2.82 & 2.60 & 3.01 & 2.41 & 0.236 & 0.523 & 0.081 \\
\hline C_18:1n9c & 41.25 & 39.12 & 42.85 & 37.52 & 0.364 & 0.001 & $<0.001$ \\
\hline C_18:1n9t & 0.66 & 0.27 & 0.44 & 0.49 & 0.150 & 0.076 & 0.817 \\
\hline C_20:1 & 0.03 & 0.03 & 0.03 & 0.03 & 0.002 & 0.768 & 0.607 \\
\hline C_221n9 & 0.01 & 0.01 & 0.02 & 0.01 & 0.001 & 0.010 & $<0.001$ \\
\hline Total MUFA & 47.13 & 44.15 & 48.71 & 42.57 & 0.403 & $<0.001$ & $<0.001$ \\
\hline C_18:2n6c ${ }^{3}$ & 12.76 & 18.67 & 15.02 & 16.41 & 0.325 & $<0.001$ & 0.005 \\
\hline C_18:2n6t & 0.72 & 0.03 & 0.50 & 0.26 & 0.273 & 0.083 & 0.541 \\
\hline C_18:2c9t11; CLA & 0.30 & 0.31 & 0.06 & 0.55 & 0.011 & 0.917 & $<0.001$ \\
\hline C_18:2t10c12; CLA & 0.01 & 0.02 & 0.01 & 0.03 & 0.009 & 0.207 & 0.105 \\
\hline C_18:2c9c11; CLA & 0.09 & 0.09 & 0.03 & 0.16 & 0.015 & 0.926 & $<0.001$ \\
\hline C_18:2t9t11; CLA & 0.05 & 0.04 & 0.03 & 0.06 & 0.003 & 0.206 & $<0.001$ \\
\hline C_18:3n3 & 1.49 & 1.49 & 1.57 & 1.41 & 0.050 & 0.915 & 0.031 \\
\hline C_1 $18: 3 n 6^{3}$ & 0.03 & 0.04 & 0.03 & 0.03 & 0.001 & 0.001 & 0.982 \\
\hline C_20:2n6 & 0.72 & 1.01 & 0.85 & 0.87 & 0.022 & $<0.001$ & 0.626 \\
\hline C_20:3n6 & 0.10 & 0.13 & 0.11 & 0.11 & 0.003 & $<0.001$ & 0.896 \\
\hline C_20:3n3 & 0.12 & 0.13 & 0.12 & 0.13 & 0.003 & 0.014 & 0.669 \\
\hline C_20:4n6 & 0.25 & 0.29 & 0.27 & 0.26 & 0.007 & 0.004 & 0.171 \\
\hline C $22: 5 n 3$ & 0.05 & 0.05 & 0.05 & 0.05 & 0.002 & 0.022 & 0.632 \\
\hline Total PUFA ${ }^{3}$ & 16.71 & 22.31 & 18.68 & 20.34 & 0.403 & $<0.001$ & 0.006 \\
\hline Total omega-3 & 1.67 & 1.69 & 1.76 & 1.60 & 0.053 & 0.811 & 0.038 \\
\hline Total omega- $6^{3}$ & 14.58 & 20.16 & 16.79 & 17.94 & 0.419 & $<0.001$ & 0.060 \\
\hline Omega-6:Omega-3 & 8.98 & 12.47 & 9.81 & 11.65 & 0.698 & 0.001 & 0.071 \\
\hline Total CLA & 0.45 & 0.46 & 0.12 & 0.80 & 0.019 & 0.704 & $<0.001$ \\
\hline PUFA:SFA ${ }^{3,4}$ & 0.40 & 0.61 & 0.52 & 0.50 & 0.015 & $<0.001$ & 0.428 \\
\hline Iodine value $^{3}$ & 63.54 & 71.66 & 69.01 & 66.19 & 0.559 & $<0.001$ & 0.001 \\
\hline
\end{tabular}

${ }^{1}$ Distillers dried grains with solubles was included at a $30 \%$ level in the diets;

${ }^{2}$ Conjugated linoleic acid was included at a $0.6 \%$ level in the diets;

${ }^{3}$ Distillers dried grains with solubles by conjugated linoleic acid interaction $(\mathrm{P}<0.05)$;

${ }^{4}$ Ratio between poly and saturated fatty acids. 
Table 3.9. Iodine value (IV) correlation analysis between belly and jowl fat depots

\begin{tabular}{|c|c|c|c|}
\hline \multicolumn{2}{|c|}{ Treatment } & \multirow{2}{*}{ Correlation (r) } & \multirow{2}{*}{ P-values } \\
\hline DDGS $^{1}$ & $\mathrm{CLA}^{2}$ & & \\
\hline- & - & 0.72 & 0.019 \\
\hline- & + & 0.78 & 0.008 \\
\hline+ & - & 0.88 & 0.001 \\
\hline+ & + & 0.83 & 0.003 \\
\hline
\end{tabular}

${ }^{1}$ Distillers dried grains with solubles was included at a $30 \%$ level in the diets;

${ }^{2}$ Conjugated linoleic acid was included at a $0.6 \%$ level in the diets. 


\title{
CHAPTER 4
}

\section{EFFECTS OF THE INCLUSION OF CONJUGATED LINOLEIC ACID (CLA) AND RACTOPAMINE (PAYLEAN ${ }^{\circledR}$ ) ON GROWTH PERFORMANCE AND FAT QUALITY CHARACTERISTICS OF GROWING-FINISHING PIGS}

\begin{abstract}
An experiment was performed in order to evaluate interactive effects, if any, of ractopamine (RAC), conjugated linoleic acid (CLA) and corn distillers dried grains with solubles (DDGS) on growth performance, and carcass and fat quality of finishing pigs. This study was defined as a $2 \times 2 \times 2$ factorial design within a completely randomized block design. A total number of 1,102 crossbred (TR4 x C22) barrows and gilts (initial weight $=100.4 \pm 1.6 \mathrm{~kg}$ ) were randomly assigned to one of eight dietary treatments which consisted of two diet sources (corn-soy and corn-soy + 20\% DDGS), two levels of RAC (0 and $6.75 \mathrm{mg} / \mathrm{kg}$ ), and two levels of CLA (0 and 0.6\%). Pens were the experimental unit with six replications per treatment for a total of 48 pens with 23 pigs per pen. Pigs had ad libitum access to water and feed during the 27 days of experimental period. RAC supplementation improved $(\mathrm{P}<0.05)$ ADG and $\mathrm{F}$ : $\mathrm{G}$ over that of the control group. Additionally, carcass weight, carcass yield, loin depth, and lean percentage were increased and backfat depth was decreased $(\mathrm{P}<0.05)$ with the feeding of a RAC program. The feeding of CLA resulted in improved ADG and F:G, increased lean
\end{abstract}


percentage, but reduced carcass yield $(\mathrm{P}<0.05)$. Distillers dried grains with solubles inclusion did not affect growth performance $(\mathrm{P}>0.10)$ but reduced $(\mathrm{P}<0.05)$ carcass yield. An increase $(\mathrm{P}<0.05)$ in the concentration of polyunsaturated fatty acids (PUFA) was observed with inclusion of DDGS, RAC and CLA. Iodine value (IV) increased (P < 0.05) in both belly and jowl samples with feeding of DDGS and RAC, while a decrease was observed when CLA was included in the diets. The main interactions found on fatty acid profiles of belly and jowl samples were between diet source and RAC indicating that dietary RAC interacts differently depending on the fat source utilized. Thus, these results suggested that the feeding of RAC and CLA could improve growth and carcass parameters and that CLA was effective in diminishing some of the negative effects, especially on IV, caused by DDGS feeding.

\section{INTRODUCTION}

The use of distillers dried grain with solubles (DDGS) in swine diets has increased due to the large availability, energy and protein content which turns DDGS into a more cost effective fat source (Stein and Shurson, 2009; Carr et al., 2009). However, DDGS has a high concentration of unsaturated fatty acids, especially linoleic acid (Xu et al., 2010a), and thus, it could cause negative impacts on growth performance and carcass and meat quality (Whitney et al., 2006) when included in swine diets.

Conjugated linoleic acid (CLA) is a group of geometric and positional isomers of linoleic acid (C18:2). Studies have shown that CLA inclusion in swine diets could diminish some of the negative effects caused by fat sources with high concentrations of unsaturated fatty acids. Improvements in belly firmness (Eggert et al., 2001; Thiel- 
Cooper et al., 2001; Weber et al., 2006; Larsen et al., 2009) and IV (Eggert et al., 2001; Averette-Gatlin et al., 2002b; Weber et al., 2006; White et al., 2009) of porcine tissues have been demonstrated with CLA supplementation.

Another feed additive that has been largely used in swine operations is ractopamine hydrochloride (RAC; Paylean ${ }^{\circledR}$, Elanco Animal Health, IN). Ractopamine is a phenethanolamine with similar properties to a beta-adrenergic agonist (Carr et al., 2009) and works by directing nutrients from fat deposition toward protein accretion. Ractopamine inclusion in swine diets has shown improvements in growth performance and carcass quality (Armstrong et al., 2004; Brumm et al., 2004; Carr et al., 2005a; Weber et al., 2006; Apple et al., 2008).

However, little is known about the interactive effects of RAC, CLA and DDGS on growth performance and carcass and fat quality when added to swine grower-finisher diets. Thus, the objective of this study was to evaluate the effects of a feeding system that included CLA, RAC and DDGS on growth performance, carcass characteristics, fat quality and IV of finishing pigs.

\section{MATERIALS AND METHODS}

\section{Animals and Diets}

A total number of 1,102 crossbred (TR4 x C22) barrows and gilts were fed a diet containing corn DDGS at $15 \%$ level until an average of $77 \mathrm{~kg}$ of body weight was reached. At this point, an acclimation phase was initiated where half of the pigs received a corn-soy diet and the other half a diet containing 20\% DDGS (Table 4.1). After pigs had reached a desired weight range of $100.4 \pm 1.6 \mathrm{~kg}$, finishing pigs were blocked by 
initial weight and randomly assigned to one of eight dietary treatments (Table 4.2) which consisted of two diet sources (corn-soy and corn-soy $+20 \%$ corn DDGS), two levels of RAC (0 and $7.4 \mathrm{ppm})$, and two levels of CLA (0 and 0.6\%) resulting in a $2 \times 2 \times 2$ factorial design within a completely randomized block design.

At this point, pigs that were fed diets containing corn-soy during the acclimation phase were assigned to the corn-soy treatments while pigs that consumed the 20\% DDGS diets were assigned to the DDGS-containing diets. Pigs had ad libitum access to water and feed during the 27 days feeding period. This study had a total of 48 pens where half of the pens had only barrows while the other half had only gilts. There were six replicates per treatment and a total of 23 pigs per pen which was considered the experimental unit.

\section{Growth Performance}

Average daily gain (ADG), average daily feed intake (ADFI), feed efficiency (F:G) and body weight were evaluated on a pen basis on days $0,7,14,21$ and 27 of the experimental period.

\section{Harvest and Carcass Quality}

On day 27, pigs were transported to the harvest plant where they were allowed to rest for a minimum of $3 \mathrm{~h}$ prior to harvest. Pigs were humanely harvested in a commercial plant following standard U.S. pork industry practices and USDA/FSIS inspection criteria. After harvest, hot carcass weights (HCW) were recorded and dressing percentage was calculated. Carcasses were chilled for $24 \mathrm{~h}$ and measurements of backfat depth, loin eye depth and lean percentage were obtained following facility protocols. 


\section{Fat sample collection and fatty acid procedure}

At $24 \mathrm{~h}$ postmortem, five pigs per pen were randomly selected and fat samples from jowl and belly were collected from the left side of the carcasses for determination of fatty acid profiles and IV. Jowl samples were collected on the anterior tip of the jowl at the site of head removal while belly fat samples were removed posterior to the sternum and anterior to the teat line. Samples were placed in sealed sample bags, placed in a cooler with ice and transported to the University of Missouri Meat Science Laboratory where they were kept at $-20^{\circ} \mathrm{C}$ until analyzes were performed.

Fatty acid profiles were obtained according to an adaptation of the methodologies utilized by Folch et al. (1957) and Morrison and Smith (1964). Approximately $100 \mathrm{mg}$ of adipose tissue was placed in a glass tube and lipids were extracted with $5 \mathrm{~mL}$ solution of chloroform:methanol ( $\left.\mathrm{CHCL}_{3}: \mathrm{CH}_{3} \mathrm{OH}, 2: 1, \mathrm{v} / \mathrm{v}\right)$. After extraction, sample was filtered through a sintered glass filter funnel fitted with a Whatman $2.4 \mathrm{~cm}$ GF/C filter.

A solution of $0.74 \% \mathrm{KCl}$ was added to the tube at a volume of $8 \mathrm{~mL}$ and after a two hours period, two distinct phases were obtained in the sample. The upper phase was carefully removed and discarded while the lower phase was evaporated to dryness with nitrogen gas in warm water bath. Then, a solution of $0.5 \mathrm{~N} \mathrm{KOH}$ in $\mathrm{MeOH}$ was added to at a volume of $1 \mathrm{~mL}$ and the sample was placed in a water bath at $70{ }^{\circ} \mathrm{C}$ for $10 \mathrm{~min}$. Next, $1 \mathrm{~mL}$ of $14 \%$ boron trifluoride $\left(\mathrm{BF}_{3}\right)$ in $\mathrm{MeOH}$ was added to the sample, flushed with nitrogen, and placed in a water bath at $70{ }^{\circ} \mathrm{C}$ for $30 \mathrm{~min}$. Following this, $2 \mathrm{~mL}$ of HPLC grade hexane and saturated $\mathrm{NaCl}$ were added to the sample and the upper layer was removed and placed in a glass tube with approximately $800 \mathrm{mg}$ of $\mathrm{Na}_{2} \mathrm{SO}_{4}$ in order to remove sample's moisture. At this point, $2 \mathrm{~mL}$ of hexane was added to the tube with 
saturated $\mathrm{NaCl}$ and once more, the upper layer was removed and combined with hexane in the same tube with $\mathrm{Na}_{2} \mathrm{SO}_{4}$.

Samples were homogenized and the liquid portion was transferred to a glass vial which was placed in a water bath at $70{ }^{\circ} \mathrm{C}$ until complete dryness. Then, samples were reconstituted in HPLC grade hexane and fatty acid methyl ester were determined by a Varian 3,800 gas chromatographer (Varian, Pala Alto, CA). The column utilized was a fused silica capillary column (SPTM - 2,560; $100 \mathrm{~m}$ x $0.25 \mathrm{~mm}$ x $0.2 \mu \mathrm{m}$ film thickness; Supelco, Bellefonte, PA) and the temperature of the injector was held constant at $240^{\circ} \mathrm{C}$ while the temperature of the flame-ionization detector was held at $260^{\circ} \mathrm{C}$. The oven was operated at $140^{\circ} \mathrm{C}$ for 5 min (temperature programmed $2.5^{\circ} \mathrm{C} / \mathrm{min}$ to $240^{\circ} \mathrm{C}$ and held for 16 min) and the carrier gas used was helium which was maintained at a constant pressure of 37 psi. Results obtained for each individual fatty acid were expressed as a percentage of the total area under the peaks.

Finally, IV was determined according to the equation described by AOCS (1998): $\mathrm{IV}=(0.95 \times \mathrm{C} 16: 1)+(0.86 \times \mathrm{C} 18: 1 \mathrm{n} 9)+(1.732 \times \mathrm{C} 18: 2 \mathrm{n} 6)+(2.616 \times \mathrm{C} 18: 3 \mathrm{n} 3)+$ $(0.785 \times$ C20:1). The ratio between polyunsaturated (PUFA) and saturated (SFA) fatty acids was calculated following the equation: $[(\mathrm{C} 18: 2 n 6 c)+(\mathrm{C} 18: 3 \mathrm{n} 3)] /[(\mathrm{C} 14: 0)+$ $(\mathrm{C} 16: 0)+(\mathrm{C} 18: 0)]$

\section{Statistical Analysis}

The experiment was defined as a $2 \times 2 \times 2$ factorial arrangement via split-split plot design where diet source was defined as the main plot, RAC as the split plot, and CLA as the split-split plot. Initial body weight served as the blocking factor. Data was analyzed using the PROC MIXED of SAS (SAS Inst., Cary, NC) with pen as the 
experimental unit. Model included the fixed effects of DDGS, RAC and CLA and all possible significant interactions. Moreover, correlation analysis for IV of belly and jowl fat depots was performed by using PROC CORR procedure of SAS. An alpha level of 5\% was considered significant.

\section{RESULTS AND DISCUSSION}

\section{Growth Performance}

According to Table 4.3, DDGS and CLA inclusion did not have an effect (P > 0.10) on the body weight of the pigs throughout the experimental period. On the other hand, RAC inclusion increased body weight of the pigs after day 7. Final weight (day 27) of the pigs increased from 123.69 to $127.79 \mathrm{~kg}(\mathrm{P}<0.05)$ when RAC was included to the diets. No interactions $(\mathrm{P}>0.05)$ between main effects were observed for body weight during the entire experiment.

By considering the first week of the experiment (day 7), Table 4.3 shows that no effects of CLA inclusion were observed on ADG ( $\mathrm{P}>0.23)$ and ADFI $(\mathrm{P}>0.18)$. Inclusion of DDGS decreased $(\mathrm{P}<0.05)$ ADFI from 2.67 to $2.50 \mathrm{~kg}$ and it tended $(\mathrm{P}=$ $0.09)$ to decrease ADG. RAC had no effect $(\mathrm{P}>0.60)$ on ADFI but increase $(\mathrm{P}<0.05)$ ADG from 0.76 to $1.07 \mathrm{~kg}$. Furthermore, diet source by CLA and RAC by CLA interactions were found $(\mathrm{P}<0.05)$ for $\mathrm{F}: \mathrm{G}$ being presented on Tables 4.4 and 4.5 , respectively.

According to Table 4.4, CLA inclusion had contrasting effects on F:G depending on diet source. When added to corn-soy diets, CLA slightly increased F:G from 2.92 to 2.95 while a positive decrease in F:G from 3.04 to 2.79 was observed when CLA was 
included to DDGS-containing diets. Moreover, Table 4.5 shows that CLA also had opposing effects on F:G when included to diets with or without RAC. A slight increase in F:G from 2.41 to 2.45 was noticed when CLA was added to RAC-containing diets while a positive decrease in F:G from 3.54 to 3.29 was observed when CLA was included to diets without RAC.

When the second week (day 14) of the study was considered, no effects $(\mathrm{P}>0.22)$ of CLA inclusion were observed on ADG, ADFI and F:G (Table 4.3). The inclusion of DDGS did not have an effect $(\mathrm{P}>0.51)$ on ADG but tended $(\mathrm{P}=0.07)$ to decrease ADFI. Ractopamine inclusion increased $(\mathrm{P}<0.05)$ ADG from 1.04 to $1.19 \mathrm{~kg}$ and decreased (P $<0.05)$ ADFI from 2.92 to $2.79 \mathrm{~kg}$. Moreover, a diet source by RAC interaction was found for F:G $(\mathrm{P}<0.05)$ being presented on Table 4.6. According to Table 4.6, RAC had similar and positive effects on F:G. When included in corn-soy diets, RAC decreased F:G by $18.5 \%$ while a reduction of $14.8 \%$ was observed when RAC was added to DDGScontaining diets.

By considering the third week (day 21) of study, no effects ( $P$ > 0.88) on ADG, ADFI and F:G were observed when DDGS was included to the diets (Table 4.3). Dietary RAC had positive effects on growth performance decreasing ADFI from 2.72 to $2.57 \mathrm{~kg}$ and F:G from 3.83 to $3.26(\mathrm{P}<0.05)$. The feeding of CLA had no effect $(\mathrm{P}>0.54)$ on F:G but tended $(\mathrm{P}=0.07)$ to increase ADFI. In addition, a RAC by CLA interaction $(\mathrm{P}<$ 0.05) was found for ADG at day 21 being presented on Table 4.5. Table 4.5 indicates that opposing effects were noticed when CLA was added to diets with or without RAC. An increase in ADG from 0.69 to $0.74 \mathrm{~kg}$ was noticed when CLA was included in diets with 
no RAC while a decrease from 0.82 to $0.78 \mathrm{~kg}$ was observed when CLA was added to RAC-containing diets.

Table 4.3 shows that during the last week of experiment (day 27), DDGS inclusion did not affect ADG $(\mathrm{P}>0.27)$ and ADFI $(\mathrm{P}>0.47)$, but tended $(\mathrm{P}=0.06)$ to decrease F:G. Ractopamine had no effect $(\mathrm{P}>0.26)$ on ADG, but decreased $(\mathrm{P}<0.05)$ ADFI from 2.82 to $2.62 \mathrm{~kg}$ and F:G from 3.01 to 2.73 . The inclusion of CLA in the diets had a positive effect $(\mathrm{P}<0.05)$ on $\mathrm{ADG}$, increasing gain from 0.91 to $1.02 \mathrm{~kg}$, and on $F: G$, decreasing the ratio from 3.00 to 2.74. No effects $(P>0.36)$ were observed on ADFI when CLA was added to the diets.

When the overall live phase ( $\mathrm{d} 0$ to 27 ) of the experiment was considered (Table 4.3), no effects on ADG and F:G were observed ( $P>0.24)$ with the feeding of DDGS. Furthermore, the inclusion of RAC had positive effects on the growth performance traits analyzed. Dietary RAC resulted in increased ADG (1.01 vs. 0.86 kg; P < 0.05), reduced ADFI (2.64 vs. 2.75 kg; $\mathrm{P}<0.05)$, and improved F:G (2.62 vs. 3.20; $\mathrm{P}<0.05)$ when compared to diets with no RAC. The feeding of CLA resulted in increased ADG (0.95 vs. 0.92 kg; $\mathrm{P}<0.05)$ and improved F:G (2.88 vs. 2.94; $\mathrm{P}<0.05)$.

Finally, Table 4.3 shows that a diet source by CLA interaction was observed for ADFI $(\mathrm{P}<0.05)$ when the entire experiment was considered. According to Table 4.4, CLA slightly reduced ADFI from 2.74 to $2.73 \mathrm{~kg}$ when included in corn-soy diets. However, when included in DDGS-containing diets, CLA increased ADFI from 2.63 to $2.70 \mathrm{~kg}$.

Regarding the feeding of DDGS, our findings on growth performance traits were in agreement with Widmer et al. (2008) who observed that the inclusion of DDGS at 10 
and 20\% levels did not affect ADG, ADFI and G:F during the entire experimental period when fed to growing-finishing pigs. Distillers dried grains with solubles inclusion to grower-finisher diets was also studied by White et al. (2009) and no effects on final body weight, ADG and feed efficiency were observed when DDGS was included at a level up to $40 \%$. Additionally, Augspurger et al. (2008) indicated that ADG, ADFI and G:F were not affected by inclusion of DDGS at levels up to $20 \%$ in amino acids fortified diets during the growing-finishing phase. Furthermore, Cook et al. (2005) showed no negative impacts on ADG, ADFI and G:F when DDGS was added to grower-finisher diets at levels up to $30 \%$.

Results obtained in this study with the feeding of RAC were in agreement with Carr et al. (2005b) who showed that late-finishing pigs fed RAC at a level of $10 \mathrm{mg} / \mathrm{kg}$ had numerically higher ADG, lower feed intake, and improved G:F when compared with pigs that did not receive RAC. Other studies have also demonstrated the ability of RAC improving swine growth performance traits with positive effects on ADG (Uttaro et al., 1993; Stoller et al., 2003; Armstrong et al., 2004; Carr et al., 2005a; Weber et al., 2006; Apple et al., 2008), ADFI (Brumm et al., 2004), feed efficiency (Adeola et al., 1990; Uttaro et al., 1993; Armstrong et al., 2004; Brumm et al., 2004; Carr et al., 2005a; Weber et al., 2006; Apple et al., 2008) and final body weight (Armstrong et al., 2004; Weber et al., 2006). However, some studies have shown that RAC did not affect ADFI (Armstrong et al., 2004; See et al., 2004; Carr et al., 2005a; Apple et al., 2008).

The positive effects of CLA supplementation on growth performance traits observed in this study were in accordance to Thiel-Cooper et al. (2001) who found a linear increase in ADG and feed efficiency with increasing levels of CLA in swine diets 
while no effects on ADFI were observed. Furthermore, positive effects on feed efficiency was observed by Cook et al. (1998) who reported a decrease in feed intake and no changes on growth rate when $0.6 \%$ of CLA was fed to finishing pigs. In addition, White et al. (2009) and Ramsay et al. (2001) reported no differences in final body weight which was also observed in the current study.

\section{Carcass Quality}

Table 4.7 shows that DDGS inclusion did not have an effect $(P>0.20)$ on backfat depth, loin depth and lean percentage. However, DDGS decreased $(\mathrm{P}<0.05)$ dressing percentage from 74.46 to $73.96 \%$ and tended $(\mathrm{P}=0.07)$ to decrease HCW from 93.79 to $92.85 \mathrm{~kg}$. These findings were in agreement with Cook et al. (2005) and Whitney et al. (2006) who found that backfat depth and percentage lean where not affected when DDGS was included in swine diets. No effects on HCW and percentage lean were also observed by Widmer et al. (2008) when growing-finishing pigs were fed diets containing DDGS at 10 or $20 \%$ levels. Furthermore, according to Stein and Shurson (2009), carcass traits such as backfat, loin depth and percentage lean were not affected in most part of the experiments where the inclusion of corn DDGS in grower-finisher diets was studied.

A decrease in carcass yield was also observed by Whitney et al. (2006) and Xu et al. (2010a). These authors reported a linear decrease in dressing percentage when pigs were fed diets containing up to 30\% DDGS. According to Kass et al. (1980), DDGS is considered a fiber-rich ingredient and when fed to pigs, it may increase gut fill and intestinal mass, decreasing dressing percentage.

According to Table 4.7, dietary RAC had positive effects on all of the carcass quality traits analyzed. RAC increased $(\mathrm{P}<0.05) \mathrm{HCW}$ from 91.17 to $95.47 \mathrm{~kg}$, dressing 
percentage from 73.70 to $74.71 \%$, loin depth from 5.92 to $6.25 \mathrm{~cm}$ and lean percentage from 52.24 to 52.96\%. On the other hand, RAC decreased $(\mathrm{P}<0.05)$ backfat depth from 20.52 to $19.53 \mathrm{~mm}$ when compared to diets without RAC inclusion. These results showed the ability of dietary RAC as a repartition agent moving nutrients away from adipose tissue accretion to increased muscle tissue synthesis and deposition (Apple et al., 2008).

Our findings were in accordance to Apple et al. (2008) who observed an increase in HCW, loin depth and lean muscle yield and a decrease in fat depth when RAC was included to swine diets at a level of $10 \mathrm{mg} / \mathrm{kg}$. Furthermore, See et al. (2004) analyzed the effects of RAC on growth performance and carcass quality of finishing pigs and found that HCW, percent yield, loin muscle area and fat-free lean increased while backfat thickness decreased when RAC was fed on a constant feeding program.

Additionally, Armstrong et al. (2004) and Carr et al. (2005a) noticed an increase on dressing percentage, HCW, loin muscle area and fat-free carcass lean in pigs fed RAC-containing diets. However, these authors reported no effects on backfat measurements. Other studies have also reported increases in HCW (Adeola et al., 1990; Weber et al., 2006; Fernández-Dueñas et al., 2008; Carr et al., 2009), dressing percentage (Carr et al., 2005b; Weber et al., 2006), loin eye area (LEA) (Stoller et al., 2003; Carr et al., 2005b; Weber et al., 2006; Carr et al., 2009), loin depth (Adeola et al., 1990; Brumm et al., 2004) and predicted lean yield (Uttaro et al., 1993; Weber et al., 2006), and decreases in leaf fat weight (Adeola et al., 1990; Carr et al., 2005b) and rib backfat measurements (Uttaro et al., 1993; Carr et al., 2005b, 2009) with RAC supplementation in swine diets. 
Finally, no effects $(\mathrm{P}>0.77)$ on HCW were observed when CLA was included to the diets (Table 4.7). However, the feeding of CLA reduced $(\mathrm{P}<0.05)$ dressing percentage from 74.50 to $73.92 \%$, and increased $(\mathrm{P}<0.05)$ lean percentage from 52.45 to 52.75\% and loin depth $(\mathrm{P}=0.05)$ from 6.05 to $6.12 \mathrm{~cm}$ when compared to diets without CLA. Finally, a trend $(\mathrm{P}=0.07)$ was observed toward a decrease in backfat depth $(19.82$ vs. $20.22 \mathrm{~mm}$ ) when CLA was added to the diets.

Similar results were obtained by Dugan et al. (1997) who found a decrease in carcass fat and an increase in the amount of carcass lean when finishing pigs where fed CLA-containing diets. Wiegand et al. (2002) reported a linear increase in LEA and decrease in first, tenth and last rib fat depth when CLA was supplemented to pigs during different lengths of time. In addition, Weber et al. (2006) showed that CLA inclusion increased predicted lean percentage, decreased last rib and tended to decrease $10^{\text {th }}$ rib fat depth when fed to genetically lean pigs. These changes in the amount of carcass fat could be related to the fact that CLA inhibits the activity of the enzyme stearoyl coenzyme A desaturase, decreasing thus, adiposity in pigs (Smith et al., 2002).

\section{Fatty acid profiles}

Table 4.8 indicates that diet source, ractopamine (RAC) and dietary CLA had an effect $(\mathrm{P}<0.05)$ on the concentration of saturated fatty acids (SFA) in belly samples. The inclusion of DDGS in the diets decreased $(\mathrm{P}<0.05)$ the concentration of SFA from 35.25 to $33.46 \%$. This was also observed with the inclusion of RAC in the diets, which decreased $(\mathrm{P}<0.05)$ the amount of SFA from 34.96 to $33.75 \%$. On the other hand, the inclusion of CLA increased $(\mathrm{P}<0.05$ ) the percentage of SFA from 33.38 to $35.34 \%$. 
These changes in the concentration of SFA in the bellies were mainly due to the palmitic (C16:0) and stearic acid (C18:0) concentrations (Table 4.8). Distillers dried grains with solubles inclusion decreased $(\mathrm{P}<0.05)$ the percentage of $\mathrm{C} 16: 0$ from 22.67 to 21.66\% and C18:0 from 10.73 to $10.03 \%$. Ractopamine inclusion also decreased (P < 0.05) the amount of $\mathrm{C} 16: 0$ and $\mathrm{C} 18: 0$ from 22.48 to $21.86 \%$ and 10.63 to $10.13 \%$, respectively. Conversely, CLA increased $(\mathrm{P}<0.05)$ C16:0 and C18:0 concentrations from 21.95 to $22.39 \%$ and 9.71 to $11.04 \%$, respectively.

The concentration of monounsaturated fatty acids (MUFA) in belly samples was only affected by dietary CLA (Table 4.8). A diet source by RAC interaction was found for MUFA being presented in Table 4.10. The addition of CLA to the diets decreased (P $<0.05$ ) the percentage of MUFA from 47.59 to $44.84 \%$. Oleic acid (C18:1n9c) was the individual fatty acid that most contributed to the changes described, which decreased from 41.10 to $38.78 \%$ with CLA inclusion.

The concentration of polyunsaturated fatty acids (PUFA) in belly samples was increased $(\mathrm{P}<0.05)$ from 19.03 to 19.83\% with CLA inclusion (Table 4.8). These changes in the percentage of PUFA were mainly driven by linoleic acid (C18:2n6c), which increased $(\mathrm{P}<0.05)$ from 17.13 to $17.65 \%$ with CLA inclusion. A diet source by RAC interaction was also found for PUFA being presented in Table 4.10. Finally, according to Table 4.8, when IV of belly samples was considered, the inclusion of CLA decreased $(\mathrm{P}<0.05)$ the IV from 69.02 to 67.85 . Once again, a diet source by RAC interaction was found for IV being also presented in Table 4.10.

Table 4.9 shows the interactive effects of dietary RAC and CLA on the fatty acid profile of belly samples. An interaction was found for C18:1n9c where the inclusion of 
CLA to diets without or with RAC decreased $(\mathrm{P}<0.05)$ the amount of C18:1n9c from 41.27 to $38.31 \%$ and from 40.93 to $39.24 \%$, respectively. However, the percent of C18:1n9c from pigs fed CLA without RAC was lower $(\mathrm{P}<0.05)$ than from pigs fed CLA with RAC.

Interactive effects of diet source by RAC on fatty acid profile of belly samples are presented on Table 4.10. The addition of RAC to the diets had contrasting effects in belly samples depending on the diet source. While RAC increased $(\mathrm{P}<0.05)$ the concentration of MUFA from 46.35 to $47.37 \%$ in corn-soy based diets, RAC decreased $(\mathrm{P}<0.05)$ the percentage of MUFA from 45.91 to 45.23\% in DDGS-containing diets. These changes arose from interactions $(\mathrm{P}<0.05)$ between diet source and RAC for C18:1n9c and palmitoleic acid (C16:1). The increase in MUFA in corn-soy diets with RAC was mainly due to an increase $(\mathrm{P}<0.05)$ in the amount of $\mathrm{C} 18: 1 \mathrm{n} 9 \mathrm{c}$ from 39.94 to $40.91 \%$, while the decrease in MUFA in DDGS diets with RAC inclusion was mainly due to a decrease in C16:1 from 2.03 to $1.73 \%$.

Table 4.10 shows that when PUFA was considered, the inclusion of DDGS to the diets without RAC increased $(\mathrm{P}<0.05)$ the concentration of PUFA in belly samples when compared to corn-soy diets without and with RAC, 20.02 vs. 17.79 and $17.99 \%$, respectively. Adding RAC further increased $(\mathrm{P}<0.05)$ the amount of PUFA in belly samples, however only in the DDGS-containing diets, where RAC increased the PUFA amount from 20.02 to $21.93 \%$. These changes in PUFA concentrations arose from the interaction seen between diet source and RAC for C18:2n6c. Mirroring the changes seen in PUFA, DDGS inclusion without RAC increased $(\mathrm{P}<0.05)$ the percentage of C18:2n6c when compared to corn-soy diets without and with RAC, 17.98 vs. 15.85 and $15.98 \%$ 
respectively. Moreover, the addition of RAC to the DDGS diets increased $(\mathrm{P}<0.05)$ the concentration of C18:2n6c from 17.98 to $19.75 \%$ when compared to DDGS diets without RAC (Table 4.10).

An interaction $(\mathrm{P}<0.05)$ was also found between diet source and dietary RAC for IV in belly samples (Table 4.10). Pigs fed the corn-soy diet without RAC had the lowest IV of 65.73. Ractopamine inclusion in the corn-soy diets led to an increase $(\mathrm{P}<0.05)$ in IV from 65.73 to 66.87 . Distillers dried grains with solubles inclusion without RAC led to a higher IV $(\mathrm{P}<0.05)$ when compared to the corn-soy diets without and with RAC, 69.24 vs. 65.73 and 66.87, respectively. Finally, the belly fat from pigs fed DDGS with RAC resulted in the highest IV $(\mathrm{P}<0.05)$ of 71.91 .

Table 4.12 shows that the amount of SFA in jowl samples was affected $(\mathrm{P}<0.05)$ by diet source, RAC and CLA inclusion. The addition of DDGS and RAC to the diets decreased the concentration of SFA in jowl samples from 33.43 to $32.18 \%$ and from 33.39 to $32.22 \%$, respectively. In contrast, the inclusion of CLA increased the total percentage of SFA from 32.04 to $33.57 \%$. These results were similar to the results obtained for belly sample and again, C16:0 and C18:0 were the two main individual fatty acids responsible for the changes in the total amount of SFA (Table 4.12). Distillers dried grains with solubles inclusion led to a decrease $(\mathrm{P}<0.05)$ in both $\mathrm{C} 16: 0$ and C18:0 from 21.74 to $20.97 \%$ and from 9.95 to $9.53 \%$, respectively. Ractopamine inclusion also decreased $(\mathrm{P}<0.05)$ the $\mathrm{C} 16: 0$ (21.66 to 21.05\%) and C18:0 (9.99 to 9.48\%) concentrations. Conjugated linoleic acid inclusion had an opposing effect, shown by an increase ( $\mathrm{P}<0.05$ ) in C16:0 from 21.19 to $21.52 \%$ and C18:0 from 9.20 to $10.28 \%$. 
Conjugated linoleic acid supplementation had an effect on the amount of MUFA in jowl samples (Table 4.12) and in addition, a diet source by RAC interaction was found for MUFA being presented in Table 4.15. The inclusion of CLA reduced $(\mathrm{P}<0.05)$ the concentration of MUFA in jowl samples from 48.55 to $46.70 \%$, indicating similar results as those obtained with belly samples. The fatty acid that most contributed to these changes was C18:1n9c, which was decreased $(\mathrm{P}<0.05)$ with CLA inclusion from 41.94 to $40.33 \%$.

By considering the total amount of PUFA in jowl samples (Table 4.12), the inclusion of DDGS and RAC to the diets increased $(\mathrm{P}<0.05)$ PUFA concentration from 18.62 to $20.51 \%$ and from 19.27 to $19.85 \%$, respectively. Unlike what was observed for belly samples, the inclusion of CLA to the diets did not have an effect $(P>0.25)$ in the percentage of PUFA in jowl samples. Linoleic acid was the main fatty acid responsible for the observed changes, being increased $(\mathrm{P}<0.05)$ from 16.58 to $18.39 \%$ with DDGS inclusion and from 17.24 to $17.73 \%$ with RAC inclusion.

Finally, when IV was considered, the inclusion of DDGS and RAC to the diets increased $(\mathrm{P}<0.05)$ the IV from 68.42 to 71.07 and from 69.10 to 70.39 , respectively. Conjugated linoleic acid had an opposite effect when added to the diets decreasing $(\mathrm{P}<$ 0.05) the IV from 70.34 to 69.15 (Table 4.12).

The main interaction found for jowl samples was between diet source and dietary RAC (Table 4.15) for the total amount of MUFA. No differences on MUFA were observed between jowl samples from pigs fed DDGS diets without or with RAC. However, the inclusion of RAC to corn-soy diets increased $(\mathrm{P}<0.05)$ the concentration of MUFA from 47.35 to $48.55 \%$ when compared to the corn-soy diets without RAC. 
These data showed that the main interactions found on the fatty acid profile of belly and jowl samples were between diet source and RAC indicating that dietary RAC interacts differently depending on the fat source utilized which was also observed by Apple et al. (2007). These authors found that RAC had little to no effect on SFA, PUFA:SFA and IV of belly samples when fed along with beef tallow as the fat source. However, when RAC was included in diets containing soybean oil (SBO), RAC exacerbated the effects caused by SBO decreasing the total amount of SFA and increasing PUFA:SFA and IV of belly samples. Additionally, RAC had no effects on MUFA and tended to increase PUFA (especially linoleic and linolenic acids) concentration, regardless of fat source.

Moreover, in another study, Apple et al. (2008) found that RAC supplementation reduced the concentrations of SFA (especially palmitic acid) and MUFA (especially oleic acid), and increased the amount of PUFA (especially linoleic, $\alpha$-linolenic, eicosadienoic, and arachidonic acids), PUFA:SFA and IV in backfat samples of finishing pigs. In addition, Xi et al. (2005) reported that 10 ppm of RAC supplementation increased the concentration of linoleic acid, total PUFA and IV in clearplate fat of finishing pigs. Weber et al. (2006) also demonstrated that RAC inclusion increased the amount of PUFA and IV in inner-layer backfat and tended to increase IV in outer-layer backfat in pigs. On the other hand, some studies have shown that RAC had little to no impact on fatty acid profile and IV of subcutaneous fat (Carr et al., 2005b) and belly fat (Xi et al., 2005; Weber et al., 2006).

Regarding the effects of DDGS on the fatty acid profile of belly and jowl fat samples, the findings of the current study were in accordance to Xu et al. (2010a) who 
reported a linear increase in PUFA and IV, and a linear decrease in SFA (especially palmitic and stearic acids) and MUFA (palmitoleic and oleic acids) concentrations with increasing levels of DDGS in grower-finisher diets. Additionally, Whitney et al. (2006) found a linear increase in PUFA concentration from 66.8 to $72.0 \%$ when levels of DDGS increased from 0 to 30\% in swine diets. White et al. (2009) also reported a decrease in the amounts of SFA, especially palmitic and oleic acids, and an increase in the concentration of unsaturated fatty acids (UFA), especially linoleic acids, in swine adipose tissues when DDGS was added to the diets.

In the current study, the results of fatty acid profiles obtained with the feeding of CLA were in agreement with Weber et al. (2006) who reported a decrease in MUFA and IV, and an increase in SFA and total CLA in belly samples from pigs fed CLAcontaining diet. Furthermore, an increase in the concentration of individual saturated fatty acids (especially myristic and stearic acids) was observed by White et al. (2009) when CLA was supplemented in swine diets. The same authors also demonstrated that CLA decreased the amount of individual monounsaturated fatty acids (especially oleic and vaccenic acids) and IV of belly and backfat samples. Other studies have also shown that dietary CLA increased the concentration of stearic acid and decreased the amount of oleic acid in porcine tissue (Ramsay et al., 2001; Larsen et al., 2009). Additionally, Wiegand et al. (2002) and Cordero et al. (2010) reported that CLA inclusion increased the concentration of SFA and decrease the amount of UFA in swine tissues while Eggert et al. (2001) and Averette-Gatlin et al. (2002b) demonstrated the ability of dietary CLA in decreasing IV of belly fat. 
In order to predict belly firmness, several pork processing plants have utilized a practice where measurements of IV of jowl fat are used to predict IV of belly fat. Thus, in order to determine if a relationship exists between IV of jowl and belly fat samples, a correlation analysis was performed and is presented in Table 4.16. According to Table 4.16, strong correlations $(\mathrm{P}<0.10)$ between IV of belly and jowl fat samples were obtained for all of the dietary treatments indicating that measurements of IV of jowl samples could be used as a predictor of IV of pork belly.

\section{IMPLICATIONS}

These data suggested that the feeding of DDGS at 20\% level to growing-finishing pigs had no impact on growth performance traits and in most of the carcass quality parameters analyzed. However, DDGS inclusion decreased yield and had negative impacts on fat quality increasing the concentration of PUFA and IV on jowl and belly fat samples which was indicative of reduced belly firmness. Conjugated linoleic acid supplementation was able to diminish the negative effects of DDGS by increasing IV and the concentration of SFA in jowl and belly fat samples. Finally, RAC inclusion showed improvements in growth performance and carcass quality, and demonstrated that it may affect fat quality differently depending on the fat source utilized. 
Table 4.1. Percentage composition of pre-study diets (as fed basis)

\begin{tabular}{lcc}
\hline & Corn-soy & DDGS $^{1}$ \\
\hline Ingredients, \% & \\
Corn & 80.90 & 64.63 \\
Soybean meal 48\% & 13.60 & 10.00 \\
DDGS & 0.00 & 20.00 \\
Choice white grease & 3.00 & 3.00 \\
Monocal & 0.65 & 0.25 \\
Limestone & 0.88 & 1.10 \\
Salt & 0.50 & 0.50 \\
L-Lysine & 0.28 & 0.34 \\
L-Threonine & 0.07 & 0.05 \\
Vitamin Premix with phytase & 0.03 & 0.03 \\
Mineral Premix & 0.10 & 0.10 \\
& & \\
Calculated Analysis & & \\
NRC ME (Mcal/kg) & 3.48 & 3.44 \\
Modified ME (Mcal/kg) & 3.37 & 2.72 \\
CP (\%) & 13.48 & 15.83 \\
Total Lysine (\%) & 0.84 & 0.88 \\
TID ${ }^{2}$ Lysine (\%) & 0.75 & 0.75 \\
Total Phosphorus (\%) & 0.46 & 0.46 \\
Available Phosphorus (\%) & 0.19 & 0.24 \\
Calcium (\%) & 0.50 & 0.50 \\
\hline Dislis & &
\end{tabular}

${ }^{1}$ Distillers dried grains with solubles;

${ }^{2}$ True ileal digestible. 
Table 4.2. Percentage composition of treatment diets (as fed basis)

\begin{tabular}{|c|c|c|c|c|c|c|c|c|}
\hline \multirow[b]{2}{*}{$\mathrm{RAC}^{2}$} & \multicolumn{4}{|c|}{ Corn-Soy } & \multicolumn{4}{|c|}{$\mathrm{DDGS}^{1}$} \\
\hline & - & - & + & + & - & - & + & + \\
\hline CLA & - & + & - & + & - & + & - & + \\
\hline \multicolumn{9}{|l|}{ Ingredients, \% } \\
\hline Corn & 82.94 & 82.94 & 73.32 & 73.32 & 67.38 & 67.38 & 55.96 & 55.96 \\
\hline Soybean-meal $48 \%$ & 13.00 & 13.00 & 22.25 & 22.25 & 8.75 & 8.75 & 20.00 & 20.00 \\
\hline DDGS & 0.00 & 0.00 & 0.00 & 0.00 & 20.00 & 20.00 & 20.00 & 20.00 \\
\hline Choice white grease & 2.00 & 1.40 & 2.00 & 1.40 & 2.00 & 1.40 & 2.00 & 1.40 \\
\hline Monocal & 0.50 & 0.50 & 0.65 & 0.65 & 0.00 & 0.00 & 0.00 & 0.00 \\
\hline Limestone & 0.85 & 0.85 & 0.80 & 0.80 & 1.10 & 1.10 & 1.13 & 1.13 \\
\hline Salt & 0.40 & 0.40 & 0.40 & 0.40 & 0.40 & 0.40 & 0.40 & 0.40 \\
\hline L-Lysine & 0.17 & 0.17 & 0.25 & 0.25 & 0.25 & 0.25 & 0.26 & 0.26 \\
\hline Alimet & 0.00 & 0.00 & 0.05 & 0.05 & 0.00 & 0.00 & 0.01 & 0.01 \\
\hline L-Threonine & 0.01 & 0.01 & 0.12 & 0.12 & 0.00 & 0.00 & 0.07 & 0.07 \\
\hline Paylean & 0.00 & 0.00 & 0.04 & 0.04 & 0.00 & 0.00 & 0.04 & 0.04 \\
\hline CLA & 0.00 & 0.60 & 0.00 & 0.60 & 0.00 & 0.60 & 0.00 & 0.60 \\
\hline Vitamin Premix with phytase & 0.03 & 0.03 & 0.03 & 0.03 & 0.03 & 0.03 & 0.03 & 0.03 \\
\hline Mineral Premix & 0.10 & 0.10 & 0.10 & 0.10 & 0.10 & 0.10 & 0.10 & 0.10 \\
\hline \multicolumn{9}{|l|}{ Calculated Analysis } \\
\hline NRC ME (Mcal/kg) & 3.44 & 3.39 & 3.43 & 3.38 & 3.41 & 3.36 & 3.40 & 3.35 \\
\hline Modified ME (Mcal/kg) & 3.33 & 3.28 & 3.30 & 3.25 & 4.89 & 2.64 & 2.65 & 2.60 \\
\hline CP (\%) & 13.22 & 13.31 & 16.98 & 17.07 & 15.34 & 15.43 & 19.79 & 19.88 \\
\hline Total Lysine (\%) & 0.74 & 0.74 & 1.06 & 1.06 & 0.78 & 0.78 & 1.10 & 1.11 \\
\hline TID $^{3}$ Lysine (\%) & 0.65 & 0.66 & 0.95 & 0.95 & 0.65 & 0.66 & 0.95 & 0.95 \\
\hline Total Phosphorus (\%) & 0.43 & 0.43 & 0.50 & 0.50 & 0.41 & 0.41 & 0.45 & 0.46 \\
\hline Available Phosphorus (\%) & 0.16 & 0.16 & 0.20 & 0.20 & 0.18 & 0.19 & 0.20 & 0.20 \\
\hline Calcium (\%) & 0.46 & 0.46 & 0.50 & 0.49 & 0.46 & 0.46 & 0.50 & 0.50 \\
\hline
\end{tabular}

${ }^{1}$ Distillers dried grains with solubles;

${ }^{2}$ Ractopamine hydrochloride;

${ }^{3}$ True ileal digestible. 
Table 4.3. Effects of diet source, ractopamine, and dietary CLA on weekly and overall performance traits of growing-finishing pigs

\begin{tabular}{|c|c|c|c|c|c|c|c|c|c|c|}
\hline \multirow[b]{2}{*}{ Variables } & \multicolumn{2}{|c|}{ Diet Source } & \multicolumn{2}{|c|}{$\mathrm{RAC}^{2}$} & \multicolumn{2}{|c|}{$\mathrm{CLA}^{3}$} & \multirow{2}{*}{$\begin{array}{c}\text { Pooled } \\
\text { SEM }\end{array}$} & \multicolumn{3}{|c|}{ P-values } \\
\hline & Corn-Soy & $\mathrm{DDGS}^{1}$ & - & + & - & + & & Source & RAC & CLA \\
\hline \multicolumn{11}{|l|}{$B W, \mathrm{~kg}$} \\
\hline day 0 & 100.45 & 100.29 & 100.34 & 100.40 & 100.35 & 100.39 & 1.56 & 0.641 & 0.898 & 0.927 \\
\hline day 7 & 107.08 & 106.53 & 105.69 & 107.92 & 106.67 & 106.94 & 1.51 & 0.187 & $<0.001$ & 0.549 \\
\hline day 14 & 114.97 & 114.29 & 112.99 & 116.27 & 114.52 & 114.75 & 1.50 & 0.190 & $<0.001$ & 0.684 \\
\hline day 21 & 120.25 & 119.63 & 118.02 & 121.85 & 119.85 & 120.03 & 1.51 & 0.228 & $<0.001$ & 0.764 \\
\hline day 27 & 125.95 & 125.53 & 123.69 & 127.79 & 125.34 & 126.13 & 1.42 & 0.383 & $<0.001$ & 0.108 \\
\hline \multicolumn{11}{|l|}{ day 7} \\
\hline ADG, kg & 0.95 & 0.89 & 0.76 & 1.07 & 0.90 & 0.93 & 0.02 & 0.093 & $<0.001$ & 0.234 \\
\hline ADFI, kg & 2.67 & 2.50 & 2.57 & 2.59 & 2.56 & 2.61 & 0.07 & 0.006 & 0.620 & 0.183 \\
\hline$F: G^{4,5,6}$ & 2.93 & 2.91 & 3.42 & 2.43 & 2.98 & 2.87 & 0.12 & 0.845 & $<0.001$ & 0.036 \\
\hline \multicolumn{11}{|l|}{ day 14} \\
\hline ADG, kg & 1.12 & 1.11 & 1.04 & 1.19 & 1.12 & 1.11 & 0.02 & 0.511 & $<0.001$ & 0.524 \\
\hline ADFI, kg & 2.89 & 2.82 & 2.92 & 2.79 & 2.86 & 2.85 & 0.09 & 0.074 & 0.017 & 0.784 \\
\hline $\mathrm{F}: \mathrm{G}^{7}$ & 2.60 & 2.56 & 2.82 & 2.35 & 2.57 & 2.60 & 0.04 & 0.488 & $<0.001$ & 0.229 \\
\hline \multicolumn{11}{|l|}{ day 21} \\
\hline $\mathrm{ADG}^{6}, \mathrm{~kg}$ & 0.75 & 0.76 & 0.72 & 0.80 & 0.76 & 0.75 & 0.02 & 0.917 & 0.007 & 0.859 \\
\hline ADFI, kg & 2.64 & 2.65 & 2.72 & 2.57 & 2.62 & 2.68 & 0.05 & 0.991 & 0.002 & 0.072 \\
\hline $\mathrm{F}: \mathrm{G}$ & 3.55 & 3.54 & 3.83 & 3.26 & 3.52 & 3.58 & 0.10 & 0.889 & $<0.001$ & 0.544 \\
\hline \multicolumn{11}{|l|}{ day 27} \\
\hline ADG, kg & 0.94 & 0.98 & 0.94 & 0.98 & 0.91 & 1.02 & 0.04 & 0.271 & 0.268 & 0.004 \\
\hline ADFI, kg & 2.74 & 2.69 & 2.82 & 2.62 & 2.70 & 2.73 & 0.06 & 0.479 & 0.005 & 0.361 \\
\hline $\mathrm{F}: \mathrm{G}$ & 2.94 & 2.80 & 3.01 & 2.73 & 3.00 & 2.74 & 0.09 & 0.063 & $<0.001$ & 0.003 \\
\hline \multicolumn{11}{|l|}{ day $0-27$} \\
\hline ADG, kg & 0.94 & 0.93 & 0.86 & 1.01 & 0.92 & 0.95 & 0.01 & 0.479 & $<0.001$ & 0.005 \\
\hline $\mathrm{ADFI}^{5}, \mathrm{~kg}$ & 2.74 & 2.66 & 2.75 & 2.64 & 2.69 & 2.72 & 0.06 & 0.167 & 0.009 & 0.105 \\
\hline $\mathrm{F}: \mathrm{G}$ & 2.93 & 2.89 & 3.20 & 2.62 & 2.94 & 2.88 & 0.06 & 0.247 & $<0.001$ & 0.029 \\
\hline
\end{tabular}

${ }^{2}$ Ractopamine hydrochloride was included at $6.75 \mathrm{~g} / \mathrm{ton}$ level in the diets;

${ }^{3}$ Conjugated linoleic acid was included at $0.6 \%$ level in the diets;

${ }^{4}$ Feed to gain ratio;

${ }^{5}$ Diet source $\times$ dietary CLA interaction $(\mathrm{P}<0.05)$;

${ }^{6}$ Ractopamine $\times$ dietary CLA interaction $(\mathrm{P}<0.05)$

${ }^{7}$ Diet source $\times$ ractopamine interaction $(\mathrm{P}<0.05)$. 
Table 4.4. Diet source by dietary CLA treatment subclass means for performance traits of growingfinishing pigs

\begin{tabular}{|c|c|c|c|c|c|c|c|c|}
\hline \multirow[b]{2}{*}{ Variables } & \multicolumn{2}{|c|}{ Corn-Soy } & \multicolumn{2}{|c|}{$20 \%$ DDGS $^{2}$} & \multirow{2}{*}{$\begin{array}{c}\text { Pooled } \\
\text { SEM }\end{array}$} & \multicolumn{3}{|c|}{ P-values } \\
\hline & CLA - & $\mathrm{CLA}^{1+}$ & CLA - & CLA + & & Source & CLA & Source $\times$ CLA \\
\hline $\mathrm{F}: \mathrm{G}^{3}-$ day 7 & 2.92 & 2.95 & 3.04 & 2.79 & 0.126 & 0.845 & 0.036 & 0.009 \\
\hline Overall ADFI, kg & 2.74 & 2.73 & 2.63 & 2.70 & 0.050 & 0.166 & 0.105 & 0.038 \\
\hline
\end{tabular}

${ }^{1}$ CLA was included at $0.6 \%$ level in the diets;

${ }^{2}$ Distillers dried grains with solubles;

${ }^{3}$ Feed to gain ratio. 
Table 4.5. RAC by dietary CLA treatment subclass means for performance traits of growing-finishing pigs

\begin{tabular}{|c|c|c|c|c|c|c|c|c|}
\hline \multirow[b]{2}{*}{ Variables } & \multicolumn{2}{|c|}{ RAC - } & \multicolumn{2}{|c|}{$\mathrm{RAC}^{1}+$} & \multirow{2}{*}{$\begin{array}{c}\text { Pooled } \\
\text { SEM }\end{array}$} & \multicolumn{3}{|c|}{ P-values } \\
\hline & CLA - & $\mathrm{CLA}^{2}+$ & CLA - & CLA + & & RAC & CLA & $\mathrm{RAC} \times \mathrm{CLA}$ \\
\hline $\mathrm{F}: \mathrm{G}^{3}-$ day 7 & 3.54 & 3.29 & 2.41 & 2.45 & 0.128 & $<0.001$ & 0.036 & 0.006 \\
\hline ADG, kg - day 21 & 0.69 & 0.74 & 0.82 & 0.78 & 0.021 & 0.007 & 0.859 & 0.015 \\
\hline
\end{tabular}

${ }^{1}$ Ractopamine hydrochloride was included at $6.75 \mathrm{~g} /$ ton level in the diets;

${ }^{2}$ CLA was included at $0.6 \%$ level in the diets;

${ }^{3}$ Feed to gain ratio. 
Table 4.6. Diet source by RAC treatment subclass means for performance traits of growing-finishing pigs

\begin{tabular}{|c|c|c|c|c|c|c|c|c|}
\hline \multirow[b]{2}{*}{ Variables } & \multicolumn{2}{|c|}{ Corn-Soy } & \multicolumn{2}{|c|}{$20 \%$ DDGS $^{2}$} & \multirow{2}{*}{$\begin{array}{l}\text { Pooled } \\
\text { SEM }\end{array}$} & \multicolumn{3}{|c|}{ P-values } \\
\hline & RAC - & $\mathrm{RAC}^{1}+$ & RAC - & RAC + & & Source & RAC & Source $\times$ RAC \\
\hline $\mathrm{F}: \mathrm{G}^{3}$ - day 14 & 2.87 & 2.34 & 2.77 & 2.36 & 0.048 & 0.488 & $<0.001$ & 0.038 \\
\hline
\end{tabular}

${ }^{1}$ Ractopamine hydrochloride was included at $6.75 \mathrm{~g} /$ ton level in the diets;

${ }^{2}$ Distillers dried grains with solubles;

${ }^{3}$ Feed to gain ratio. 
Table 4.7. Effects of diet source, ractopamine, and dietary CLA on carcass traits of growing-finishing pigs

\begin{tabular}{|c|c|c|c|c|c|c|c|c|c|c|}
\hline \multirow[b]{2}{*}{ Variables } & \multicolumn{2}{|c|}{ Diet Source } & \multicolumn{2}{|c|}{$\mathrm{RAC}^{2}$} & \multicolumn{2}{|c|}{$\mathrm{CLA}^{3}$} & \multirow{2}{*}{$\begin{array}{l}\text { Pooled } \\
\text { SEM }\end{array}$} & \multicolumn{3}{|c|}{ P-values } \\
\hline & Corn-Soy & DDGS $^{1}$ & - & + & - & + & & Source & RAC & CLA \\
\hline HCW, kg & 93.79 & 92.85 & 91.17 & 95.47 & 93.39 & 93.25 & 1.131 & 0.076 & $<0.001$ & 0.771 \\
\hline Dressing Percentage & 74.46 & 73.96 & 73.70 & 74.71 & 74.50 & 73.92 & 0.131 & 0.029 & $<0.001$ & 0.015 \\
\hline Backfat depth, mm & 20.20 & 19.84 & 20.52 & 19.53 & 20.22 & 19.82 & 0.802 & 0.205 & 0.011 & 0.072 \\
\hline Loin depth, cm & 6.10 & 6.10 & 5.92 & 6.25 & 6.05 & 6.12 & 0.046 & 0.936 & $<0.001$ & 0.057 \\
\hline Lean, \% & 52.52 & 52.68 & 52.24 & 52.96 & 52.45 & 52.75 & 0.344 & 0.367 & $<0.001$ & 0.005 \\
\hline
\end{tabular}

${ }^{1}$ Distillers dried grains with solubles was included at $20 \%$ level in the diets;

${ }^{2}$ Ractopamine hydrochloride was included at $6.75 \mathrm{~g} / \mathrm{ton}$ level in the diets;

${ }^{3}$ CLA was included at $0.6 \%$ level in the diets. 
Table 4.8. Main effects of diet source, ractopamine, and dietary CLA on fatty acid profile of belly samples of growing-finishing pigs

\begin{tabular}{|c|c|c|c|c|c|c|c|c|c|c|}
\hline \multirow[b]{2}{*}{ Variables } & \multicolumn{2}{|c|}{ Diet Source } & \multicolumn{2}{|c|}{ Ractopamine } & \multicolumn{2}{|c|}{ CLA } & \multirow{2}{*}{$\begin{array}{c}\text { Pooled } \\
\text { SEM }\end{array}$} & \multicolumn{3}{|c|}{ P-values } \\
\hline & Corn-Soy & $20 \%$ DDGS $^{5}$ & $0 \mathrm{~g} / \mathrm{ton}$ & $6.75 \mathrm{~g} / \mathrm{ton}$ & $0 \%$ & $0.6 \%$ & & Diet Source & RAC & CLA \\
\hline C_14:0 $0^{1}$ & 1.32 & 1.26 & 1.34 & 1.24 & 1.22 & 1.36 & 0.021 & 0.079 & 0.002 & $<0.001$ \\
\hline C_16:0 & 22.67 & 21.66 & 22.48 & 21.86 & 21.95 & 22.39 & 0.182 & 0.001 & 0.001 & 0.007 \\
\hline C_16:1 $1^{2}$ & 2.06 & 1.88 & 2.06 & 1.88 & 2.03 & 1.91 & 0.038 & 0.020 & 0.004 & 0.082 \\
\hline C_ $17: 0^{2}$ & 0.35 & 0.35 & 0.34 & 0.36 & 0.33 & 0.36 & 0.009 & 0.644 & 0.109 & 0.001 \\
\hline C_17:1 & 0.27 & 0.26 & 0.26 & 0.27 & 0.27 & 0.25 & 0.006 & 0.651 & 0.156 & 0.002 \\
\hline C_18:0 & 10.73 & 10.03 & 10.63 & 10.13 & 9.71 & 11.04 & 0.108 & 0.001 & 0.004 & $<0.001$ \\
\hline C_18:1n9t ${ }^{2}$ & 0.10 & 0.10 & 0.10 & 0.10 & 0.10 & 0.11 & 0.007 & 0.877 & 0.791 & 0.506 \\
\hline C_18:1n9c $c^{1,2}$ & 40.42 & 39.45 & 39.79 & 40.08 & 41.10 & 38.78 & 0.136 & 0.016 & 0.074 & $<0.001$ \\
\hline C_18:1n7 & 3.29 & 3.15 & 3.24 & 3.20 & 3.34 & 3.10 & 0.036 & 0.051 & 0.583 & 0.001 \\
\hline C_18:2n6t & 0.22 & 0.18 & 0.19 & 0.21 & 0.20 & 0.21 & 0.018 & 0.287 & 0.370 & 0.824 \\
\hline C_18:2n6 $\mathrm{c}^{2}$ & 15.92 & 18.87 & 16.92 & 17.87 & 17.13 & 17.65 & 0.341 & 0.000 & 0.002 & 0.037 \\
\hline C_20:0 & 0.19 & 0.17 & 0.19 & 0.18 & 0.18 & 0.19 & 0.006 & 0.052 & 0.077 & 0.280 \\
\hline C_18:3n6 & 0.07 & 0.03 & 0.06 & 0.04 & 0.06 & 0.04 & 0.013 & 0.039 & 0.390 & 0.374 \\
\hline C_20: $1^{3}$ & 0.66 & 0.63 & 0.62 & 0.67 & 0.66 & 0.63 & 0.020 & 0.550 & 0.035 & 0.200 \\
\hline C_18:3n3 & 0.57 & 0.64 & 0.58 & 0.63 & 0.59 & 0.62 & 0.019 & 0.056 & 0.024 & 0.141 \\
\hline C_18:9c11t & 0.13 & 0.14 & 0.14 & 0.13 & 0.02 & 0.25 & 0.007 & 0.582 & 0.562 & $<0.001$ \\
\hline C_18:10t12c & 0.02 & 0.03 & 0.03 & 0.02 & 0.00 & 0.06 & 0.004 & 0.141 & 0.022 & $<0.001$ \\
\hline C_20:2n6 $6^{2}$ & 0.65 & 0.75 & 0.68 & 0.72 & 0.71 & 0.70 & 0.008 & $<0.001$ & 0.001 & 0.323 \\
\hline C_20:3n6 & 0.06 & 0.07 & 0.06 & 0.07 & 0.07 & 0.06 & 0.004 & 0.051 & 0.080 & 0.151 \\
\hline C_22:1n9 & 0.02 & 0.03 & 0.02 & 0.04 & 0.03 & 0.03 & 0.006 & 0.120 & 0.001 & 0.600 \\
\hline C_20:4n6 & 0.24 & 0.26 & 0.25 & 0.26 & 0.26 & 0.24 & 0.006 & 0.030 & 0.146 & 0.022 \\
\hline C_24:1 & 0.04 & 0.07 & 0.05 & 0.05 & 0.06 & 0.04 & 0.005 & 0.003 & 0.152 & 0.005 \\
\hline SFA & 35.25 & 33.46 & 34.96 & 33.75 & 33.38 & 35.34 & 0.273 & $<0.001$ & $<0.001$ & $<0.001$ \\
\hline MUFA $^{2}$ & 46.86 & 45.57 & 46.13 & 46.30 & 47.59 & 44.84 & 0.165 & 0.009 & 0.417 & $<0.001$ \\
\hline PUFA $^{2}$ & 17.89 & 20.97 & 18.91 & 19.96 & 19.03 & 19.83 & 0.362 & 0.001 & 0.002 & 0.004 \\
\hline PUFA:SFA ${ }^{2,4}$ & 0.48 & 0.60 & 0.51 & 0.56 & 0.54 & 0.53 & 0.015 & 0.001 & 0.001 & 0.177 \\
\hline Total omega- $6^{2}$ & 17.16 & 20.16 & 18.15 & 19.17 & 18.42 & 18.90 & 0.352 & 0.001 & 0.002 & 0.064 \\
\hline Total omega-3 & 0.57 & 0.64 & 0.58 & 0.63 & 0.59 & 0.62 & 0.019 & 0.056 & 0.024 & 0.141 \\
\hline Omega-6:Omega-3 & 30.68 & 31.54 & 31.47 & 30.75 & 31.72 & 30.50 & 0.841 & 0.617 & 0.454 & 0.314 \\
\hline Iodine value $^{2}$ & 66.30 & 70.57 & 67.48 & 69.39 & 69.02 & 67.85 & 0.529 & $<0.001$ & 0.001 & 0.002 \\
\hline
\end{tabular}

${ }^{1}$ Diet ractopamine $\times$ dietary CLA interaction $(\mathrm{P}<0.05)$;

${ }^{2}$ Diet source $\times$ dietary ractopamine interaction $(\mathrm{P}<0.05)$;

${ }^{3}$ Diet source $\times$ dietary CLA interaction $(\mathrm{P}<0.05)$;

${ }^{4}$ Ratio between poly and saturated fatty acids;

${ }^{5}$ Distillers dried grains with solubles. 
Table 4.9. Diet RAC by dietary CLA treatment subclass means for fatty acid profile of belly samples of growingfinishing pigs

\begin{tabular}{|c|c|c|c|c|c|c|c|c|}
\hline \multirow{2}{*}{ Variables } & \multicolumn{2}{|c|}{ RAC - } & \multicolumn{2}{|c|}{$\mathrm{RAC}^{1}+$} & \multirow{2}{*}{$\begin{array}{c}\text { Pooled } \\
\text { SEM }\end{array}$} & \multicolumn{3}{|c|}{ P-values } \\
\hline & CLA - & $\mathrm{CLA}^{2}+$ & CLA - & CLA + & & RAC & CLA & $\mathrm{RAC} \times \mathrm{CLA}$ \\
\hline C_14:0 & $1.23^{\mathrm{b}, \mathrm{c}}$ & $1.44^{\mathrm{a}}$ & $1.20^{\mathrm{c}}$ & $1.28^{b}$ & 0.025 & 0.002 & $<0.001$ & 0.007 \\
\hline C_18:1n9c & $41.27^{\mathrm{a}}$ & $38.31^{c}$ & $40.93^{a}$ & $39.24^{b}$ & 0.166 & 0.074 & $<0.001$ & 0.001 \\
\hline
\end{tabular}

${ }^{1}$ Ractopamine hydrochloride was included at $6.75 \mathrm{~g} /$ ton level in the diets;

${ }^{2}$ CLA was included at $0.6 \%$ level in the diets;

a,b,c within a row, means lacking a common superscript differ from each other $(\mathrm{P}<0.05)$. 
Table 4.10. Diet source by dietary RAC treatment subclass means for fatty acid profile of belly samples of growingfinishing pigs

\begin{tabular}{|c|c|c|c|c|c|c|c|c|}
\hline \multirow{2}{*}{ Variables } & \multicolumn{2}{|c|}{ Corn-Soy } & \multicolumn{2}{|c|}{$20 \%$ DDGS $^{2}$} & \multirow{2}{*}{$\begin{array}{c}\text { Pooled } \\
\text { SEM }\end{array}$} & \multicolumn{3}{|c|}{ P-values } \\
\hline & RAC - & $\mathrm{RAC}^{1}+$ & RAC - & $\mathrm{RAC}+$ & & Diet Source & RAC & Diet Source $\times$ RAC \\
\hline C_16:1 & $2.09^{a}$ & $2.04^{a}$ & $2.03^{a}$ & $1.73^{b}$ & 0.050 & 0.020 & 0.004 & 0.023 \\
\hline C_17:0 & $0.35^{\mathrm{a}, \mathrm{b}}$ & $0.34^{\mathrm{a}, \mathrm{b}}$ & $0.33^{b}$ & $0.38^{\mathrm{a}}$ & 0.013 & 0.644 & 0.109 & 0.019 \\
\hline C_18:1n9t & $0.12^{a}$ & $0.09^{a}$ & $0.09^{a}$ & $0.11^{a}$ & 0.010 & 0.877 & 0.791 & 0.032 \\
\hline C_18:1n9c & $39.94^{b}$ & $40.91^{\mathrm{a}}$ & $39.64^{b}$ & $39.26^{b}$ & 0.194 & 0.016 & 0.074 & 0.001 \\
\hline C_18:2n6c & $15.85^{c}$ & $15.98^{c}$ & $17.98^{b}$ & $19.75^{\mathrm{a}}$ & 0.388 & 0.001 & 0.002 & 0.005 \\
\hline C_20:2n6 & $0.65^{c}$ & $0.66^{c}$ & $0.71^{\mathrm{b}}$ & $0.78^{\mathrm{a}}$ & 0.010 & $<0.001$ & 0.001 & 0.007 \\
\hline MUFA & $46.35^{b}$ & $47.37^{\mathrm{a}}$ & $45.91^{b}$ & $45.23^{c}$ & 0.237 & 0.009 & 0.417 & 0.002 \\
\hline PUFA & $17.79^{\mathrm{c}}$ & $17.99^{\mathrm{c}}$ & $20.02^{b}$ & $21.93^{\mathrm{a}}$ & 0.415 & 0.001 & 0.002 & 0.008 \\
\hline PUFA:SFA ${ }^{3}$ & $0.47^{\mathrm{c}}$ & $0.49^{\mathrm{c}}$ & $0.56^{\mathrm{b}}$ & $0.64^{\mathrm{a}}$ & 0.017 & 0.001 & 0.001 & 0.020 \\
\hline Iodine value & $65.73^{\mathrm{d}}$ & $66.87^{c}$ & $69.24^{\mathrm{b}}$ & $71.91^{\mathrm{a}}$ & 0.578 & $<0.001$ & 0.001 & 0.036 \\
\hline
\end{tabular}

\footnotetext{
${ }^{1}$ Ractopamine hydrochloride was included at $6.75 \mathrm{~g} /$ ton level in the diets;

${ }^{2}$ Distillers dried grains with solubles;

${ }^{3}$ Ratio between poly and saturated fatty acids;

a,b,c,d within a row, means lacking a common superscript differ from each other $(\mathrm{P}<0.05)$.
} 
Table 4.11. Diet source by dietary CLA treatment subclass means for fatty acid profile of belly samples of growingfinishing pigs

\begin{tabular}{|c|c|c|c|c|c|c|c|c|}
\hline \multirow{2}{*}{ Variables } & \multicolumn{2}{|c|}{ Corn-Soy } & \multicolumn{2}{|c|}{$20 \% \mathrm{DDGS}^{2}$} & \multirow{2}{*}{$\begin{array}{l}\text { Pooled } \\
\text { SEM }\end{array}$} & \multicolumn{3}{|c|}{ P-values } \\
\hline & CLA - & $\mathrm{CLA}^{1}+$ & CLA - & $\mathrm{CLA}+$ & & Diet Source & CLA & Diet Source $\times$ CLA \\
\hline C_20:1 & $0.641^{\mathrm{a}, \mathrm{b}}$ & $0.672^{\mathrm{a}, \mathrm{b}}$ & $0.673^{\mathrm{a}}$ & $0.581^{b}$ & 0.031 & 0.550 & 0.200 & 0.015 \\
\hline
\end{tabular}

${ }^{1}$ CLA was included at $0.6 \%$ level in the diets;

${ }^{2}$ Distillers dried grains with solubles;

${ }^{\mathrm{a}, \mathrm{b}}$ within a row, means lacking a common superscript differ from each other $(\mathrm{P}<0.05)$. 
Table 4.12. Main effects of diet source, ractopamine, and dietary CLA on fatty acid profile of jowl samples of growingfinishing pigs

\begin{tabular}{|c|c|c|c|c|c|c|c|c|c|c|}
\hline \multirow[b]{2}{*}{ Variables } & \multicolumn{2}{|c|}{ Diet Source } & \multicolumn{2}{|c|}{ Ractopamine } & \multicolumn{2}{|c|}{ CLA } & \multirow{2}{*}{$\begin{array}{c}\text { Pooled } \\
\text { SEM }\end{array}$} & \multicolumn{3}{|c|}{ P-values } \\
\hline & Corn-Soy & $20 \%$ DDGS $^{5}$ & 0g/ton & $6.75 \mathrm{~g} / \mathrm{ton}$ & $0 \%$ & $0.6 \%$ & & Diet Source & RAC & CLA \\
\hline C_14:0 $0^{1,2}$ & 1.21 & 1.15 & 1.22 & 1.14 & 1.14 & 1.23 & 0.015 & 0.058 & 0.001 & $<0.001$ \\
\hline C_16:0 & 21.74 & 20.97 & 21.66 & 21.05 & 21.19 & 21.52 & 0.183 & 0.006 & 0.001 & 0.028 \\
\hline C_16:1 & 2.05 & 1.93 & 2.01 & 1.97 & 2.03 & 1.96 & 0.027 & 0.001 & 0.250 & 0.162 \\
\hline C_17:0 & 0.36 & 0.34 & 0.35 & 0.35 & 0.34 & 0.36 & 0.010 & 0.195 & 0.700 & 0.111 \\
\hline C_17:1 & 0.28 & 0.27 & 0.27 & 0.28 & 0.28 & 0.27 & 0.006 & 0.323 & 0.336 & 0.061 \\
\hline C_18:0 & 9.95 & 9.53 & 9.99 & 9.48 & 9.20 & 10.28 & 0.114 & 0.002 & 0.005 & $<0.001$ \\
\hline C_18:1n9t & 0.10 & 0.10 & 0.10 & 0.10 & 0.09 & 0.11 & 0.009 & 0.599 & 0.788 & 0.198 \\
\hline C_18:1n9c & 41.35 & 40.93 & 40.91 & 41.36 & 41.94 & 40.33 & 0.148 & 0.143 & 0.123 & $<0.001$ \\
\hline C_18:1n7 & 3.32 & 3.19 & 3.18 & 3.32 & 3.33 & 3.18 & 0.049 & 0.101 & 0.036 & 0.050 \\
\hline C_18:2n6t & 0.18 & 0.18 & 0.17 & 0.19 & 0.18 & 0.18 & 0.013 & 0.981 & 0.077 & 0.804 \\
\hline C_18:2n6c & 16.58 & 18.39 & 17.24 & 17.73 & 17.39 & 17.58 & 0.252 & 0.001 & 0.052 & 0.456 \\
\hline C_20:0 & 0.17 & 0.17 & 0.17 & 0.17 & 0.17 & 0.17 & 0.006 & 0.900 & 0.368 & 0.930 \\
\hline C_18:3n6 & 0.05 & 0.06 & 0.05 & 0.05 & 0.04 & 0.06 & 0.013 & 0.287 & 0.810 & 0.144 \\
\hline C_20: $1^{3}$ & 0.75 & 0.77 & 0.74 & 0.78 & 0.76 & 0.75 & 0.019 & 0.633 & 0.154 & 0.623 \\
\hline C_18:3n $3^{3}$ & 0.61 & 0.61 & 0.60 & 0.62 & 0.62 & 0.60 & 0.019 & 0.888 & 0.281 & 0.338 \\
\hline C_18:9c11t & 0.09 & 0.09 & 0.10 & 0.09 & 0.01 & 0.17 & 0.005 & 0.702 & 0.271 & $<0.001$ \\
\hline C_18:10t12c & 0.01 & 0.01 & 0.01 & 0.01 & 0.00 & 0.02 & 0.003 & 0.637 & 0.756 & $<0.001$ \\
\hline C_20:2n6 $6^{2}$ & 0.76 & 0.83 & 0.77 & 0.81 & 0.81 & 0.78 & 0.011 & 0.006 & 0.008 & 0.053 \\
\hline C_20:3n6 & 0.08 & 0.09 & 0.08 & 0.09 & 0.09 & 0.08 & 0.004 & 0.169 & 0.008 & 0.112 \\
\hline C_22:1n9 & 0.05 & 0.05 & 0.05 & 0.05 & 0.05 & 0.05 & 0.008 & 0.125 & 0.311 & 0.974 \\
\hline C_20:3n3 & 0.01 & 0.00 & 0.00 & 0.01 & 0.01 & 0.00 & 0.007 & 0.237 & 0.260 & 0.183 \\
\hline C_20:4n6 & 0.24 & 0.25 & 0.24 & 0.25 & 0.26 & 0.24 & 0.005 & 0.024 & 0.536 & 0.001 \\
\hline C_24:1 $1^{2}$ & 0.06 & 0.08 & 0.07 & 0.07 & 0.07 & 0.07 & 0.004 & 0.069 & 0.623 & 0.143 \\
\hline SFA & 33.43 & 32.18 & 33.39 & 32.22 & 32.04 & 33.57 & 0.291 & 0.003 & 0.001 & $<0.001$ \\
\hline MUFA $^{3}$ & 47.95 & 47.31 & 47.33 & 47.92 & 48.55 & 46.70 & 0.141 & 0.047 & 0.047 & $<0.001$ \\
\hline PUFA & 18.62 & 20.51 & 19.27 & 19.85 & 19.41 & 19.71 & 0.277 & 0.001 & 0.036 & 0.253 \\
\hline PUFA:SFA ${ }^{4}$ & 0.53 & 0.61 & 0.55 & 0.58 & 0.58 & 0.56 & 0.013 & 0.001 & 0.003 & 0.050 \\
\hline Total omega-6 & 17.90 & 19.79 & 18.57 & 19.12 & 18.77 & 18.92 & 0.269 & 0.001 & 0.038 & 0.552 \\
\hline Total omega- $3^{3}$ & 0.62 & 0.61 & 0.60 & 0.63 & 0.63 & 0.60 & 0.021 & 0.863 & 0.156 & 0.272 \\
\hline Omega-6:Omega-3 & 29.75 & 35.11 & 33.93 & 30.93 & 30.97 & 33.89 & 1.733 & 0.064 & 0.208 & 0.200 \\
\hline Iodine Value & 68.42 & 71.07 & 69.10 & 70.39 & 70.34 & 69.15 & 0.477 & 0.001 & 0.001 & 0.001 \\
\hline
\end{tabular}

Diet source $\times$ dietary CLA interaction $(\mathrm{P}<0.05)$;

${ }^{2}$ Diet ractopamine $\times$ dietary CLA interaction $(\mathrm{P}<0.05)$;

${ }^{3}$ Diet source $\times$ dietary ractopamine interaction $(\mathrm{P}<0.05)$;

${ }^{4}$ Ratio between poly and saturated fatty acids;

${ }^{5}$ Distillers dried grains with solubles. 
Table 4.13. Diet source by dietary CLA treatment subclass means for fatty acid profile of jowl samples of growingfinishing pigs

\begin{tabular}{|c|c|c|c|c|c|c|c|c|}
\hline \multirow{2}{*}{ Variables } & \multicolumn{2}{|c|}{ Corn-Soy } & \multicolumn{2}{|c|}{$20 \%$ DDGS $^{2}$} & \multirow{2}{*}{$\begin{array}{c}\text { Pooled } \\
\text { SEM }\end{array}$} & \multicolumn{3}{|c|}{ P-values } \\
\hline & CLA - & $\mathrm{CLA}^{1}+$ & CLA - & $\mathrm{CLA}+$ & & Diet Source & CLA & Diet Source $\times$ CLA \\
\hline C_14:0 & $1.14^{\mathrm{b}, \mathrm{c}}$ & $1.27^{\mathrm{a}}$ & $1.13^{\mathrm{c}}$ & $1.18^{b}$ & 0.019 & 0.058 & $<0.001$ & 0.020 \\
\hline
\end{tabular}

${ }^{1}$ CLA was included at $0.6 \%$ level in the diets;

${ }^{2}$ Distillers dried grains with solubles;

a,b,c within a row, means lacking a common superscript differ from each other $(\mathrm{P}<0.05)$. 
Table 4.14. Diet RAC by dietary CLA treatment subclass means for fatty acid profile of jowl samples of growingfinishing pigs

\begin{tabular}{|c|c|c|c|c|c|c|c|c|}
\hline \multirow{2}{*}{ Variables } & \multicolumn{2}{|c|}{ RAC - } & \multicolumn{2}{|c|}{$\mathrm{RAC}^{1}+$} & \multirow{2}{*}{$\begin{array}{c}\text { Pooled } \\
\text { SEM }\end{array}$} & \multicolumn{3}{|c|}{ P-values } \\
\hline & CLA - & $\mathrm{CLA}^{2}+$ & CLA - & CLA + & & RAC & CLA & $\mathrm{RAC} \times \mathrm{CLA}$ \\
\hline C_14:0 & $1.16^{\mathrm{b}, \mathrm{c}}$ & $1.28^{\mathrm{a}}$ & $1.12^{\mathrm{c}}$ & $1.17^{\mathrm{b}}$ & 0.018 & 0.001 & $<0.001$ & 0.039 \\
\hline C_20:2n6 & $0.77^{\mathrm{b}}$ & $0.78^{\mathrm{b}}$ & $0.84^{\mathrm{a}}$ & $0.79^{b}$ & 0.014 & 0.008 & 0.053 & 0.010 \\
\hline C_24:1 & $0.066^{\mathrm{b}}$ & $0.072^{\mathrm{a}, \mathrm{b}}$ & $0.083^{a}$ & $0.061^{\mathrm{b}}$ & 0.005 & 0.623 & 0.143 & 0.015 \\
\hline
\end{tabular}

${ }^{1}$ Ractopamine hydrochloride was included at $6.75 \mathrm{~g} /$ ton level in the diets;

${ }^{2}$ CLA was included at $0.6 \%$ level in the diets;

a,b,c within a row, means lacking a common superscript differ from each other $(\mathrm{P}<0.05)$. 
Table 4.15. Diet source by dietary RAC treatment subclass means for fatty acid profile of jowl samples of growingfinishing pigs

\begin{tabular}{|c|c|c|c|c|c|c|c|c|}
\hline \multirow{2}{*}{ Variables } & \multicolumn{2}{|c|}{ Corn-Soy } & \multicolumn{2}{|c|}{$20 \% \mathrm{DDGS}^{2}$} & \multirow{2}{*}{$\begin{array}{l}\text { Pooled } \\
\text { SEM }\end{array}$} & \multicolumn{3}{|c|}{ P-values } \\
\hline & RAC - & $\mathrm{RAC}^{1}+$ & RAC - & RAC + & & Diet Source & RAC & Diet Source $\times$ RAC \\
\hline C_20:1 & $0.69^{b}$ & $0.81^{\mathrm{a}}$ & $0.78^{\mathrm{a}, \mathrm{b}}$ & $0.75^{\mathrm{a}, \mathrm{b}}$ & 0.029 & 0.633 & 0.154 & 0.023 \\
\hline C_18:3n3 & $0.63^{a, b}$ & $0.59^{\mathrm{a}, \mathrm{b}}$ & $0.57^{\mathrm{b}}$ & $0.65^{\mathrm{a}}$ & 0.025 & 0.888 & 0.281 & 0.015 \\
\hline MUFA & $47.35^{b}$ & $48.55^{\mathrm{a}}$ & $47.32^{b}$ & $47.30^{b}$ & 0.233 & 0.047 & 0.047 & 0.041 \\
\hline Total omega-3 & $0.63^{\mathrm{a}, \mathrm{b}}$ & $0.61^{\mathrm{a}, \mathrm{b}}$ & $0.57^{\mathrm{b}}$ & $0.66^{\mathrm{a}}$ & 0.026 & 0.863 & 0.156 & 0.018 \\
\hline
\end{tabular}

${ }^{1}$ Ractopamine hydrochloride was included at $6.75 \mathrm{~g} /$ ton level in the diets;

${ }^{2}$ Distillers dried grains with solubles;

${ }^{\mathrm{a}, \mathrm{b}}$ within a row, means lacking a common superscript differ from each other $(\mathrm{P}<0.05)$. 
Table 4.16. Correlation analysis between iodine value (IV) of belly and jowl fat depots of growing-finishing pigs

\begin{tabular}{|c|c|c|c|c|}
\hline DDGS $^{1}$ & RAC $^{2}$ & CLA $^{3}$ & Correlation (r) & P - values \\
\hline- & - & - & 0.787 & 0.0634 \\
\hline- & - & + & 0.986 & 0.0003 \\
\hline- & + & - & 0.965 & 0.0018 \\
\hline- & + & + & 0.733 & 0.0971 \\
\hline+ & - & - & 0.952 & 0.0034 \\
\hline+ & - & + & 0.894 & 0.0163 \\
\hline+ & + & - & 0.971 & 0.0012 \\
\hline+ & + & + & 0.965 & 0.0018 \\
\hline
\end{tabular}

${ }^{1}$ Distillers dried grains with solubles was included at 20\% level in the diets;

${ }^{2}$ Ractopamine hydrochloride was included at $6.75 \mathrm{~g} / \mathrm{ton}$ level in the diets;

${ }^{3}$ CLA was included at $0.6 \%$ level in the diets. 


\section{LITERATURE CITED}

Aalhus, J. L., S. D. M. Jones, A. L. Schaefer, A. K. W. Tong, W. M. Robertson, J. K. Merrill, and A. C. Murray. 1990. The effect of ractopamine on performance, carcass composition and meat quality of finishing swine. Can. J. Anim. Sci. 70:943-952.

Adeola, O., E. A. Darko, P. He, and L. G. Young. 1990. Manipulation of porcine carcass composition by ractopamine. J. Anim. Sci. 68:3633-3641.

Allee, G. L., D. H. Baker, and G. A. Leveille. 1971. Influence of level of dietary fat on adipose tissue lipogenesis and enzymatic activity in the pig. J. Anim. Sci. 33:12481254.

Anderson, D. B., R. G. Kauffman, and L. L. Kastenschmidt. 1972. Lipogenic enzyme activities and cellularity of porcine adipose tissue from various anatomical locations. J. Lipid Res. 13:593-599.

AOCS. 1998. Recommended practice Cd 1c-85. In official methods and recommended practices of the AOCS, 5th ed. Am. Oil Chem. Soc., Champaign, IL.

Apple, J. K. 2010. Nutritional effects on pork quality in swine production. National swine nutrition guide. PIG 12-02-02. Pages 1-13.

Apple, J. K., C. V. Maxwell, D. L. Galloway, S. Hutchison, and C. R. Hamilton. 2009a. Interactive effects of dietary fat source and slaughter weight in growing-finishing swine: I. Growth performance and longissimus muscle fatty acid composition. J. Anim. Sci. 87:1407-1422.

Apple, J. K., C. V. Maxwell, D. L. Galloway, C. R. Hamilton, and J. W. S. Yancey. 2009b. Interactive effects of dietary fat source and slaughter weight in growingfinishing swine: II. Fatty acid composition of subcutaneous fat. J. Anim. Sci. 87:1423-1440.

Apple, J. K., C. V. Maxwell, B. R. Kutz, L. K. Rakes, J. T. Sawyer, Z. B. Johnson, T. A. Armstrong, S. N. Carr, and P. D. Matzat. 2008. Interactive effect of ractopamine and dietary fat source on pork quality characteristics of fresh pork chops during simulated retail display. J. Anim. Sci. 86:2711-2722.

Apple, J. K., C. V. Maxwell, J. T. Sawyer, B. R. Kutz, L. K. Rakes, M. E. Davis, Z. B. Johnson, S. N. Carr, and T. A. Armstrong. 2007. Interactive effect of ractopamine and dietary fat source on quality characteristics of fresh pork bellies. J. Anim. Sci. 85:2682-2690.

Armstrong, T. A., D. J. Ivers, J. R. Wagner, D. B. Anderson, W. C. Weldon, and E. P. Berg. 2004. The effect of dietary ractopamine concentration and duration of feeding on growth performance, carcass characteristics, and meat quality of finishing pigs. J. Anim. Sci. 82:3245-3253. 
Augspurger, N. R., G. I. Petersen, J. D. Spencer, and E. N. Parr. 2008. Alternating dietary inclusion of corn distillers dried grains with solubles (DDGS) did not impact growth performance of finishing pigs. J. Anim. Sci. 86(Suppl. 1):523. (Abstr.)

Averette-Gatlin, L., M. T. See, J. A. Hansen, D. Sutton, and J. Odle. 2002a. The effects of dietary fat sources, levels, and feeding intervals on pork fatty acid composition. J. Anim. Sci. 80:1606-1615.

Averette-Gatlin, L., M. T. See, D. K. Larick, X. Lin, and J. Odle. 2002b. Conjugated linoleic acid in combination with supplemental dietary fat alters pork quality. J. Nutr. 132:3105-3112.

Azain, M. J. 2001. Fat in Swine Nutrition. Pages 95-106 in Swine Nutrition. 2nd ed. A. J. Lewis and L. L. Southern, ed. CRC Press, Boca Raton, FL.

Bark, L. J., T. S. Stahly, G. L. Cromwell, and J. Miyat. 1992. Influence of genetic capacity for lean tissue growth on rate and efficiency of tissue accretion in pigs fed ractopamine. J. Anim. Sci. 70:3391-3400.

Bauman, D. E., L. H., Baumgard, B. A. Corl, and J. M. Griinari. 1999. Biosynthesis of conjugated linoleic acid in ruminants. In Proceedings of the American Society of Animal Science. http://www.asas.org/jas/symposia/proceedings/0937.pdf. Accessed on Apr. 1, 2010.

Bee, G., S. Gebert, and R. Messikommer. 2002. Effect of dietary energy supply and fat source on the fatty acid pattern of adipose and lean tissues and lipogenesis in the pig. J. Anim. Sci. 80:1564-1574.

Berg. E. P. 2001. Swine Nutrition, the Conversion of Muscle to Meat, and Pork Quality. Pages 632-658 in Swine Nutrition. 2nd ed. A. J. Lewis and L. L. Southern, ed. CRC Press, Boca Raton, FL.

Bergen, W. G., S. E. Johnson, D. M. Skjaerlund, A. S. Babiker, N. K. Ames, R. A. Merkel, and D. B. Anderson. 1989. Muscle protein metabolism in finishing pigs fed ractopamine. J. Anim. Sci. 67:2255-2262.

Boyd, R. D., M. E. Johnston, K. Scheller, A. A. Sosnicki, and E. R. Wilson. 1997. Relationship between dietary fatty acid profile and body fat composition in growing pigs. PIC USA R\&D Technical Memo 153. Pig Improvement Company USA, Franklin, KY.

Boyer, R. 2002. Interactive concepts in biochemistry. http://www.wiley.com/legacy /college/boyer/0470003790/animations/animations.htm. Accessed Mar. 1, 2010.

Bretillo, L., J. M. Chardigny, S. Gregoire, O. Berdeaux, and J. L. Sébédio. 1999. Effect of conjugated linoleic acid isomers on the hepatic microsomal desaturation activities in vitro. Lipids 34:965-969. 
Brooks, C. C. 1971. Fatty acid composition of pork lipids as affected by basal diet, fat source, and fat level. J. Anim. Sci. 33:1224-1231.

Brumm, M. C., P. S. Miller, and R. C. Thaler. 2004. Response of barrows to space allocation and ractopamine. J. Anim. Sci. 82:3373-3379.

Busboom, J. R., D. C. Rule, D. Colin, T. Heald, and A. Mazhar. 1991. Growth, carcass characteristics, and lipid composition of adipose tissue and muscle of pigs fed canola. J. Anim. Sci. 69:1101-1108.

Camara, M., J. Mourot, and C. Fevrier. 1996. Influence of two dairy fats on lipid synthesis in the pig: Comparative study of liver, muscle and the two backfat layers. Ann. Nutr. Metab. 40:287-295.

Carr, S. N., D. N. Hamilton, K. D. Miller, A. L. Schroeder, D. Fernández-Dueñas, J. Killefer, M. Ellis, and F. K. McKeith. 2009. The effect of ractopamine hydrochloride (Paylean ${ }^{\circledR}$ ) on lean carcass yields and pork quality characteristics of heavy pigs fed normal and amino acid fortified diets. Meat Sci. 81:533-539.

Carr, S. N., D. J. Ivers, D. B. Anderson, D. J. Jones, D. H. Mowrey, M. B. England, J. Killefer, P. J. Rincker, and F. K. McKeith. 2005a. The effects of ractopamine hydrochloride on lean carcass yields and pork quality characteristics. J. Anim. Sci. 83:2886-2893.

Carr, S. N., P. J. Rincker, J. Killefer, D. H. Baker, M. Ellis, and F. K. McKeith. 2005b. Effects of different cereal grains and ractopamine hydrochloride on performance, carcass characteristics, and fat quality in late-finishing pigs. J. Anim. Sci. 83:223230.

Chin, S. F., W. Liu, J. M. Storkson, Y. L. Ha, and M. W. Pariza. 1992. Dietary sources of conjugated dienoic isomers of linoleic acid, a newly recognized class of anticarcinogens. J. of Food Composition and Analysis. 5:185-197.

Cook, M. E. 1999. Conjugated linoleic acid. Proceedings from Reciprocal Meat Conference, 52, 43-46.

Cook, M. E., D. L. Jerome, T. D. Crenshaw, D. R. Buege, M. W. Pariza, K. J. Albright, S. P. Schmidt, J. A. Scimeca, P. A. Lofgren, and E. J. Hentges. 1998. Feeding conjugated linoleic acid improves feed efficiency and reduces carcass fat in pigs FASEB J. 11:3347.

Cook, D., N. Paton, and M. Gibson. 2005. Effect of dietary level of distillers dried grains with solubles (DDGS) on growth performance, mortality, and carcass characteristics of grow-finish barrows and gilts. J. Anim. Sci. 83(Suppl. 1):335. (Abstr.) 
Cordero, G., B. Isabel, D. Menoyo, A. Daza, J. Morales, C. Piñeiro, and C. J. LópezBote. 2010. Dietary CLA alters intramuscular fat and fatty acid composition of pig skeletal muscle and subcutaneous adipose tissue. Meat Sci. 85:235-239.

Corino, C., M. Musella, G. Pastorelli, R. Rossi, K. Paolone, L. Costanza, A. Manchisi, and G. Maiorano. 2008. Influences of dietary conjugated linoleic acid (CLA) and total lysine content on growth, carcass characteristics and meat quality of heavy pigs. Meat Sci. 79:307-316.

Cromwell, G. L. 2009. ASAS Centennial Paper: Landmark discoveries in swine nutrition in the past century. J. Anim. Sci. 87:778-792.

Cromwell, G. L., K. L. Herkelman, and T. S. Stahly. 1993. Physical, chemical, and nutritional characteristics of distillers dried grains with solubles for chicks and pigs. J. Anim. Sci. 71:679-686.

DeDecker, J. M., M. Ellis, B. F. Wolter, J. Spencer, D. M. Webel, C. R. Bertelsen, and B. A. Peterson. 2005. Effects of dietary level of distiller dried grains with solubles and fat on the growth performance of growing pigs. J. Anim. Sci. 83(Suppl. 2):79. (Abstr.)

Demaree, S. R., C. D. Gilbert, H. J. Mersmann, and S. B. Smith. 2002. Conjugated linoleic acid differentially modifies fatty acid composition in subcellular fractions of muscle and adipose tissue but not adiposity of postweanling pigs. J. Nutr. 132:3272-3279.

Deshaies, Y., J. Willemot, and J. Leblanc. 1981. Protein synthesis, amino acid uptake, and pools during ISO-induced hypertrophy of the rat heart and tibialis muscle. Can. J. Physiol. Pharmacol. 59:113-121.

Dikeman, M. E. 2007. Effects of metabolic modifiers on carcass traits and meat quality. Meat Sci. 77:121-135.

Dobrzyn, A., and J. M. Ntambi. 2005. The role of stearoyl-CoA desaturase in the control of metabolism. Prostaglandins Leukot. Essent. Fatty Acids 73:35-41.

Drescher, A. J., L. J. Johnston, G. C. Shurson, and J. Goihl. 2008. Use of 20\% dried distillers grains with solubles (DDGS) and high amounts of synthetic amino acids to replace soybean meal in grower-finisher swine diets. J. Anim. Sci. 86(Suppl. 2):28. (Abstr.)

Dugan, M. E. R., J. L. Aalhus, L. E. Jeremiah, J. K. G. Kramer, and A. L. Schaefer. 1999. The effects of feeding conjugated linoleic acid on subsequent pork quality. Can. J. Anim. Sci. 79:45-51.

Dugan, M. E. R., J. L. Aalhus, A. L. Schaefer, and J. K. G. Kramer. 1997. The effect of conjugated linoleic acid on fat to lean repartitioning and feed conversion in pigs. Can. J. Anim. Sci. 77:723-725. 
Dunshea, F. R., D. N. D’Souza, D. W. Pethic, G. S. Harper, and R. D. Warner. 2005. Effects of dietary factors and other metabolic modifiers on quality and nutritional value of meat. Meat Sci. 71:8-38.

Dunshea, F. R., R. H. King, R. G. Campbell, R. D. Sainz, and Y. S. Kim. 1993. Interrelationships between sex and ractopamine on protein and lipid deposition in rapidly growing pigs. J. Anim. Sci. 71:2919-2930.

Duttlinger, A. W., M. D. Tokach, S. S. Dritz, J. M. DeRouchy, J. L. Goodband, R. D. Goodband, and H. J. Prusa. 2008. Effects of increasing dietary glycerol and dried distillers grains with solubles on growth performance of finishing pigs. J. Anim. Sci. 86(Suppl. 1):607. (Abstr.)

Eggert, J. M., M. A. Belury, A. Kempa-Steczko, S. E. Mills, and A. P. Schinckel. 2001. Effects of conjugated linoleic acid on the belly firmness and fatty acid composition of genetically lean pigs. J. Anim. Sci. 79:2866-2872.

Eggert, J. M., A. L. Grant, and A. P. Schinckel. 2007. Factors affecting fat distribution in pork carcasses. Prof. Anim. Sci. 23:42-53.

Ellis, N. R., and H. S. Isbell. 1926. Soft pork studies. II. The influence of the character of the ration upon the composition of the body fat of hogs. J. Biol. Chem. 69:219-238.

Engel, J. J., J. W. Smith II, J. A. Unruh, R. D. Goodband, P. R. O’Quinn, M. D. Tokach, and J. L. Nelssen. 2001. Effects of choice white grease or poultry fat on growth performance, carcass leanness, and meat quality characteristics of growingfinishing pigs. J. Anim. Sci. 79:1491-1501.

Enser, M. .2001. The role of fats in human nutrition. In B. Rossell (Ed.), Oils and fats, Vol. 2. Animal carcass fats. Leatherhead, Surrey, UK: Leatherhead Publishing. Pages 77-122.

Enser, M., K. Hallett, B. Hewett, G. A. J. Fursey, and J. D. Wood. 1996. Fatty acid content and composition of English beef, lamb and pork at retail. Meat Sci. 44:443458.

Enser, M., K. G. Hallett, B. Hewett, G. A. J. Fursey, J. D. Wood, and G. Harrington. 1998. Fatty acid content and composition of UK beef and lamb muscle in relation to production system and implications for human nutrition. Meat Sci. 49:329-341.

Fain, J. N., and J. A. Garcia-Sainz. 1983. Adrenergic regulation of adipocytes metabolism. J. Lipid Res. 24:945-986.

Fairbanks, B. W., J. L. Krider, and W. E. Carroll. 1944. Distillers by-products in swine rations. I. Creep-feeding and growing-fattening rations. J. Anim. Sci. 3:29-40. 
Fairbanks, B. W., J. L. Krider, and W. E. Carroll. 1945. Distillers by-products in swine rations. III. Dried corn distillers' solubles, alfalfa meal, and crystalline B-vitamins compared for growing-fattening pigs in drylot. J. Anim. Sci. 4:420-429.

Fernández-Dueñas, D. M., A. J. Myers, S. M. Scramlin, C. W. Parks, S. N. Carr, J. Killefer, and F. K. McKeith. 2008. Carcass, meat quality, and sensory characteristics of heavy body weight pigs fed ractopamine hydrochloride (Paylean). J. Anim. Sci. 86:3544-3550.

Folch, J., M. Lees, and S. G. H. Stanley. 1957. A simple method for the isolation and purification of total lipids from animal tissues. J. Biol. Chem. 226:497-509.

Forsberg, N. E., M. A. Ilian, A. Ali-Bar, P. R. Cheeke, and N. B. Wehr. 1989. Effects of cimaterol on rabbit growth and myofribillar protein degradation and on calciumdependent proteinase and calpastatin activities in skeletal muscle. J. Anim. Sci. 67:3313-3321.

Fritsche, J., and H. Steinhardt. 1998. Amounts of conjugated linoleic acid (CLA) in German foods and evaluation of daily intake. Zeitschrift für LebensmittelUntersuchung und -Forschung A - Food Research and Technology 206:77-82.

Fu, S. X., M. Johnston, R. W. Fent, D. C. Kendall, J. L. Usry, R. D. Boyd, and G. L. Allee. 2004. Effect of corn distiller's dried grains with solubles (DDGS) on growth, carcass characteristics, and fecal volume in growing finishing pigs. J. Anim. Sci. 82(Suppl. 2):80. (Abstr.)

Gaines, A. M., G. I. Petersen, J. D. Spencer, and N. R. Augspurger. 2007a. Use of corn distillers dried grains with solubles (DDGS) in finishing pigs. J. Anim. Sci. 85(Suppl. 2):96. (Abstr.)

Gaines, A. M., J. D. Spencer, G. I. Petersen, N. R. Augspurger, and S. J. Kitt. 2007b. Effect of corn distillers dried grains with solubles (DDGS) withdrawal program on growth performance and carcass yield in grow-finish pigs. J. Anim. Sci. 85(Suppl.1):438. (Abstr.)

Gatlin, L. A., M. T. See, J. A. Hansen, and J. Odle. 2003. Hydrogenated dietary fat improves pork quality of pigs from two lean genotypes. J. Anim. Sci. 81:1989-1997.

Gatlin, L. A., M. T. See, J. A. Hansen, D. Sutton, and J. Odle. 2002. The effects of dietary fat sources, levels, and feeding interval on pork fatty acid composition. J. Anim. Sci. 80:1606-1615.

Gill, B. P., J. Mellange, and J. A. Rooke. 2000. Growth performance and apparent nutrient digestibility in weaned piglets offered wheat-, barley-, or sugar-beet pulpbased diets supplemented with food enzymes. J. Anim. Sci. 70:107-118. 
Goodband, B., J. DeRouchey, M. Tokach, S. Dritz, and J. Nelssen. 2006. A practical look at nutritional attempts to improve pork quality. Pages 125-139 in London Swine Conference Proc., London, UK.

Griinari, J. M., and D. E. Bauman. 1999. Biosynthesis of conjugated linoleic acid and its incorporation into meat and milk in ruminants. In M. P. Yurawecz, M. M. Mossoba, J. K. G. Kramer, M. W. Pariza, \& G. Nelson (Eds.), Advances in conjugated linoleic acid research. Pages 180-200. Champaign, IL: American Oil Chemists Society Press.

Griinari, J. M., B. A. Corl, S. H. Lacy, P. Y. Chouinard, K. V. V. Nurmela, and D. E. Bauman. 2000. Conjugated linoleic acid is synthesized endogenously in lactating dairy cows by D9-desaturase. J. Nutr. 130:2285-2291.

Gu, Y., A. P. Schinckel, J. C. Forrest, C. H. Kuei, and L. E. Watkins. 1991a. Effects of ractopamine, genotype and growth phase on finishing performance and carcass value in swine. I. Growth performance and carcass merit. J. Anim. Sci. 69:26852693.

Gu, Y., A. P. Schinckel, J. C. Forrest, C. H. Kuei, and L. E. Watkins. 1991b. Effects of ractopamine, genotype and growth phase on finishing performance and carcass value in swine. II. Estimation of lean growth rate and lean feed efficiency. J. Anim. Sci. 69:2694-2702.

Helferich, W. G., D. B. Jump, D. B. Anderson, D. M. Skjaerlund, R. A. Merkel, and W. G. Bergen. 1990. Skeletal muscle $\alpha$-actin synthesis is increased in pretranslationally in pigs fed the phenethanolamine ractopamine. Endocrinology 126:3096-3100.

Hinson, R., G. Allee, G. Grinstead, B. Corrigan, and J. Less. 2007. Effect of amino acid program (Low vs. High) and dried distiller's grains with solubles (DDGS) on finishing pig performance and carcass characteristics. J. Anim. Sci. 85(Suppl. 1):437. (Abstr.)

Hollis, G. R., and S. E. Curtis. 2001. General Characteristics of the U.S. Swine Industry. Pages 19-30 in Swine Nutrition. 2nd ed. A. J. Lewis and L. L. Southern, ed. CRC Press, Boca Raton, FL.

House, R. L., J. P. Cassady, E. J. Eisen, M. K. McIntosh, and J. Odle. 2005. Conjugated linoleic acid evokes de-lipidation through the regulation of genes controlling lipid metabolism in adipose and liver tissue. Obes. Rev. 6:247-258.

Irie, M. 1999. Evaluation of porcine fat with fiber-optic spectroscopy. J. Anim. Sci. 77:2680-2683.

Joo, S. T., J. I. Lee, Y. L. Ha, and G. B. Park. 2002. Effects of dietary conjugated linoleic acid on fatty acid composition, lipid oxidation, color, and water-holding capacity of pork loin. J. Anim. Sci. 80:108-112. 
Kass, M. L., P. J. van Soest, and W. G. Pond. 1980. Utilization of dietary fiber from alfalfa by growing swine. I. Apparent digestibility of diet components in specific segments of the gastrointestinal tract. J. Anim. Sci. 50:175-191.

Killefer, J., and M. Koohmarie. 1994. Bovine skeletal calpastatin: Cloning, sequence analysis, and steady state mRNA expression. J. Anim. Sci. 72:606-614.

Knight, T. W., S. Knowles, and A. F. Death. 2003. Factors affecting the variation in fatty acid concentrations in lean beef from grass-fed cattle in New Zealand and the implications for human health. New Zealand Journal of Agricultural Research. 46:83-95.

Koch, D. E., A. M. Pearson, W. T. Magee, J. A. Hoefer, and B. S. Schweigert. 1968. Effect of diet on the fatty acid composition of pork fat. J. Anim. Sci. 27:360-365.

Kouba, M., and J. Mourot. 1999. Effect of a high linoleic acid diet on lipogenic enzymes activities and on the composition of the lipid fraction of fat and lean tissues in the pig. Meat Sci. 52:39-45.

Larsen, T. M., S. Toubro, and A. Astrup. 2003. Efficacy and safety of dietary supplements containing CLA for the treatment of obesity: evidence from animal and human studies. J. Lipid Research, 44:2234-2241.

Larsen, S. T., B. R. Wiegand, F. C. Parrish, Jr., J. E. Swan, and J. C. Sparks. 2009. Dietary conjugated linoleic acid changes belly and bacon quality from pigs fed varied lipid sources. J. Anim. Sci. 87:285-295.

Lauridsen, C., H. Mu, and P. Henckel. 2005. Influence of dietary conjugated linoleic acid (CLA) and age at slaughtering on performance, slaughter- and meat quality, lipoproteins, and tissue deposition of CLA in barrows. Meat Sci. 69:393-399.

Lee, K. N., M. W. Pariza, and J. M. Ntambi. 1998. Conjugated linoleic acid decreases hepatic stearoyl-CoA-desaturase mRNA expression. Biochem. Biophys. Res. Commun. 248:817-821.

Li, J. B., and L. S. Jefferson. 1977. Effect of ISO on amino acids levels and protein turnover in skeletal muscle. Am. J. Physiol. 232:E243-E249.

Linneen, S. K., J. M. DeRouchy, S. S. Dritz, R. D. Goodband, M. D. Tokach, and J. L. Nelssen. 2008. Effects of dried distillers grains with solubles on growing and finishing pig performance in a commercial environment. J. Anim. Sci. 86:1579_ 1587.

Livingstone, R. M., and D. M. S. Livingston. 1969. A note on the use of distillers' byproducts in diets for growing pigs. Anim. Prod. 11:259-261.

Martin, A. H., H. T. Fredeen, G. M. Weiss and R. B. Carson. 1972. Distribution and composition of porcine carcass fat. J. Anim. Sci. 35:534-541. 
McEwen, P. L. 2006. The effects of distillers dried grains with soluble inclusion rate and gender on pig growth performance. Can. J. Anim. Sci. 86:594. (Abstr.)

McKeith, F. K., Y. H. Lan, and D. H. Beermann. 1994. Sensory characteristics of meat from animals given partitioning agents. In H. D. Hafs and R. G. Zimbleman (Eds.), Low Fat Meats. San Diego, CA: Academic Press, Inc. Pages 233-252.

Miner J. L., A. S. Robertson, and K. L. Houseknecht. 2001. Nutrient Effects on Gene Expression. Pages 609-630 in Swine Nutrition. 2nd ed. A. J. Lewis and L. L. Southern, ed. CRC Press, Boca Raton, FL.

Moody, D. E., D. L. Hancock, and D. B. Anderson. 2000. Phenethanolamine repartitioning agents. Pages 65-95 in Farm Animal Metabolism and Nutrition. J. P. F. D’Mello, ed. CAB Int., New York.

Morgan, J. B., G. C. Smith, J. Cannon, F. McKeith, and J. Heavner. 1994. Pork distribution channel audit report. Pages 30-40 in Pork Chain Quality Audit Progress Report. D. Meeker and S. Sonka, ed. Natl. Pork Prod. Counc., Des Moines, IA.

Morrison, W. R., and L. M. Smith. 1964. Preparation of fatty acid methyl esters and dimethylacetals from lipids with boron fluoride-methanol. J. Lipid Res. 5:600-608.

Mourot, J., M. Kouba, and P. Peiniau. 1995. Comparative study of in vitro lipogenesis in various adipose tissues in the growing pig (Sus domesticus), Comp. Biochem. Physiol., 111B:379.

Moya-Camarena, S. Y., J. P. Vanden Heuvel, S. G. Blanchard, L. A. Lesnitzner, and M. A. Belury. 1999. Conjugated linoleic acid is a potent naturally-occurring ligand and activator of PPAR- $\alpha$. J. Lipid Res. 40:1426-1433.

Nelson, R. H., and M. M. Cox. 2000. Lehninger: Principles of Biochemistry. 3rd Ed. Worth Publisher, New York, N.Y.

Nordstrom, J. W., B. R. Behrends, R. J. Meade, and E. H. Thompson. 1972. Effects of feeding high oil corns to growing-finishing swine. J. Anim. Sci. 35:357-361.

NPPC. 1999. Pork Quality Standards. National Pork Producers Council, Des Moines, IA.

NPPC. 2000. Pork fat quality. In Pork Carcass Composition and Quality Assessment Procedures. Berg, E. P., Ed., National Pork Producers Council, Des Moines, IA, 32.

NRC. 1998. Nutrient Requirement of Swines, 10th ed., National Academy Press, Washington, D.C.

NSNG, 2010. National swine nutrition guide tables on nutrient recommendations, ingredient composition, and use rates. National swine nutrition guide. PIG 07-0209. Page 25. 
O’Hea, E. K., and G. A. Leveille. 1969. Significance of adipose tissue and liver as sites of fatty acid synthesis in the pig and the efficiency of utilization of various substrates for lipogenesis. J. Nutr. 99:338-344.

Ostrowska, E., M. Muralitharan, R. F. Cross, D. E. Bauman, and F. R. Dunshea. 1999. Dietary conjugated linoleic acid increase lean tissue and decrease fat deposition in growing pigs. J. Nutr. 129:2037-2042.

Pedersen, C., M. G. Boersma, and H. H. Stein. 2007. Digestibility of energy and phosphorus in 10 samples of distillers dried grains with solubles fed to growing pigs. J. Anim. Sci. 85:1168-1176.

Pluske, J. R., B. Black, D. W. Pethick, B. P. Mullan, and D. J. Hampson. 2003. Effects of different sources and levels of dietary fibre in diets on performance, digesta characteristics and antibiotic treatment of pigs after weaning. Anim. Feed Sci. Technol. 107:129-142.

Pond, W. G., and X. G. Lei. 2001. Of Pigs and People. Pages 3-18 in Swine Nutrition. 2nd ed. A. J. Lewis and L. L. Southern, ed. CRC Press, Boca Raton, FL.

Ramsay, T. G., C. M. Evock-Clover, N. C. Steele, and M. J. Azain. 2001. Dietary conjugated linoleic acid alters fatty acid composition of pig skeletal muscle and fat. J. Anim. Sci. 79:2152-2161.

Rausch, K. D., and R. L. Belyea. 2006. The future of coproducts from corn processing. Appl. Biochem. Biotechnol. 128:47-86.

Rentfrow, G., T. E. Sauber, G. L. Allee, and E. P. Berg. 2003. The influence of diets containing either conventional corn, conventional corn with choice white grease, high oil corn, or high oil high oleic corn on belly/bacon quality. Meat Sci. 64:459466.

Rosenvold, K., and H. J. Andersen. 2003. Factors of significance for pork quality - a review. Meat Sci. 64:219-237.

Rule, D. C., S. B. Smith, and J. R. Romans. 1995. Fatty acid composition of muscle and adipose tissue of meat animals. In: S. B. Smith and D. R. Smith (ed.) The Biology of Fat in Meat Animals: Current Advances. pp 144165. American Society of Animal Science, Champaign, IL.

Sather, A. P., S. D. M. Jones, W. M. Robertson, and S. Zawadski. 1995. Sex effects on fat hardness meter readings of market weight hogs. Can. J. Anim. Sci. 75:509-515.

Schmid, A., M. Collomb, R. Sieber, and G. Bee. 2006. Conjugated linoleic acid in meat and meat products: a review. Meat Sci. 73:29-41.

Scollan, N. D., J-F. Hocquette, K. Nuernberg, D. Dannenberger, R. I. Richardson, and A. Maloney. 2006. Innovations in beef production systems that enhance the nutritional 
and health value of beef lipids and their relationship with meat quality. Meat Sci. 74:17-33.

See, M. T., T. A. Armstrong, and W. C. Weldon. 2004. Effect of a ractopamine feeding program on growth performance and carcass composition in finishing pigs. J. Anim. Sci. 82:2474-2480.

Seerley, R. W., J. P. Briscoe, and H. C. McCampbell. 1978. A comparison of poultry fat and animal fat on performance, body composition and tissue lipids of swine. J. Anim. Sci. 46:1018-1023.

Smith, S. B., T. S. Hively, G. M. Cortese, J. J. Han, K. Y. Chung, P. Castenada, C. D. Gilbert, V. L. Adams, and H. J. Mersmann. 2002. Conjugated linoleic acid depresses the $\delta^{9}$ desaturase index and stearoyl coenzyme A desaturase enzyme activity in porcine subcutaneous adipose tissue. J. Anim. Sci. 80:2110-2115.

Spiehs, M. J., M. H. Whitney, and G. C. Shurson. 2002. Nutrient database for distiller's dried grains with solubles produced from new ethanol plants in Minnesota and South Dakota. J. Anim. Sci. 80:2639-2645.

Stein, H. H. 2007. Distillers dried grains with solubles (DDGS) in diets fed to swine. HHS-Swine Focus-001.2007 publication. Dept. of Animal Science, University of Illinois, Urbana.

Stein H. H., and G. C. Shurson. 2009. The use and application of distillers dried grains with solubles in swine diets. J. Anim. Sci. 87:1292-1303.

Stender, D., and M. S. Honeyman. 2008. Feeding pelleted DDGS based diets to finishing pigs in deep-bedded hoop barns. J. Anim. Sci. 86(Suppl. 2):50. (Abstr.)

Stoller, G. M., H. N. Zerby, S. J. Moeller, T. J. Baas, C. Johnson, and L. E. Watkins. 2003. The effect of feeding ractopamine (Paylean) on muscle quality and sensory characteristics in three diverse genetic lines of swine. J. Anim. Sci. 81:1508-1516.

Strader, C. D., I. S. Sigal, and R. A. F. Dixon. 1989. Structural basis of $\beta$-adrenergic receptor function. FASEB J. 3:1825-1832.

Thiel-Cooper, R. L., F. C. Parrish, Jr, J. C. Sparks, B. R. Wiegand, and R. C. Ewan. 2001. Conjugated linoleic acid changes swine performance and carcass composition. J. Anim. Sci. 79:1821-1828.

Uttaro, B. E., R. O. Ball, P. Dick, W. Rae, G. Vessie, and L. E. Jeremiah. 1993. Effect of ractopamine and sex on growth, carcass characteristics, processing yield, and meat quality characteristics of crossbred swine. J. Anim. Sci. 71:2439-2449.

Wang, S. Y., and D. H. Beerman. 1988. Reduced calcium-dependent proteinase activity in cimaterol-induced muscle hypertrophy in lambs. J. Anim. Sci. 66:2545-2550. 
Warnants, N., M. J. Van Oeckel, and C. V. Boucque. 1999. Incorporation of dietary polyunsaturated fatty acids into pork fatty tissues. J. Anim. Sci. 77:2478-2490.

Watkins, B. A., and M. F. Seifert. 2000. Conjugated linoleic acid and bone biology. J. Am. Coll. Nutr. 19:478S-486S.

Weber, T. E., B. T. Richert, M. A. Belury, Y. Gu, K. Enright, and A. P. Schinckel. 2006. Evaluation of the effects of dietary fat, conjugated linoleic acid, and ractopamine on growth performance, pork quality, and fatty acid profiles in genetically lean gilts. J. Anim. Sci. 84:720-732.

Weimer, D., J. Stevens, A. Schinckel, M. Latour, and B. Richert. 2008. Effects of feeding increasing levels of distillers dried grains with solubles to grow-finish pigs on growth performance and carcass quality. J. Anim. Sci. 86(Suppl. 2):51. (Abstr.)

White, H., B. Richert, S. Radcliffe, A. Schinckel, and M. Latour. 2007. Distillers dried grains decreases bacon lean and increases fat iodine values (IV) and the ratio of n6:n-3 but conjugated linoleic acids partially recovers fat quality. J. Anim. Sci. 85(Suppl. 2):78. (Abstr.)

White, H. M., B. T. Richert, J. S. Radcliffe, A. P. Schinckel, J. R. Burgess, S. L. Koser, S. S. Donkin, and M. A. Latour. 2009. Feeding conjugated linoleic acid partially recovers carcass quality in pigs fed dried corn distillers grains with solubles. J. Anim. Sci. 87:157-166.

Whitney, M. H., G. C. Shurson, L. J. Johnson, D. M. Wulf, and B. C. Shanks. 2006. Growth performance and carcass characteristics of grower-finisher pigs fed highquality corn distillers dried grain with solubles originating from a modern Midwestern ethanol plant. J. Anim. Sci. 84:3356-3363.

Whittington, F. M., N. J. Prescott, J. D. Wood, and M. Enser. 1986. The effect of dietary linoleic acid on the firmness of backfat in pigs on $85 \mathrm{~kg}$ live weight. J. Sci. Food Agric. 37:753-761.

Widmer, M. R., L. M. McGinnis, D. M. Wulf, and H. H. Stein. 2008. Effects of feeding distillers dried grains with solubles, high-protein distillers dried grains, and corn germ to growing-finishing pigs on pig performance, carcass quality, and the palatability of pork. J. Anim. Sci. 86:1819-1831.

Wiegand, B. R., F. C. Parrish, Jr., J. E. Swan, S. T. Larsen, and T. J. Baas. 2001. Conjugated linoleic acid improves feed efficiency, decreases subcutaneous fat, and improves certain aspects of meat quality in stress-genotype pigs. J. Anim. Sci. 79:2187-2195.

Wiegand, B. R., J. C. Sparks, F. C. Parrish, Jr., and D. R. Zimmerman. 2002. Duration of feeding conjugated linoleic acid influences growth performance, carcass traits, and meat quality of finishing barrows. J. Anim. Sci. 80:637-643. 
Wiseman, J., and J. A. Agunbiade. 1998. The influence of changes in dietary fats and oils on fatty acid profiles of carcass fat in finishing pigs. Livest. Prod. Sci. 54:217-227.

Wood, J. D. 1984. Fat deposition and the quality of fat tissue in meat animals. In J. Wiseman (Ed.), Fats in animal nutrition. Pages. 407-435. London: Butterworths.

Wood, J. D. 1990. Consequences for meat quality of reducing carcass fatness. In J. D. Wood \& A. V. Fisher (Eds.), Reducing fat in meat animals. Pages 344-397. London: Elsevier Applied Science.

Wood, J. D., and M. Enser. 1997. Factors influencing fatty acids in meat and the role of antioxidants in improving meat quality. Br. J. Nutr. 78:S49-S60.

Wood, J. D., M. Enser, A. V. Fisher, G. R. Nute, P. R. Sheard, R. I. Richardson, S. I. Hughes, and F. M. Whittington. 2008. Fat deposition, fatty acid composition and meat quality: A review. Meat Sci. 78:343-358.

Wood, J. D., M. Enser, F. M. Whittington, C. B. Moncrieff, and A. J. Kempster. 1989. Backfat composition in pigs: Differences between fat thickness groups and sexes. Livest. Prod. Sci. 22:351-362.

Wood, J. D., A. V. Fisher, G. R. Nute, F. M. Whittington, and R. I. Richardson. 2005. Effects of diets on fatty acids and meat quality. In: Molina Alcaide E. (ed.), Ben Salem H. (ed.), Biala K. (ed.), Morand-Fehr P. (ed.). Sustainable grazing, nutritional utilization and quality of sheep and goat products = Pâturage durable, utilisation nutritionnelle et qualité des produits des ovins et des caprins . CIHEAMIAMZ, Series A, 67:133-141.

Wood, J. D., R. C. D. Jones, M. A. Francombe, and O. P. Whelehan. 1986. The effects of fat thickness and sex on pig meat quality with special reference to the problems associated with overleanness. 2. Laboratory and trained taste panel results. Animal Production 43:535-544.

Wood, J. D., R. I. Richardson, G. R. Nute, A. V. Fisher, M. M. Campo, E. Kasapidou, P. R. Sheard, and M. Enser. 2003. Effects of fatty acids on meat quality: a review. Meat Sci. 66:21-32.

Xi, L., M. T. See, K. N. Wentz, J. Odle, B. A. Belstra, T. A. Armstrong, P. D. Matzat, P. J. Rincker, F. K. McKeith, M. Culbertson, W. Herring, and J. Hansen. 2005. The effect of ractopamine feeding level on fatty acid profiles in belly and clearplate fat of finishing pigs. J. Anim. Sci. 83(Suppl. 2):28 (Abstr.).

Xu, G., S. K. Baidoo, L. J. Johnston, D. Bibus, J. E. Cannon, and G. C. Shurson. 2010a. Effects of feeding diets containing increasing content of corn distillers dried grains with solubles to grower-finisher pigs on growth performance, carcass composition, and pork fat quality. J. Anim. Sci. 88:1398-1410. 
Xu, G., S. K. Baidoo, L. J. Johnston, D. Bibus, J. E. Cannon, and G. C. Shurson. 2010b. The effects of feeding diets containing corn distillers dried grains with solubles, and withdrawal period of distillers dried grains with solubles, on growth performance and pork quality in grower-finisher pigs. J. Anim. Sci. 88:1388-1397.

Xu, G., S. K. Baidoo, L. J. Johnston, J. E. Cannon, and G. C. Shurson. 2007. Effects of adding increasing levels of corn dried distillers grains with solubles (DDGS) to corn-soybean meal diets on growth performance and pork quality of growingfinishing pigs. J. Anim. Sci. 85(Suppl. 2):76. (Abstr.)

Yen, J. 2001. Anatomy of the Digestive System and Nutritional Physiology. Pages 31-64 in Swine Nutrition. 2nd ed. A. J. Lewis and L. L. Southern, ed. CRC Press, Boca Raton, FL. 